\title{
REVISTA
}

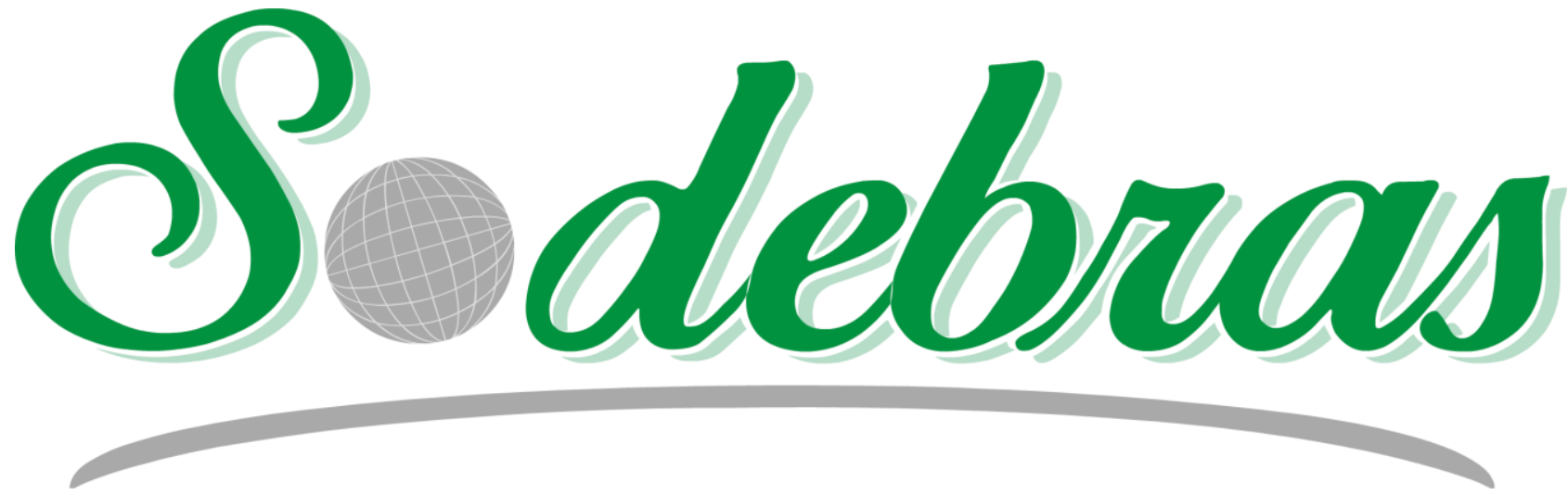

SOLUÇÕES PARA O DESENVOLVIMENTO DO PAÍS 


\title{
ARTIGOS PUBLICADOS
}

\author{
PUBLICAÇÃO MENSAL
}

Nesta edição

SALA DE AULA INVERTIDA COMO MÉTODO DE APRENDIZAGEM DO ALUNO: UM RELATO DE EXPERIÊNCIA THE FLIPPED

CLASSROOM AS A METHOD FOR A STUDENT LEARNING: A EXPERIENCE REPORT - Jane Leroy

Evangelista; Juliana Lopes De Almeida Souza; Izabela Alves De Souza

REGULADORES VEGETAIS: UMA BREVE REVISÃO SOBRE A GIBERELINA

REGULATORS PLANT: A BRIEF REVIEW ON GIBBERELLIN - Marcos Massuo Kashiwaqui; Bruna Penha Costa; Carlos Augusto Rocha De Moraes Rego; João Henrique Silva Caetano; Marinez Carpiski Sampaio; Vandeir Francisco Guimarães; Antonio Carlos Torres Da Costa

GERENCIAMENTO DE PUBLICIDADES NA PLATAFORMA DAS REDES SOCIAIS DE ACORDO COM CATEGORIAS DE CONTEÚDO

ADVERTISING MANAGEMENT ON SOCIAL NETWORKS PLATFORMS ACCORDING TO CONTENT CATEGORIES - Gustavo Nogueira De Sousa; Isabelle Da Silva Guimarães; Antonio Fernando Lavareda Jacob; Fábio Manoel França Lobato

DINÂMICA E CONTROLE VETORIAL DE UM MOTOR DE INDUÇÃO TRIFÁSICO

DYNAMIC AND VECTOR CONTROL OF THREE-PHASE INDUCTION MOTOR - Maxwell Diógenes

Bandeira De Melo; Ivan Ney Alvizuri Romani; Sérgio Manuel Rivera Sanhueza

ANÁLISE DE VIABILIDADE FINANCEIRA DE UM PROJETO DE GERAÇÃO DE ENERGIA FOTOVOLTAICA CONSIDERANDO DIFERENTES CENÁRIOS E LOCALIDADES BRASILEIRAS

FINANCIAL FEASIBILITY ANALYSIS OF A PHOTOVOLTAIC GENERATION PROJECT CONSIDERING DIFFERENT BRAZILIAN SCENARIOS AND LOCATIONS - Sang Koo Monomi; Thyago Carvalho Marques; Sandrerley Ramos Pires

VIABILIDADE PARA A IMPLEMENTAÇÃO DE UMA USINA DE RECICLAGEM DE RESIDUOS DA CONSTRUÇÃO CIVIL NA REGIÃO METROPOLITANA DE GOIÂNIA

VIABILITY FOR THE IMPLEMENTATION OF A CIVIL CONSTRUCTION WASTE RECYCLING COMPANY IN THE METROPOLITAN REGION OF GOIÂNIA - Gabriel De Faria Feris; Thyago Carvalho Marques

MELHORIA NO FLUXO EM UMA TRANSPORTADORA DE VALORES: UM ESTUDO DE CASO

IMPROVEMENT FLOW IN A CASH TRUCK: CASE STUDY - Richele Querino; Arcione Ferreira Viagi;

Hamzagic Miroslava; Jose Carlos Borges De Paula

DETECÇÃO DE FALHAS NO PROCESSO DE COMUNICAÇÃO E ANÁLISE DOS IMPACTOS SOBRE A SEGURANÇA DE VÔO PELO CONTROLE DE TRÁFEGO AÉREO

DETECTION OF FAILURES IN THE COMMUNICATION PROCESS AND ANALYSIS OF IMPACTS ON

FLIGHT SECURITY BY AIR TRAFFIC CONTROL - Robervandro Silva De Lima; Clauderino Da Silva Batista .. 


\section{Área: Ciências Humanas e Sociais}

\section{6-9 SALA DE AULA INVERTIDA COMO MÉTODO DE APRENDIZAGEM DO} ALUNO: UM RELATO DE EXPERIÊNCIA

THE FLIPPED CLASSROOM AS A METHOD FOR A STUDENT LEARNING:

A EXPERIENCE REPORT

Jane Leroy Evangelista; Juliana Lopes De Almeida Souza; Izabela Alves De Souza 


\title{
Revista SODEBRAS - Volume 14 \\ $\mathrm{N}^{\circ} 166$ - OUTUBRO/ 2019
}

\section{A SALA DE AULA INVERTIDA COMO MÉTODO DE APRENDIZAGEM DO ALUNO: UM RELATO DE EXPERIÊNCIA}

\section{THE FLIPPED CLASSROOM AS A METHOD FOR A STUDENT LEARNING: A EXPERIENCE REPORT}

\author{
JANE LEROY EVANGELISTA ${ }^{1}$; JULIANA LOPES DE ALMEIDA SOUZA²; \\ IZABELA ALVES DE SOUZA ${ }^{3}$ \\ 1; $2 ; 3$ - CENTRO UNIVERSITÁRIO UNA - INSTITUTO ÂNIMA, BELO HORIZONTE \\ jane.evangelista@prof.una.br; julianasouza@prof.una.br; izalvessh@gmail.com
}

\begin{abstract}
Resumo - O artigo apresenta a metodologia de sala de aula invertida, em uma disciplina específica, como proposta de experiência de aprendizagem do aluno no ensino híbrido. A disciplina aqui estudada aborda competências relacionadas ao pensamento lógico, propondo conteúdo diverso, além do estudo da capacidade de transformar informação em conhecimento. A reflexão aqui apresentada, por meio de um relato, tem como questionamento os usos das estratégias metodológicas de sala de aula invertida, tentando compreender de que maneira configuram a aprendizagem do aluno. $O$ instrumento de coleta de informações utilizado foi um questionário estruturado com perguntas objetivas e uma pergunta descritiva, o qual foi enviado para os alunos de duas turmas. Os professores desta disciplina foram questionados sobre a forma como conduziram o ensino $e$ de que maneira refletiu nos resultados mais satisfatórios em sala de aula. Como conclusão, pode-se relatar o baixo aproveitamento dos alunos no ensino híbrido, sendo a principal razão estar relacionada a não comprometimento do aluno no momento do seu estudo no ambiente online.
\end{abstract}

Palavras-chave: Sala de Aula Invertida. Aprendizagem. Metodologia Ativa.

Abstract - The article presents the flipped classroom methodology, in a specific subject, as a proposal for student learning experience in hybrid education. The analyzed discipline addresses competences related to logical thinking, proposing diverse content, besides the study of the ability to transform information into knowledge. The reflection presented here, through a report, has as its question the uses of the methodological strategies of the flipped classroom, trying to understand how they configure the student learning. The information collection instrument used was a structured questionnaire with objective questions and a descriptive question, which was sent to students from two classes. Teachers in this subject were asked how they conducted the teaching and how it reflected in the most satisfactory classroom outcomes. In conclusion, it can be reported the low achievement of students in hybrid education, the main reason being related to the noncommitment of the student when studying in the online environment.

Keywords: Flipped Classroom. Learning. Active Methodology.

\section{INTRODUÇÃO}

A proposta do Centro Universitário analisado, de usar o ensino híbrido, vem justamente ao encontro do objetivo de promover a inovação no ensino superior, e ainda incentivar a autonomia do aluno, requisitos estes essenciais à evolução da educação nos tempos atuais. No caso em estudo, esta inovação acontece justamente quando se usam novas estratégias de ensino para desenvolver uma aprendizagem mais eficaz por parte do aluno. Desta forma, este relato de experiência tem como proposta apresentar a sala de aula invertida como metodologia, no ensino híbrido, para a aprendizagem do aluno. Neste sentido, a pergunta que norteia este relato é: De que maneira as estratégias metodológicas de sala de aula invertida norteiam a aprendizagem do aluno no ensino híbrido? Para tanto, como objetivo geral, o estudo visa avaliar a percepção do aluno e do professor em relação às estratégias metodológicas do ensino híbrido. Os objetivos específicos constituem em identificar as estratégias metodológicas utilizadas por professores em salas de aula invertidas, bem como entender as mais adequadas ao ensino híbrido e assim verificar de que modo o aluno utiliza metodologias de estudo nesta modalidade de ensino para ter experiências de aprendizagem na disciplina Institucional I.

Nos cursos de graduação do Centro Universitário estudado, a nova matriz, estabelecida em 2017, propõe o ensino híbrido em pelo menos uma disciplina em todos os módulos de estudo. Dentre as disciplinas ensinadas de forma híbrida, algumas têm o propósito de se trabalhar competências gerais ao profissional do século XXI. A disciplina Institucional I é uma delas e trata especificamente da competência relacionada ao pensamento lógico, propondo conteúdo diverso, além do estudo da capacidade de transformar informação em conhecimento, da lógica de situações cotidianas, de estratégias de construção do raciocínio lógico e de abordagens criativas na resolução de problemas. Assim, entende-se que para lograr com estes estudos, é necessário o uso de estratégias metodológicas ativas com o objetivo de promover discussões e reflexões em um âmbito de aprendizagem mais efetivo.

Este relato se dá a partir da experiência de duas turmas diferentes, conduzidas por professores presenciais distintos nos períodos de 2018-2 e 2019-1. Em ambas as turmas usou-se metodologia qualitativa para tratamento das informações e de pesquisa descritiva para retratar a experiência vivida no ensino/estudo híbrido. A escolha do método qualitativo descritivo se dá porque como afirma Godoy (1995) o contato direto e prolongado do pesquisador 
com o ambiente e a situação que está sendo estudada é valorizado. Neste sentido, é importante perceber o fenômeno estudado ao se manifestar no cotidiano (GODOY, 1995). Para este relato, na análise de dados considerou-se a observação participante de uma das autoras que é também aluna, e outra autora que é também professora da disciplina.

$\mathrm{O}$ instrumento de avaliação utilizado foi um questionário estruturado (encontra-se no Apêndice) com perguntas objetivas e uma pergunta descritiva qual foi enviado para todos os alunos de ambas as turmas. Foram analisadas as respostas recebidas no prazo de uma semana, durante o mês de julho de 2019. O direcionamento das perguntas para os alunos foi no sentido de analisar se eles estudavam, de forma autônoma, o conteúdo online, antes dos encontros presenciais (sala de aula invertida), se sentiam maior aproveitamento dos encontros presenciais, e se as metodologias usadas em sala de aula eram proveitosas para o aprendizado. Ao professor, se questionou se ele entendia que essa forma de conduzir o ensino refletia resultados mais satisfatórios em sala de aula. As pesquisas foram conduzidas de modo anônimo com os alunos.

A seguir apresenta-se o referencial teórico sobre os pontos principais deste estudo que tem como pontos de partida os temas: a sala de aula invertida, estratégias metodológicas e metodologia ativa. Os temas abordados são norteadores para a compreensão do relato, na medida em que se configura um processo contínuo de experiências, tanto para o aluno quanto para o professor envolvido em ensino híbrido.

\section{REVISÃO DE LITERATURA}

\section{Sala de aula invertida: metodologia para o ensino híbrido}

Ao fazer um levantamento da literatura sobre sala de aula invertida, encontra-se, de forma recorrente, a pesquisa de Bergmann e Sams (2013). Camillo (2017) explica que a sala de aula invertida é uma metodologia que foi realizada em escolas de ensino médio, nos Estados Unidos. Bergmann e Sams (2012b) desenvolveram experiências com alunos que precisavam ausentar das aulas por algum tempo. A estratégia utilizada por estes autores foi inverter a lógica das aulas, fazendo com que os alunos, por conta própria, estudassem de acordo com o local e tempo escolhido por eles (CAMILLO, 2017).

Conforme Camillo (2017), entende-se por sala de aula invertida o processo no qual o conteúdo é passado aos alunos por meio de um recurso tecnológico, como vídeos, em que o aluno assiste em casa, enquanto que na sala de aula seja explorado o máximo de elementos possíveis. Neste sentido, é interessante destacar que a metodologia usada na sala de aula invertida deve ser pauta de discussão entre pesquisadores, professores e profissionais da área da educação. $\mathrm{O}$ uso de tecnologias em sala de aula auxilia no aprendizado e incentiva uma maior participação dos alunos nas aulas, contudo, não deve ser o único recurso a ser pensado no processo de ensino-aprendizagem.

Para a compreensão da inversão da sala de aula, é necessário, conforme aponta Camillo (2017), quatro aspectos: a) atividades de questionamentos ou resoluções de problemas para que os alunos se envolvam com a aprendizagem ativa, fazendo com que o aluno tente encontrar respostas no material online; b) realização de feedbacks das atividades no momento presencial da aplicação daquele conteúdo referente ao que foi estudado previamente; c) propor avaliações formativas, que tragam evidências de aprendizagem, tanto em sua participação nas atividades online quanto nas presenciais; e d) os materiais ou recursos utilizados devem ser bem planejados e estruturados, para que se tem a percepção do que efetivamente se consegue obter como indícios de aprendizado.

\section{Estratégias metodológicas no ensino híbrido: relação efetiva para a aprendizagem}

Nas diversas possibilidades do ensino híbrido, o aluno com mais autonomia se torna um requisito bastante instigador, de maneira que a atuação do professor precisa ser revisitada para que novas formas de uma relação mais efetiva para a aprendizagem seja construída. Logicamente que uma grande mudança de cultura, estrutura de sala de aula e treinamento dos professores são também necessários, uma vez que a presença física constante, já não é mais a única que poderá capturar a atenção dos alunos e seu envolvimento, como no formato tradicional.

Desta forma, renovadas estratégias devem ser utilizadas na interação com o aluno para efetivar em maior grau a construção da aprendizagem ou ainda revistas para uso com resultados efetivos no ensino híbrido. Estratégias de ensino em geral são meios, procedimentos ou métodos que o professor utiliza para atender seus objetivos de ensino (VEIGA, 2012). Algumas destas estratégias, conforme cita Masetto (2003), são as mesmas presentes nos formatos tradicionais de aula, tais como: o seminário, o estudo de texto e o estudo dirigido, os quais podem ser utilizados também no ensino híbrido. Mas, conforme lembra Gil (2019), para que a aprendizagem não fique apenas no nível da memorização, elas devem ser usadas no sentido de proporcionar construção de aprendizagem, com exemplos, jogos, dramatizações ou com trabalhos práticos, para justamente promover a discussão em diversos pontos de vista.

Também para Maria Castanho (2007) algumas estratégias como o portfólio, a tempestade de ideias, o mapa conceitual, a lista de discussão por meios informatizados, a solução de problemas, o grupo de verbalização e observação, a dramatização, o júri simulado, o estudo de caso, o simpósio, o painel, o fórum, a oficina, podem ser exemplos de superação/renovação de métodos tradicionais. Contudo, também ressalta que devem ser usadas sempre de acordo com o objetivo de ensino - que para a compreensão deste relato de experiência, entende-se como objetivo de aprendizagem ao invés de ensino - estabelecido previamente.

Assim, é possível identificar que conhecer estratégias e saber como aplicá-las pode ser uma forma de causar melhor aproveitamento nos encontros esporádicos do ensino híbrido, principalmente quando o aluno já tem algum conteúdo previamente estudado, pois as reflexões e discussões se tornam mais ricas.

\section{Metodologia ativa no processo de aprendizagem do aluno}

As metodologias ativas, de acordo com Paiva (2016, p.145), "rompem com o modelo tradicional de ensino e fundamentam-se em uma pedagogia problematizadora, onde o aluno é estimulado a assumir uma postura ativa em seu processo de aprender, buscando a autonomia do educando e a aprendizagem significativa." As metodologias ativas 
focam no processo de aprendizagem do aluno por meio do seu protagonismo na aquisição e na prática do saber. Essa nova metodologia vem sendo implantada no ensino superior e vem trazendo grandes debates sobre as mudanças que sua prática implica dentro das salas de aula. O aluno passa a ser peça fundamental no seu próprio caminho de aprendizagem e o desenvolver deste processo parte do princípio de uma análise mais crítica do conteúdo visando sua prática em sala de aula. O professor sai um pouco de cena, enquanto o aluno se torna cada vez mais responsável por assimilar aquela disciplina. O impacto gerado tanto de maneira individual para professor quanto para o aluno, dentro da sala de aula, e também na relação professor-aluno, evidencia o quanto o contato com a novidade traz reações muitas vezes positivas, e em outros momentos de forma negativa na busca por uma experiência do saber.

Paiva ainda afirma que: (2016, p.151) "entende-se que todas as alternativas de metodologias ativas colocam o aluno diante de problemas e/ou desafios que mobilizam o seu potencial intelectual, enquanto estuda para compreendê-los e/ou superá-los." Portanto, as metodologias ativas vêm para colocar o aluno perante situações-problemas que sejam mais eficazes na sua linha de raciocínio de resolução do que apenas teorias. Neste contexto, a problematização em questão, de deixar a experiência de aprendizagem do aluno mais ativa e independente, oferece oportunidades de reflexão e de avaliação sobre quais são formas mais eficazes de aplicabilidade, já que quando se fala de metodologias ativas, pressupõe-se que não existe apenas uma forma de agir mediante os diversos métodos de ensino-aprendizagem.

Nota-se que a mudança ocorrida na sala de aula, por meio das novas metodologias - aqui percebidas como ativas -, vem para enfatizar a importância do esforço do aluno para adquirir o conhecimento necessário ao colocar em prática as competências propostas pelo material de ensino e pelo apoio do professor.

\section{RESULTADOS}

Com o intuito de responder ao questionamento proposto neste estudo, de avaliar a percepção do professor em relação às estratégias metodológicas do ensino híbrido, conforme relatado pelos professores da disciplina, é notado nos encontros presenciais que os alunos têm ainda dificuldade em se dedicar ao estudo prévio. O que confirma os estudos de Bergmann e Sams (2013), ao proporem experiências em que os alunos se ausentam das aulas por meio do estudo online. Muitos acabam consultando o material durante o encontro e poucos são aqueles que levam para o encontro com o professor suas anotações e faz uso delas durante o aprendizado presencial. Este resultado interfere diretamente na dinâmica da aula, uma vez que esta é preparada levando em consideração maior participação de alunos. As estratégias metodológicas utilizadas pelos professores entrevistados no ensino híbrido da disciplina Institucional I pressupõem troca e interação com os alunos. Como diz um dos professores entrevistados: "As atividades propostas buscavam fazer provocações a respeito dos principais temas da disciplina. A partir de um vídeo, um texto, um anúncio, uma situação hipotética etc., os estudantes trabalhavam em grupo para refletir e solucionar os problemas propostos". Pela fala do professor, nota-se que há preocupação com a aprendizagem do aluno, a partir das escolhas das estratégias metodológicas aplicadas pelo professor presencial. Esta estratégia é comprovada por Reis e Lima (2019) que concluem que uma prática inovadora pode se desdobrar em três situações: na prática pedagógica, na forma de abordagem dos conteúdos e, nas metodologias e técnicas utilizadas. Neste caso, o uso se deu na prática pedagógica.

Entretanto, discussões em grupo ou aplicação de jogos aconteceram de forma prejudicada uma vez que eles não tinham conhecimento ou compreensão do assunto para então partir para análise e julgamento. Muitas vezes as atividades precisavam de um tempo muito maior que o programado, uma vez que os alunos precisavam se inteirar do assunto para então executá-las. Isso, claramente prejudicava também $\mathrm{o}$ andamento do encontro como um todo.

A presente pesquisa foi enviada a 90 alunos, em duas turmas que cursaram a disciplina Institucional I, e obteve 28 respostas durante o período de uma semana, no mês de julho de 2019. Desses 28 alunos que responderam, um total de 16 alunos cursaram a disciplina em 2018 com um professor presencial e 12 alunos cursaram em 2019 com outro. O direcionamento das perguntas foi no sentido de analisar se os alunos estudaram de forma autônoma o conteúdo online antes dos encontros presenciais (sala de aula invertida), se sentiam maior aproveitamento dos encontros presenciais, e se as metodologias usadas em sala de aula eram proveitosas para o aprendizado.

No total de respostas, foi encontrado um percentual alto $(62,4 \%)$ de alunos demonstrando que se dedicaram pouco ao estudo prévio online. $\mathrm{Na}$ análise não foram detectadas diferenças nos percentuais com relação às duas turmas que responderam ao questionário (tendo em vista que não há diferença se for analisada uma turma separada da outra).

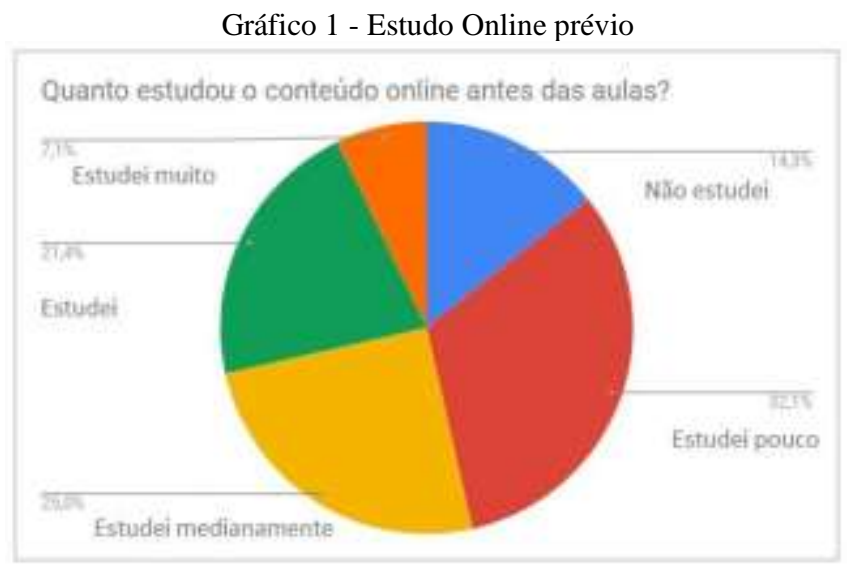

Fonte: Elaborado pelas autoras.

Com relação à utilização de metodologias ativas em sala de aula, a impressão que se tem é que os alunos as confundem com o tipo de conteúdo da disciplina. Pelo Gráfico 2 abaixo se nota que a avaliação de grande parte dos alunos não é boa $(78,5 \%)$, com muitos deles não as considerando como adequadas ao aprendizado. Isto se comprova pois se compararmos os percentuais das respostas mostrados no gráfico aos comentários tecidos na pergunta aberta sobre a experiência com o método da disciplina vê-se que há uma confusão entre isto e o seu conteúdo. Como exemplo, tem-se algumas falas nas piores notas: "Creio que a disciplina não acrescenta em nada em meu futuro profissional" ou "Não é nada estimulante, tanto para o estudo a distância como para o presencial. Não é apenas pela disciplina, mas esse tipo de disciplina não engaja". 
Gráfico 2 - Avaliação de atividades aplicadas nos encontros presenciais

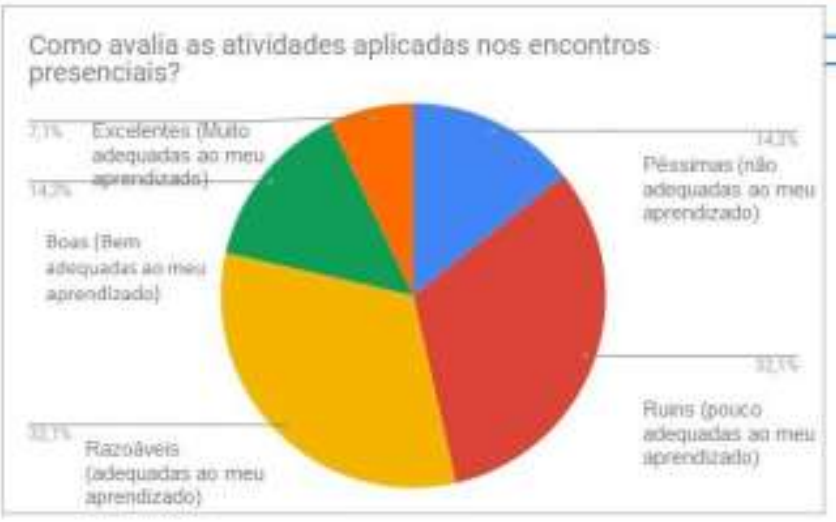

Fonte: Elaborado pelas autoras.

Sobre a reflexão dos alunos e seu aproveitamento em sala de aula, o resultado é diverso, pois cerca de mais da metade deles acreditam serem razoáveis ou boas para o aprendizado, o que comprova os dizeres de Paiva (2016) sobre metodologias ativas. No entanto, cerca de pouco mais de um terço deles acredita que o resultado é de pouco aprendizado ou quase nenhum. Em um comentário, o aluno afirma que "os 3 semestres que fiz com a disciplina híbrida não senti tanto aproveitamento nas aulas presenciais, o material no site é bem razoável." Algumas possibilidades para este baixo aproveitamento podem ser elencadas, como a dificuldade com os conteúdos (o que foi já citado anteriormente), ou ainda devido ao não comprometimento do aluno no momento online (como já dito também na percepção dos professores). Uma das respostas sinaliza este caminho: "acho que os estudantes ainda não estão tão aptos a estudar desta forma, principalmente em determinadas matérias". No entanto, a partir desta constatação de baixo aproveitamento, a pergunta para os alunos sobre acreditar que estudar antes dos encontros auxilia no aprendizado, comprova que eles concordam com a afirmação, porém não a praticam. Do total de 28 respostas, 20 alunos concordam que estudar antes o conteúdo online, ajuda no aprendizado (modelo de sala de aula invertida). Pois como diz um dos comentários "é um método que te "obriga" além de estudar, correr atrás das próprias respostas", ou ainda este: "considero que ter uma disciplina híbrida me fez ter mais responsabilidade com a matéria em questão”.

Gráfico 3 - Aproveitamento nos encontros presenciais

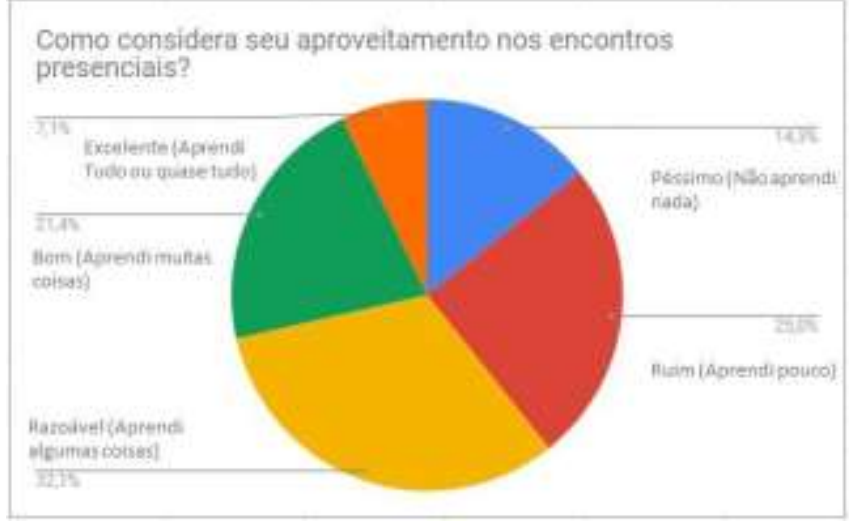

Fonte: Elaborado pelas autoras.

Pelo ponto de vista da experiência da aluna que escreve este relato, há uma grande mudança neste processo de aquisição do saber. Um fator apontado e observado em seus pares é ainda a imaturidade para lidar com a responsabilidade da absorção do que lhe é proposto e em como colocar aquilo em prática. Vê-se ainda um desgosto por vezes não se notar resultados satisfatórios com a disciplina, dado que o aluno tem ainda suas dificuldades para se desenvolver bem com o conteúdo online que lhe é confiado. Além disso, o aluno não consegue perceber suas próprias barreiras ou mesmo como conseguir superá-las. Este relato comprova o dito por Marin (2010) sobre a importância do esforço do aluno para saber como transformar o conteúdo absorvido em conhecimento prático, por meio do material de estudo e do apoio do professor.

Como resultado geral deste relato, pode-se dizer que muitos alunos ainda não estão acostumados com o fato de se tornarem autores de seu próprio aprendizado. Sabem que poderiam se dedicar mais e com isso obter melhores resultados, porém adotam uma postura cômoda sem muita interação e dedicação ao processo de aprendizagem. Do ponto de vista dos professores, estes sabem que precisam aprimorar técnicas para promover aprendizagem significativa através do uso de metodologias ativas e atualizadas, e assim o fazem nos encontros presenciais. Fica entendido que se está diante então de um paradoxo, que se torna o grande desafio do ensino híbrido. Como fazer com que os alunos se rendam ao estudo prévio online da mesma forma que interagem nas aulas presenciais? Uma possível solução seria adotar também no ambiente online, conteúdo dinâmico e instigador que provoque no aluno a autonomia e o desafio para resolver problemas, como evidenciado por Paiva (2016), ser necessário para promover o aprendizado.

Esta sugestão se dá, também, por outros fatores que fogem a junção apenas da dinâmica de ensino-aprendizagem satisfatória com o uso de metodologias ativas e sala de aula invertida. Em algumas respostas foram encontradas reclamações quanto a qualidade do material online, quanto a tecnologia utilizada no ambiente online (diz um relato que "a plataforma é extremamente complicada, com muitos textos, o que "desanima" no estudo anterior às aulas, e, geralmente, as disciplinas híbridas são assuntos muito importantes, que são vistos de "qualquer jeito"), mas também quanto a conexão entre professor presencial e online.

Desta forma, assim como foi um processo de adaptação aos professores no início da implantação da hibridização de ensino, para o aluno ocorre um baque na mudança da sala de aula tradicional para uma sala de aula invertida, onde o protagonista é ele próprio. No transcorrer dos anos, os estudantes foram ensinados e até mesmo treinados para absorver o conteúdo em sala de aula, com orientação e aprendizado por partes dos professores, e intensificar o estudo em casa por meio de atividades individuais ou em grupo. Dado que este cenário se inverte com as metodologias ativas de ensino, o aluno parte de um papel coadjuvante em sala, toma o papel principal e tende a aprender a caminhar com as próprias pernas rumo ao saber, desenvolver e criar novas habilidades, além de potencializar as já existentes no seu processo de ensino.

A estudante relata que quando passou pela primeira experiência com o ensino híbrido, no primeiro semestre de 2018, sob orientação de um professor presencial, e de outros dois professores online (houve uma mudança no meio do semestre, tendo o primeiro professor ficando metade do período e o segundo o restante), foi perceptível a mudança 
de atmosfera que vivenciava nas outras disciplinas e nesta disciplina específica (disciplina em questão).

De acordo com Diesel (2017, p.272) "a construção efetiva de profissionais diferenciados requer, na concepção da equipe do projeto, uma abordagem baseada na utilização de metodologias ativas de ensino na formação inicial desses sujeitos.", ou seja, as metodologias ativas instauram na vida do aluno uma oportunidade de autonomia no aprendizado e independência para que assim se construa uma profissionalização mais concreta e independente.

A dinâmica que se propõe no modelo de sala de aula invertida é absorver o conteúdo na plataforma online e colocar em prática em sala de aula. Neste contexto, tomando de base a disciplina Institucional I, que aborda o raciocínio lógico, a forma de resolução de problemas e os modos de pensar, evidencia-se o quanto a prática é essencial para se fixar a teoria e também o contrário, o quanto a falta da teoria prejudicaria a prática.

Claro que foram percebidos obstáculos para o aprendizado fora da sala de aula, como a metodologia propõe a responsabilidade do aluno pela fixação, leitura e manuseio do conteúdo que é disponibilizado. Há certa resistência até os alunos perceberem que são altamente (senão unicamente) responsáveis por aprender ou não aquele assunto.

A experiência em sala de aula com o professor presencial era uma orientação embasada no conteúdo que os alunos deveriam ter estudado anteriormente para que se conseguisse aguçar a curiosidade deles. Para a partir daí se entender quanto tinham absorvido do conteúdo e se havia sido suficiente para saber como colocar em prática, abordando as vertentes necessárias para conseguir bons resultados. A prática daqueles encontros mensais por meio das atividades avaliativas aplicadas, deveria fazer com que a turma se exercitasse na rotina do estudo anterior ao encontro, se arriscasse numa aventura antes desconhecida e confiasse mais na potencialidade do ensino adquirido anteriormente e durante o desenvolvimento do que foi aprendido.

A forma de operar e de se adequar às novas modalidades de ensino, principalmente dentro das metodologias ativas, colocam tanto professor quanto aluno numa posição de desafio. O desafio de viver um novo processo e de se propor a romper os limites do costume. Os benefícios colhidos como fruto desse arriscar-se se dão no decorrer da mudança observada nos alunos a cada aula presencial. À medida que a turma vai se adaptando à metodologia que aquela disciplina implica, mais positivos devem ser os resultados.

A turma de Institucional I, citada em questão, foi encontrando dificuldades principalmente na adaptação às novas aplicações de metodologias na parte processual online. Estudar anteriormente por meio da leitura e fixação do conteúdo se tornou um tanto quanto desafiador para o aluno. Ao passar a se ter uma visão do professor apenas como um facilitador num encontro mensal, foi deixando a desejar e, muitas vezes até, fazendo com que houvesse desânimo da parte dos alunos. Então a falta de absorção do conteúdo, conforme era proposto, fez com que os alunos se sentissem perdidos diante das atividades dadas em sala de aula.

A alegação de muitos alunos foi a falta de contextualização entre o conteúdo proposto, o professor online, o professor presencial e a atividade dada em sala de aula, como se todos estes fossem desconexos. Claro que se encontra uma ironia entre o aluno querer ver conexão de conteúdo, quando este não está a par do conteúdo. Porém, entende-se a dificuldade na adaptação de uma nova técnica de aprendizagem e o susto por perceber que depende de ninguém, além do próprio aluno, o aprendizado daquela disciplina. Neste sentido, entende-se a partir dos estudos de Paiva e Moura (2019, p.11), que o aluno é que deve "desenvolver suas habilidades, segurança e maturidade". Contudo, nota-se que esta autonomia não é clara para o aluno, na medida em que este precisa compreender a importância de estudar previamente para ir à aula presencial.

\section{CONSIDERAÇÕES FINAIS}

A sala de aula invertida é uma metodologia que desenvolve experiências de aprendizagem dos alunos. A estratégia é utilizada para que os alunos estudem previamente o conteúdo e consigam aplicar os conhecimentos adquiridos em momentos presenciais. No relato, foi possível avaliar a percepção sob a perspectiva do aluno e do professor neste modelo de ensino híbrido. Para tanto, foi interessante perceber, a partir das respostas do questionário, quais estratégias metodológicas de sala de aula invertida configuram a aprendizagem do aluno. Os professores, ao utilizarem as diversas estratégias, como portfólio, a tempestade de ideias, o mapa conceitual, a lista de discussão por meios informatizados, a solução de problemas, entre outras, perceberam que os alunos não se comprometem com a proposta de inversão do estudo (ser previamente pelo ambiente online).

Apesar de se constatar que o uso de tecnologias em sala de aula auxilia no aprendizado e incentivam uma maior participação dos alunos nas aulas, a percepção dos alunos foi que estes se confundiam com o conteúdo e a proposta do ensino. É importante destacar que o aluno passa a ser central no seu percurso de aprendizagem. Dessa maneira, encontrase no processo uma análise crítica do conteúdo e sua relação com a prática em sala de aula. O professor percebe que seu papel é diferenciado ao escolher estratégias metodológicas neste modelo de metodologias ativas.

A pesquisa feita com 28 alunos apresenta um diagnóstico desafiador para este modelo de sala de aula invertida com uso de metodologias ativas, na medida em que se percebe um desânimo dos alunos com disciplinas híbridas. Os dados apontam para um baixo envolvimento dos alunos com a dedicação dos estudos prévios, assim como uma insatisfação com o modelo usado no ensino híbrido.

O relato de experiência aqui apresentado apontou para problemas diagnosticados sobre o modelo existente para se pensar no aprendizado do aluno. Entre os problemas, observa-se que o aluno não está acostumado a estudar previamente a aula presencial, o aluno não percebe a importância de sua jornada autônoma no processo de aprendizagem, além de estar acomodado com estratégias de ensino baseado em aulas expositivas. Como este percurso tem como parceiro o professor, sabe-se que este entende o cenário e procura investir em estratégias e técnicas para promoção das experiências de aprendizagem do aluno.

\section{REFERÊNCIAS}

BERGMANN, J.; SAMS, A. Flip Your Students' Learning. Educational Leadership, v. 70, n. 6, p. 16-20, 2013. 
BERGMANN, J.; SAMS, A. Before you flip, consider this. Phi Delta Kappan, Bloomington, v. 94, n. 2, p. 25, 2012a.

BERGMANN, J.; SAMS, A. How the Flipped Classroom is radically transforming learning. Learning, Innovation \& tech. The Daily Riff, 15 Abril 2012 b.

CAMILLO, C. M. Blended learning: uma proposta para o ensino híbrido. Revista EaD \& Tecnologias Digitais na Educação, v. 5, n. 7, p. 64-74, 2017.

GIL, A. C. Métodos e técnicas de pesquisa social. São Paulo: Atlas, $7^{\mathrm{a}}$.edição, 2019.

GODOY, Arlida Schmidt. Introdução à pesquisa qualitativa e suas possibilidades. Revista de administração de empresas, v. 35, n. 2, p. 57-63, 1995.

MASETTO, Marcos T. Competência pedagógica do professor universitário. São Paulo: Summus, 2003.

DIESEL, Aline. Os princípios das metodologias ativas de ensino: uma abordagem teórica, Revista Thema, v. 14, p. 268-288, 2017.

PAIVA, Marlla Rúbya Ferreira. Metodologias Ativas de Ensino-Aprendizagem: Revisão Integrativa. SANARE, Sobral - v.15 n.02, p.145-153, Jun./Dez. 2016

PAIVA, Jaizer Nely; MOURA, Luciana Teles. As inteligências múltiplas no contexto escolar da educação infantil como facilitadoras no processo de ensino aprendizagem. Revista Sodebras [on line]. v.14, $\mathrm{n}^{\circ} 160$, Abr/2019, p. 11-19. https://doi.org/10.29367/issn.1809-3957.14.2019.160.11

REIS, Márcia Lopes; LIMA, Amanda Barbosa Gaspar. O pacto nacional para a alfabetização na idade certa como ação inovadora para o letramento de crianças no Brasil. Revista Sodebras [on line]. v.14, $\mathrm{n}^{\circ} 157$, Jan/2019, p. 1121. DOI: https://doi.org/10.29367/issn.18093957.14.2019.157.11

VEIGA, Ilma (org.). Técnicas de Ensino: Por que não? SP, Capinas, Papirus: 2012.

\section{COPYRIGHT}

Direitos autorais: Os autores são os únicos responsáveis pelo material incluído no artigo.

\section{APÊNDICE}

1. Ano/Semestre que cursou a disciplina *

$$
\text { - 2018-1 }
$$

-2019-1

2. Quanto você considera que estudou o conteúdo online para as aulas (antes delas acontecerem)? *

Escala Likert para:

1 - Não estudei

5 - Estudei muito todo o material

3. Como avalia as atividades aplicadas nos encontros presenciais? *

Escala Likert para:

1- Péssimas (não adequadas ao meu aprendizado)

5- Excelentes (muito adequadas ao meu aprendizado)

4. Como considera o seu aproveitamento nas aulas presenciais? *
Escala Likert para:

1- Péssimo aproveitamento (não aprendi nada)

5 - Excelente aproveitamento (aprendi muito)

5. Você percebe que ter estudado antes ajudou a fazer atividades em sala? *

Sim

Não

6. Deixe um comentário sobre a sua experiência com o método desta disciplina. *

Submetido em: 12/09/2019

Aprovado em: 21/09/2019 


\section{Área: Ciências Agrárias e Biológicas}

\begin{tabular}{|l|l|}
\hline $5-1$ & REGULADORES VEGETAIS: UMA BREVE REVISÃO SOBRE A GIBERELINA \\
& $\begin{array}{l}\text { REGULATORS PLANT: A BRIEF REVIEW ON GIBBERELLIN } \\
\text { Marcos Massuo Kashiwaqui; Bruna Penha Costa; Carlos Augusto Rocha De } \\
\text { Moraes Rego; João Henrique Silva Caetano; Marinez Carpiski Sampaio; Vandeir } \\
\text { Francisco Guimarães; Antonio Carlos Torres Da Costa }\end{array}$ \\
\hline
\end{tabular}




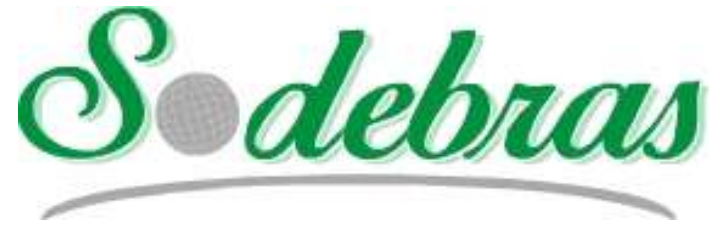

\author{
Revista SODEBRAS - Volume 14 \\ $\mathrm{N}^{\circ} 166$ - OUTUBRO/ 2019
}

\title{
REGULADORES VEGETAIS: UMA BREVE REVISÃO SOBRE A GIBERELINA
}

\author{
REGULATORS PLANT: A BRIEF REVIEW ON GIBBERELLIN
}

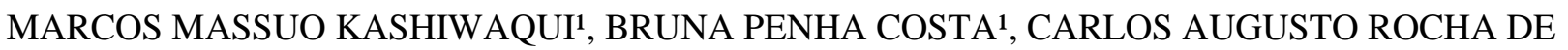 \\ MORAES REGO ${ }^{1}$, JOÃO HENRIQUE SILVA CAETANO ${ }^{1}$, MARINEZ CARPISKI SAMPAIO ${ }^{1}$, VANDEIR \\ FRANCISCO GUIMARÃES ${ }^{1}$, ANTONIO CARLOS TORRES DA COSTA ${ }^{1}$ \\ 1 - UNIVERSIDADE ESTADUAL DO OESTE DO PARANÁ \\ mkashiwaqui@yahoo.com.br; bruna.penhacosta@hotmail.com; cassielcarlos@hotmail.com; \\ jhscaetano@bol.com.br;mari_marinez@hotmail.com;vandeirfg@yahoo.com.br; \\ antonio.unioeste@hotmail.com
}

\begin{abstract}
Resumo - Este trabalho tem como objetivo trazer um agrupamento do conhecimento sobre a giberelina apresentando seu histórico, síntese, distribuição e efeitos fisiológicos, principais substâncias ativas do grupo e potenciais para aplicações na agricultura. Entre todos os hormônios vegetais conhecidos, as giberelinas são os que mostram os mais comprováveis efeitos quando aplicados às plantas, como por exemplo a promoção do alongamento celular $e$ o desenvolvimento de frutos sem fecundação. Em função disso, há uma expectativa sobre sua utilização comercial e espera-se um aumento de produtividade com o emprego desses fitohormônios. Com o progresso das pesquisas as giberelinas tornaram-se comercialmente viáveis, devido a sua expressão universal em plantas, presentes nas diferentes fases de desenvolvimento, desde a germinação até a frutificação e a sua possibilidade de produção industrial.
\end{abstract}

Palavras-chave: Botânica. Fitohormônio. Hormônio Vegetal.

Abstract - This work aims to bring a grouping of knowledge about gibberellin presenting its history, synthesis, distribution and physiological effects, main active substances of the group and potentials for agricultural applications. Among all known plant hormones, gibberellins show the most probable effects when applied to plants, such as promoting cell lengthening and fruit development without fertilization. Due to this, there is an expectation about its commercial use and it is expected an increase of productivity with the use of these phytohormones. With the progress of gibberellins research become commercially viable, due to its universal expression in plants, present in different stages of development, from germination to fruiting and its possibility of industrial production.

Keywords: Botany. Phytohormone. Plant Hormone.

\section{INTRODUÇÃO}

As giberelinas são hormônios que ocorrem naturalmente em plantas e regulam diversos processos desde a germinação, crescimento e desenvolvimento, por meio da divisão e alongamento celular, se estendendo até o desenvolvimento reprodutivo, atuando na floração e formação de sementes (TAIZ et al., 2017). Além dessas propriedades cientificamente comprovadas, as giberelinas estão envolvidas em outras interações, ambientais, ou com outros hormônios, tal como ocorre com as auxinas.

As pesquisas com as giberelinas iniciaram no final do século XIX, no Japão, expressadas na forma da doença chamada de 'bakanae', em plantas de arroz (Oryza sativa L.) que cresciam descontroladamente, em resposta aos metabólitos secundários produzidos pelo fungo Gibberella fujikuroi (HEDDEN \& SPONSEL, 2015). Posteriormente, os pesquisadores conseguiram isolar esses metabólitos, e demonstrar que esses metabólitos eram eficientes em promover o crescimento de outras espécies de plantas, além do arroz (KUMAR \& LONSANE, 1989).

$\mathrm{O}$ incremento das pesquisas sobre hormônios vegetais, incluindo as giberelinas aconteceu nos pouco mais de cem anos desde sua descoberta, pela demonstração da capacidade de influenciar muitos processos no desenvolvimento de plantas estimulando sua produção em maior escala. No entanto, há ainda necessidade de novas pesquisas, para elucidação dos processos bioquímicos envolvidos, interações ambientais, ou mesmo na melhor compreensão sobre a regulação exercida pelas giberelinas em plantas (HEDDEN \& SPONSEL, 2015).

Com a comprovação das propriedades desse hormônio na fisiologia vegetal, se estabeleceu um mercado consumidor de giberelinas, que atualmente é maior que ao de outros hormônios de crescimento, como as citocininas ou o as auxinas. Assim, o consumo mundial de giberilina em diversos cultivos agrícolas e finalidades de aplicação é de aproximadamente 60 toneladas anualmente (SINGH et al., 2017) com projeções de aumento no consumo ao longo nos próximos anos (PLANT GROWTH REGULATORS, 2017).

O objetivo deste trabalho é reunir os conhecimentos já existentes sobre a giberelina que envolve, dentre outros, o histórico das pesquisas, sua síntese e distribuição nas plantas, efeitos fisiológicos, principais substâncias ativas do grupo e as aplicações na agricultura desse importante regulador do metabolismo vegetal.

\section{HISTÓRICO}

$\mathrm{Na}$ origem das pesquisas com plantas de arroz, as mudas manifestavam alongamento excessivo, esterilidade ou redução no rendimento nas áreas de produção. Em diferentes localidades essas plantas eram popularmente nomeadas, em função dos seus sintomas, como bakanae (muda-boba), ahonae (muda-estúpida), yurei (fantasma), 
otokonae (mudas macho), onnanae (mudas femininas), dentre outros (KUMAR \& LONSANE, 1989).

Alguns autores atribuem a primeira publicação sobre o 'bakanae' ao pesquisador japonês Shotaro Hori, em 1898, que associou a ocorrência dos sintomas da doença com a infecção por fungos (KUMAR \& LANSANE, 1989; HEDDEN \& SPONSELL, 2015). Este fungo foi descrito posteriormente como a forma teleomórfica de Fusarium fujikuroi cuja forma anamórfica se denomina G. fujikuroi (BÖMKE \& TUDZYNSKI, 2009).

Nesse período, houve grande esforço dos pesquisadores japoneses para a compreensão da doença, bem como conhecer os produtos formados em decorrência da infecção e sua atividade sobre outras plantas. Uma das descobertas relevantes foi sobre os efeitos da aplicação do meio de cultura do fungo no crescimento de outras plantas que é atribuída ao pesquisador Eiichi Kurosawa, em 1926 (KUMAR \& LANSANE, 1989; HEDDEN \& SPONSELL, 2015). Em 1938, Yabuki e Sumiki isolaram duas substâncias secretadas por G. fujikuroi, chamadas giberelina A e B (HEDDEN \& SPONSELL, 2015).

$\mathrm{Na}$ década de 50 do século $\mathrm{XX}$, as pesquisas envolvendo o tema ganharam relevância internacional, e pesquisadores de outros países reconheceram a oportunidade de exploração aplicada dessas substâncias, com a participação destacada de pesquisadores da Imperial Chemistry Industry (ICI), do Reino Unido e do Departamento de Agricultura dos Estados Unidos (USDA). Dessa forma, no Reino Unido, Curtis e Cross, em 1954, conseguiram isolar a giberelina $\mathrm{A} 3$, que foi chamada de ácido giberélico (HEDDEN \& SPONSELL, 2015).

Takahashi et al. (1955) caracterizaram a natureza química da giberelina $\mathrm{A}$, obtendo três compostos, as giberelinas A1, A2 e A3, esta última, isolada anteriormente por Curtis e Cross (1954). Essas substâncias, ésteres metílicos, foram caracterizadas pela fórmula $\mathrm{C}_{20} \mathrm{H}_{26} \mathrm{O}_{6}$, $\mathrm{C}_{21} \mathrm{H}_{30} \mathrm{O}_{6}$ e $\mathrm{C}_{20} \mathrm{H}_{24} \mathrm{O}_{6}$, respectivamente. Posteriormente, a nomenclatura utilizada por Takahashi et al (1955), foi padronizada para todas as giberelinas isoladas (GA1, GA2, $\mathrm{GA} 3, \ldots, \mathrm{GA}_{\mathrm{n}}$ ), conforme a ordem cronológica de descobrimento (BÖMKE \& TUDZYNSKI, 2009; HEDDEN $\&$ SPONSELL, 2015).

Após a década de 60 do século XX, a continuidade das pesquisas das giberelinas levou a novas descobertas e confirmações que contribuíram para complementar o conhecimento dessas substâncias, tais como a sua síntese a partir de fungos e plantas, e a descoberta de novas substâncias reconhecidas como giberelinas, atualmente quantificadas em 136 (BÖMKE; TUDZYNSKI, 2009; HEDDEN; SPONSEL, 2015), das quais poucas são importantes pela sua atividade, mas como precursoras de formas ativas ou de produtos derivados de sua desativação (TAIZ et al., 2017).

Dessa forma, a demanda mundial de ácido giberélico para aplicação agrícola, no início da década de 80 , do século $\mathrm{XX}$, estava entre 12 e $15 \mathrm{t}^{\text {ano }^{-1}}$ (KUMAR; LONSANE, 1989). Dentre os reguladores de crescimento vegetal, as giberelinas tem sido consideradas as mais importantes pela sua comercialização e consumo, seguido por citocininas e auxinas. Atualmente, pela extensa possibilidade de aplicações e aumento da área plantada dos cultivos em que essas substâncias são utilizadas, a demanda mundial de giberelinas está estimada em torno de 60 toneladas por ano (SINGH et al., 2017).

\section{PRINCIPAIS HORMÔNIOS ENDÓGENOS QUE COMPÕEM O GRUPO}

As giberelinas são definidas por sua estrutura química baseada em um esqueleto ent-giberelano tetracíclico (com 20 átomos de carbono). Podem ser divididas em dois grupos de acordo com sua estrutura, representadas por GA-C20 e GA-C19, este último grupo se forma por giberelinas que perderam o átomo de carbono na posição 20 durante o metabolismo (KERBAUY, 2008).

Atualmente, entre as 136 giberelinas conhecidas, o ácido giberélico (GA3) se destaca, uma vez que é o principal componente bioativo das plantas. As giberelinas consideradas como mais ativas biologicamente são GA1, GA3, GA4, GA5, GA6 e GA7. Essas GAs ativas são GAsC19 e possuem um anel 4,10-lactona. As GAs-C20 não possuem atividade biológica, mas podem ser metabolizadas em GAs-C19 que podem ser bioativas (TAIZ et al., 2017).

O ácido giberélico favorece a germinação de sementes, ativando a síntese de enzimas hidrolíticas que atuam no desdobramento das substâncias de reserva e também estimulam o alongamento e a divisão celular (VIEIRA \& MONTEIRO, 2002). De acordo com Taiz et al. (2017) a GA1 é a giberelina biologicamente ativa que controla o crescimento do caule. Rodrigues e Leite (2004) afirmaram que as giberelinas GA1, GA3, GA4, GA7 e GA20 são ativas no crescimento vegetal, e, portanto importantes fisiologicamente e têm sido utilizadas para incremento da produção agrícola.

\section{SÍNTESE E DISTRIBUIÇÃO NAS PLANTAS}

O ácido giberélico ou giberelina é um fitohormônio característico de regiões de crescimento, sementes em germinação, endosperma, frutos, folhas jovens, ápices de caules e em alguns casos, nas raízes. Sua síntese geralmente ocorre no mesmo local da síntese de auxina e posteriormente distribui-se por toda a planta (LAVAGNINI et al., 2014; TAIZ et al., 2017).

A giberelina é caracterizada como um grande grupo de compostos relacionados, muitos dos quais biologicamente inativos, até o momento definidos mais por sua estrutura química do que por sua atividade biológica (TAIZ et al., 2017), classificados como diterpenóides tetracíclicos, constituídos de quatro unidades de isoprenóides.

Um terpenóide é um composto que resulta da junção de 5 unidades de carbono, o isopreno. A unidade biológica do isopreno é o isopentenil de pirofosfato (IPP), sendo que até pouco tempo acreditava-se que o ácido mevalônico era o precursor imediato do IPP na biossíntese de todos os terpenóides. Contudo, foram demonstradas a existência de duas rotas da biossíntese dos terpenóides, uma dependente e outra independente do ácido mevalônico (Figura 1) (DEWICK, 1997).

Embora a biossíntese das giberelinas ocorra no mesmo local da auxina, o seu transporte pela planta segue um fluxo inverso, devido ao caráter apolar dessas substâncias, ou seja, ocorre sem a polarização. O transporte é feito pelos vasos condutores (xilema e floema), dependendo da zona de produção do mesmo, do ápice até a base e vice-versa (LAVAGNINI et al., 2014; MONTANS, 2007). A biossíntese segue um estrito controle genético, ambiental e de desenvolvimento. $\mathrm{O}$ fotoperíodo e a temperatura, por exemplo, podem modificar a transcrição gênica de enzimas da síntese de giberelina (ARGYRIS et al., 2008). 
Figura 1 - Biossíntese de terpenos com formação de IPP - via mevalonato (a) e via melonato independente Rohmer (b) (DEWICK, 1997).

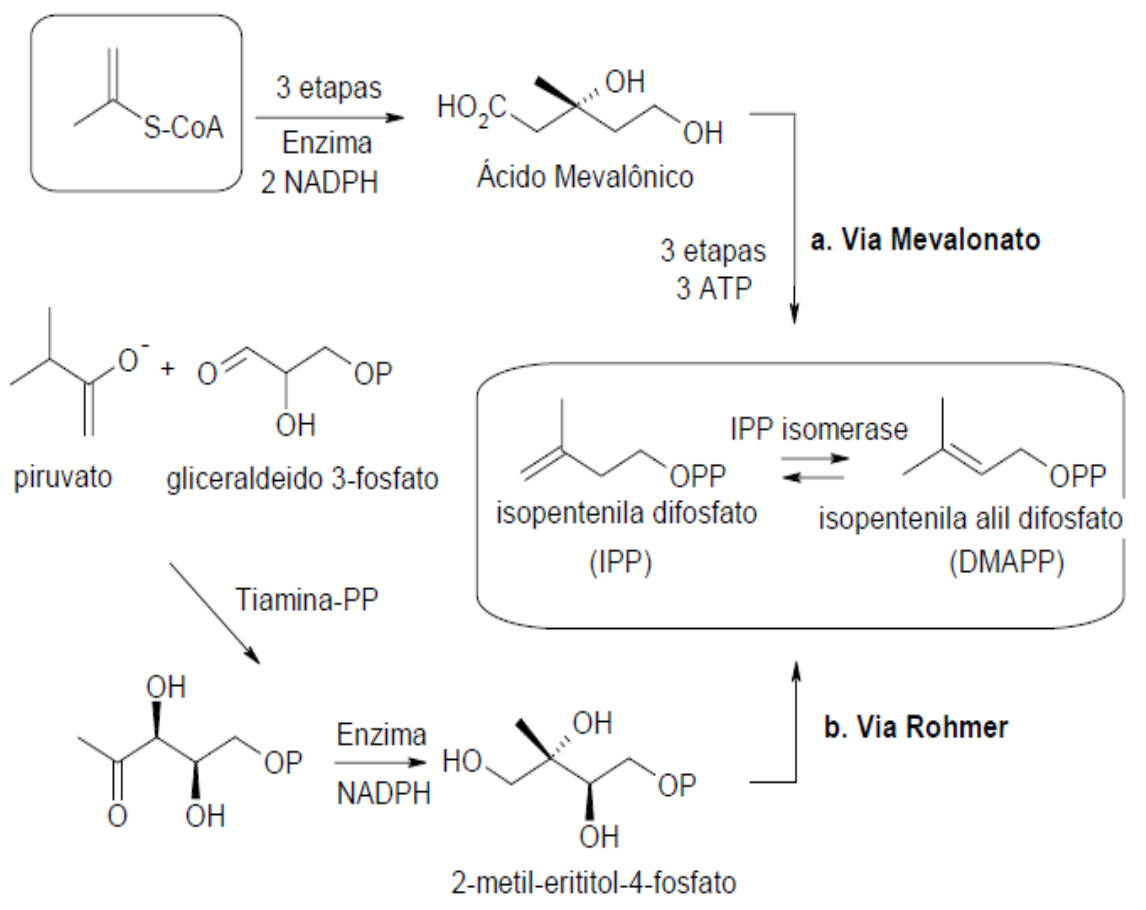

Fonte: Petersen (2006).

A via de formação da giberelina inicia-se a partir da acetil-coenzima A, formada a partir da via glicolítica. Ao invés de serem aproveitadas pelo ciclo de Krebs, duas moléculas deste metabólito sofrem uma condensação catalisada pela tiolase, resultando na acetoacetil-CoA. Esta, por sua vez, condensa-se com outra acetil-CoA, para resultar o 3-hidroxi-3-metilglutaril-CoA. Ocorrendo a redução deste último, pela nicotinamida-adenosina-dinucleotideo-fosfato, dá-se origem ao mevalonato (HEDDEN et al., 1978).

O mevalonato formado sofre rearranjo para dar como resultado os pontos chaves da via, o IPP e o pirofosfato de $\gamma, \gamma$, trimetilalila, compostos identificados com a unidade isopreno, bloco formador dos compostos terpenóides e que acabam por se unir em quatro unidades, formando os diterpenos (HEDDEN et al., 1978).

A primeira via, associada à biossíntese do esterol, ocorre no citossol; a segunda, associada à biossíntese de carotenoides e compostos associados, ocorre no cloroplasto. Considerandose que as primeiras reações para a biossíntese de giberelinas ocorrem nos proplastídeos, o precursor IPP pode não ser originado do ácido mevalônico. Nos plastídeos, a rota biosintética de terpenóides que resulta na síntese do IPP ocorre preferencialmente a partir do gliceraldeído-3-fosfato e do piruvato (OLSZEWSKI et al., 2002; TAIZ et al., 2017).

A biossíntese de giberelina nas plantas superiores pode ser dividida em três fases: Primeiro, ocorre síntese de entcaurenos nos proplastídeos. Em seguida, no retículo endoplasmático, ent-caurenos é oxidado para GA12-aldeído, precursor geral das giberelinas, através monooxigenases do citocromo P450 microssomal e por fim, no citosol, onde ocorre a conversão de GA12-aldeído em diversas giberelinas (OLSZEWSKI et al., 2002; TAIZ et al., 2017).

A síntese dos ácidos giberélicos é dividida em três fases, a saber:

\section{$1^{a}$ fase - reação de ciclização:}

Na primeira fase, quatro unidades de isoprenóides são ligadas para formar uma molécula linear de vinte carbonos, o geranil geranil difosfato (GGPP), que sofre uma reação de ciclização, formando um composto tetracíclico, o entcaureno. Esta reação é catalisada por duas enzimas presentes nos plastídios (TAIZ et al., 2017).

$2^{a}$ fase - oxidação para formação do GA12-aldeído

A segunda fase ocorre no retículo endoplasmático, a partir da oxidação do grupo metil a ácido carboxílico, levando à conversão de ent-caureno à GA12-aldeído e a enzima envolvida nesta fase são enzimas citocromo P450 monoxigenases como a ent-caureno oxidase e a ácido entcaurenóico hidroxilase (TAIZ et al., 2017).

$3^{a}$ fase - Formação dos diferentes ácidos giberélicos

É na terceira fase que ocorre a conversão de GA12aldeído para a formação dos diferentes ácidos giberélicos. Esta fase ocorre no citoplasma sob a ação de enzimas dioxigenases, sendo o GA12 a primeira giberelina formada, que será a precursora das demais giberelinas pela atividade da enzima $3 \beta$-hidroxilase e, esta, por sua vez, converte giberelinas de 20 carbonos a giberelinas de 19 carbonos. Dessa forma, ocorre a conversão de GA20 para GA1 pela $3 \beta$-hidroxilase, que é a forma biologicamente mais ativa na planta e a giberelina mais ativa no alongamento celular (HECKMAN et al., 2002; TAIZ et al., 2017).

\section{FATORES QUE CONTROLAM O NÍVEL ENDÓGENO NAS PLANTAS}

A giberelina desempenha a função de intermediar os efeitos de estímulos ambientais no desenvolvimento das plantas, além dos intrínsecos do próprio gênero e/ou, espécie vegetal. Os níveis endógenos de giberelina ativa regulam sua própria síntese, por catalisar ou inibir a transcrição de genes para enzimas que participam da biossíntese ou da degradação da giberelina (TAIZ et al., 2017).

O conteúdo de GA bioativas atuam de modo a promover a sua homeostase através da regulação via feedback negativo sobre as enzimas GA3 e GA20 oxidase, que são responsáveis pelas etapas finais da biossíntese das GAs, e por feedback positivo sobre a GA2 oxidase, que 
realiza a inativação das GAs (HEDDEN \& KAMIYA, 1997; HEDDEN \& PROEBSTING, 1999). Existe também evidências de que os estímulos ambientais, do ambiente físico, incluindo luz e temperatura, podem afetar aspectos do desenvolvimento da planta, por alterar as concentrações de giberelinas e/ou alterar a capacidade da planta em responder ao seu efeito fitorregulador (OLSZEWSKI et al., 2002).

A luz interfere na biossíntese de GA1 por meio da regulação da transcrição do gene da degradação da giberelina e também causa um decréscimo na capacidade de resposta do alongamento do caule à presença de giberelina. Assim, quando uma planta cresce na luz, a taxa de extensão diminui devido a variações nos níveis hormonais ou na sensibilidade aos reguladores vegetais (TAIZ et al., 2017). Consequentemente, a temperatura atua na desnaturação de enzimas que estão envolvidas na síntese da giberelina.

\section{MODO DE AÇÃO E EFEITOS FISIOLÓGICOS}

As GAs regulam vários processos de desenvolvimento ao longo do ciclo de vida da planta, desde a germinação das sementes até a expansão da folha, alongamento do caule, indução da floração e desenvolvimento dos frutos e sementes. Elas promovem a divisão e o alongamento celular preferencialmente em células jovens e por isso, sua aplicação provoca o alongamento dos entrenós em várias espécies.

As giberelinas são sintetizadas no meristema apical, nas raízes, folhas jovens e atuam no desenvolvimento de sementes e frutos, estimulando a divisão celular devido à condensação do IPP. Depois estes são transportados para diversas partes da planta de forma não polar, através do floema e xilema, para tecidos diferenciadas e para tecidos não diferenciados o transporte é polar. Na planta, os frutos e sementes em desenvolvimento, concentram as maiores quantidades de giberelinas (TAIZ et al., 2017).

As giberelinas também alteram a morfologia e a fisiologia da planta, afetando as modificações qualitativas e quantitativas na produção. $\mathrm{O}$ uso agrícola de ácido giberélico provoca um estímulo no crescimento do caule, e contribui para o aumento em produtividade, com maiores respostas para gramíneas, hortaliças e plantas ornamentais (WEAVER, 1972). Frequentemente sua ação ocorre de maneira integrada a outros hormônios, promovendo o alongamento celular, por exercer efeitos sobre a parede celular, principalmente em células jovens.

Inicialmente o ácido mevalônico (MVA) é transportado no citoplasma, onde sofre uma sequência de conversões até Isopentenil-PP (IPP), o qual adentra no protoplastídeo - o mesmo composto pode ser proveniente de piruvato e, ou, 3-Fosfato Gliceraldeído (3-PGALD) no próprio plastídeo - formando Farnesil-PP (de acordo com o estímulo externo poderá seguir rotas distintas e dar origem ao ABA ou GA), o qual é convertido a Geranil Geranil PP (GGPP), dando início a rota de síntese das GAs. A partir de então a rota é metabolicamente dividida em: regulação do crescimento, floração e ciclo celular (KERBAUY, 2008).

A divisão celular e o aumento do tamanho das células que ocorrem no desenvolvimento dos vegetais é atribuído à ação das giberelinas (MÉTRAUX, 1987). Para a expansão celular, há envolvimento da enzima xiloglucano endo-transglicosilase, que participa da expansão da parede celular, resultando no rompimento das ligações de hidrogênio entre os polissacarídeos aumentando sua elasticidade, obstruindo assim a pressão interna, o que possibilitaria a entrada de água e o alongamento celular (TAIZ et al., 2017).

Além de seus efeitos no alongamento celular, o ácido giberélico pode agir simultaneamente em outros fatores de crescimento, tais como na permeabilidade da membrana celular, na atividade enzimática, na variação do potencial osmótico e na mobilização de açúcares (MÉTRAUX, 1987). Um dos sistemas mais estudados é a indução pelo $A G$ da síntese e secreção de $\alpha$-amilase na camada de aleurona de cereais, envolvendo a presença de receptores para esse hormônio. O endosperma dos cereais é composto pelo endosperma amiláceo e pela camada de aleurona, a qual circunda o endosperma amiláceo e contém numerosos corpos proteicos, bem como vesículas armazenadoras de lipídios, os oleossomos.

Os compostos de reserva da semente são metabolizados por enzimas hidrolíticas durante a germinação, originando açúcares, aminoácidos e outros produtos que são transportados ao embrião em diferenciação. As enzimas $\alpha$ e $\beta$-amilase atuam sobre a degradação do amido; a primeira produz oligossacarídios, que são, então, degradados pela segunda, resultando no dissacarídio maltose, que é, finalmente, convertido a glicose pela enzima maltase. As giberelinas são sintetizadas e liberadas pelo embrião e transportadas ao endosperma durante a germinação, mostrando que o embrião de sementes de cereais embebidas pode regular a mobilização de suas reservas pela secreção de giberelinas que estimulam a função digestiva na camada de aleurona (KERBAUY, 2008).

A aplicação do GA pode favorecer a indução floral e a determinação do sexo, evento geneticamente regulado, mas que pode também ser influenciado por outros fatores, notadamente os ambientais. A exemplo, temos o milho, onde a aplicação de GA resulta no aumento na proporção de flores femininas, com aumento de cerca de 100 vezes nos níveis de GA no pendão (KERBAUY, 2008). No entanto, em algumas dicotiledôneas, como Cucumis sativus, Spinacia oleracea e Cannabis sativa, o ácido giberélico exógeno exerce efeitos contrários, observando-se a formação de flores estaminadas (KERBAUY, 2008).

Em algumas espécies, ocorre uma acentuada queda de frutos depois da polinização, e as auxinas presentes no tecido vegetal, podem estimular a fixação e o crescimento destes. Contudo, nem todas as espécies respondem favoravelmente às auxinas, e, nesses casos, esses efeitos ocorrem com a aplicação de GA, permitindo que os frutos no pé mantenham a coloração verde por um período maior, permitindo ao produtor programar a colheita, bem como favorecer a preservação da qualidade de frutos, por ocasião do armazenamento na pós-colheita.

Foi constatado que a presença da giberelina pode aumentar o comprimento do pedúnculo de uvas sem sementes. Devido ao pequeno comprimento dos pedúnculos individuais dos frutos, os cachos de uvas sem sementes são muito compactos e o crescimento das bagas é limitado. A aplicação de giberelina estimula o crescimento dos pedúnculos, permitindo que as uvas cresçam mais pela diminuição da compactação, promovendo o alongamento do fruto. Um efeito adicional, é que pode causar o desenvolvimento de frutos partenocárpicos (KERBAUY, 2008).

Em algumas espécies cultivadas as giberelinas podem quebrar a dormência das sementes, promovendo o 
crescimento do embrião e a emergência da plântula. A germinação das sementes de algumas espécies, principalmente não-domesticadas, é dependente da luz ou de baixas temperaturas, cujos efeitos podem ser substituídos pelo GA exógeno (TAIZ et al., 2017). Como as mudanças nos níveis endógenos desse hormônio nas sementes são normalmente observadas como resposta ao tratamento com baixas temperaturas, as giberelinas têm sido consideradas reguladoras naturais de processos germinativos. Elas podem diminuir o tempo necessário de tratamento em baixa temperatura para a quebra da dormência. A dormência das sementes de algumas espécies pode ser superada por uma combinação de baixas temperaturas, escarificação e aplicação de giberelinas. O efeito benéfico na quebra da dormência é atribuído ao estímulo do alongamento celular, fazendo com que a radícula tenha mais possibilidades de romper o tegumento (FEITOSA et al., 2015).

\section{UTILIZAÇÕES PRÁTICAS NA AGRICULTURA}

A presença generalizada de ácido giberélico em plantas permitiu o estudo de seu uso comercial em muitas culturas. No decorrer do tempo, a ação desses hormônios na agricultura foi sendo ajustada e propostas nas mais diversas atividades, da pesquisa ao uso comercial. No Brasil, são registrados 4 produtos no Ministério da Agricultura que têm em sua composição o ácido giberélico. $\mathrm{O}$ produto PROGIBB 400 (ADAPAR, 2017a) é composto exclusivamente com giberelinas na concentração de $40 \mathrm{~m} / \mathrm{v}$ e os produtos PROMALIN (ADAPAR, 2017b), composto com GA4+7 na concentração de $1,8 \mathrm{~m} / \mathrm{v}$ além de Citocinina (C 6-Benziladenina) e STIMULATE (ADAPAR, 2017c), composto com de GA3 $0,005 \mathrm{~m} / \mathrm{v}$, ácido indol butírico $0,005 \mathrm{~m} / \mathrm{v}$ (AIB) e cinetina (Citocinina) a $0,009 \mathrm{~m} / \mathrm{v}$.

Conforme a recomendação dos fabricantes, PROGIBB 400 tem seu uso registrado nas culturas de arroz, azevém, banana, batata, cana-de-açúcar, laranja, limão, milho, soja, trigo e uva. Para arroz, trigo e milho, o seu uso é recomendado para a promoção da germinação. Para banana, limão e laranja, para o retardamento do amadurecimento, visando o tempo de prateleira e o controle da mosca-dasfrutas. No azevém, para estimular o desenvolvimento das plantas. Para a soja, seu uso é indicado para aumentar o alongamento dos entrenós e desenvolvimento de flores e vagens (ADAPAR, 2017a).

O produto PROMALIN é recomendado apenas para macieiras. Atua no alongamento dos frutos aumentando seu tamanho e melhorando a relação comprimento/diâmetro dos frutos e possui efeito raleante, dispensando sua necessidade posterior. O STIMULATE é recomendado pelo fabricante para o tratamento de sementes, como promotor da germinação, até a formação de frutos (ADAPAR, 2017c) e congrega 3 reguladores de crescimento. O produto está registrado para o uso em alface, algodão, arroz, café, canade-açúcar, cevada, citros, feijão, milho, soja, tomate, trigo e uva, para o aumento de produtividade, enraizamento, crescimento e desenvolvimento vegetal.

\section{CONSIDERAÇÕES FINAIS}

A importância das giberelinas para a fisiologia vegetal, não foi percebida de imediato, com a sua descoberta numa espécie patogênica de fungo. As pesquisas envolvendo essas substâncias, que inicialmente estava restrito aos pesquisadores japoneses, ganhou grande impulso com o envolvimento de pesquisadores ingleses e americanos.

Comparado as auxinas, as giberelinas diferem quanto a sua estrutura, sendo classificadas como substâncias promotoras de crescimento, cujos efeitos podem ou não ser semelhantes. Já, como grupo, são quimicamente homogêneas. De todos os hormônios conhecidos, as giberelinas são os que mostram as maiores respostas quando aplicados às plantas.

Um dos efeitos comprovados cientificamente das GAs biologicamente ativas é a indução do alongamento do entrenó de plântulas anãs, entretanto tais efeitos não são verificados em plantas selvagens. Em função disso, houve uma expectativa sobre sua utilização comercial e esperavase uma revolução produtiva a partir do emprego destes.

Verificou-se, no entanto, que todos os seus efeitos eram essencialmente normais, mesmo assim em poucos anos as giberelinas tornaram-se comercialmente viáveis, devido a sua expressão universal em plantas, principalmente no desenvolvimento de frutos sem a fecundação, gerando produtos sem a presença de sementes como uvas, melancias, maças entre outras, favorecendo o fornecimento de produtos diferenciados para o mercado e viabilizando sua produção e utilização nesses fins.

\section{AGRADECIMENTOS}

O presente trabalho foi realizado com apoio da Coordenação de Aperfeiçoamento de Pessoal de Nível Superior - Brasil (CAPES) - Código de Financiamento 001. Os autores agradecem ao Prof. Dr. Marcelo Leandro Bueno pela leitura e sugestões.

\section{REFERÊNCIAS}

ADAPAR. Progib400, 2017a. Disponível em: http://www.adapar.pr.gov.br/arquivos/File/defis/DFI/Bulas/ Outros/progibb400.pdf. Acesso em: 28/09/2019.

ADAPAR. Promalin, 2017b. Disponível em: http://www.adapar.pr.gov.br/arquivos/File/defis/DFI/Bulas/ Outros/promalin.pdf. Acesso em: 28/08/2019.

ADAPAR. Stimulate ${ }^{\circledR}$ 2017c. Disponível em: http://www.adapar.pr.gov.br/arquivos/File/defis/DFI/Bulas/ Outros/STIMULATE_280519.pdf. Acesso em: 28/08/2019.

ARGYRIS, J.; DAHAL, P.; HAYASHI, E.; STILL, D.W.; BRADFORD, K.J. Genetic variation for lettuce seed thermoinhibition is associated with temperature-sensitive expression of abscisic Acid, gibberellin, and ethylene biosynthesis, metabolism, and response genes. Plant Physiol, v.148, n.2, p. 926-947, 2008.

BÖMKE, C.; TUDZYNSKI, B. Diversity, regulation, and evolution of the gibberellin biosynthetic pathway in fungi compared to plants and bactéria. Phytochemistry, v.70, n.15, p.1876-1893, 2009.

DEWICK, P. M. Medicinal natural products: A biosynthetic approach. Chichester: John Wiley e Sons, 1997, 509p.

FEITOSA, F. M.; JÚNIOR, I. O. A.; DAVID, A. M. S. S.; RODRIGUES, B. R. A.; DAMASCENA, N. S.; ARAÚJO, E. D.; AMARO, H. T. R. Efeito dos reguladores giberelina e citocinina na quebra de dormência de sementes de capim- 
andropogon. Revista de Ciências Agrárias, v.38, n.1, p.3440, 2015.

HECKMAN, N. L.; Horst, G. L.; GAUSSOIN, R. E.; TAVENER, B. T. Trinexapac-ethyl influence on cell membrane thermostability of Kentucky bluegrass leaf tissue. Scientia Horticulturae, v.92, p.183-6, 2002.

HEDDEN, P., PROEBSTING, W. M. Genetic Analysis of Gibberellin Biosynthesis. Plant Physiol, v.119, p.365-370, 1999.

HEDDEN, P.; MACMILLAN, J.; PHINNEY, B.O. The metabolism of the gibberellins. Annual Review of Plant Physiology, v.29, p.149-192, 1978.

HEDDEN, P.; SPONSEL, V. A century of gibberellin research. Journal Plant Growth Regulation, v.34, n.4, p.740-760, 2015.

HEDDEN, P.; KAMIYA, Y. Gibberellin Biosynthesis: Enzymes, Genes and Their Regulation. Plant Physiology, v.48, p.431-460, 1997.

KERBAUY, G. B. Fisiologia Vegetal, $2^{\mathrm{a}}$ ed. Rio de Janeiro: Guanabara Koogan, 2008. p.452

KUMAR, P. K. R.; LONSANE, B. K. Microbial Production of Gibberellins: state of the art. Advances in Applied Microbiology, v.34, p.29-139, 1989.

LAVAGNINI, C. G.; DI CARNE, C. A. V.; CORREA, F.; HENRIQUE, F.; TOKUMO, L. E.; SILVA, M. H.; SANTOS, P. C. S. Fisiologia Vegetal - Hormônio Giberelina. Revista Científica Eletrônica de Agronomia, Garça, v.25, n.1, p.48-52, 2014.

MÉTRAUX, J. P. Gibberellins and plant cell elongation. In: DAVIES, P.J. (Ed). Plant hormones and their role in plant growth and development. Dordrecht: Martinus Nijhoff Publishers, 1987. p.296-317.

MONTANS, F. M. Inoculação e aplicação de regulador vegetal em amendoim Runner IAC $886 \mathrm{em}$ solos de diferentes texturas. 39p. Dissertação (Mestrado em Agronomia) - Faculdade de Ciências Agrárias. Universidade de Marília, 2007.

OLSZEWSKI, N.; SUN, T.P.; GUBLER, F. Gibberellin signaling: biosynthesis, catabolism, and response pathways. Plant Cell, v.14, p.61- 80, 2002.

PETERSEN, R. Z. Biotransformação de terpenóides por culturas de células vegetais e fungos filamentosos. $206 \mathrm{p}$. Tese (Doutorado) - Faculdade de Farmácia. Universidade Federal do Rio Grande do Sul, 2006.

PLANT GROWTH REGULATORS. Plant Growth Regulators Market by Type (Auxins, Cytokinins, Gibberellins, Ethylene), Crop Type (Cereals \& Grains, Fruits \& Vegetables, Oilseeds \& Pulses, Turf \& Ornamentals), Formulation, Function, Origin, and Region - Forecast to 2022, 2017. Disponível em: http://www.marketsandmarkets.com. Acesso em: 27/08/2019.

RODRIGUES, T. J. D.; LEITE, I. C. Fisiologia vegetal: hormônios das plantas. Jaboticabal: Funep, 2004. p.78
SINGH, R.; KUMAR, M.; MITTAL, A.; MEHTA, P.K. Microbial metabolites in nutrition, healthcare and agriculture. 3 Biotech, v.7, n.1, p.15, 2017.

TAIZ, L.; ZEIGER, E.; MOLLER, I.; MURPHY, A. Fisiologia e desenvolvimento vegetal. $6^{\mathrm{a}}$ ed. Porto Alegre: Artmed, 2017. p.888

TAKAHASHI, N.; KITAMURA, H.; KAWARADA, A.; SETA, Y.; TAKAI, M. TAMURA, S.; SUMIKI, Y. Isolation of gibberellins and their properties. Bulletin of the Agricultural Chemical Society of Japan, v.19, n.4, p.267$277,1955$.

VIEIRA, E. L.; MONTEIRO, C. A. Hormônios vegetais In: CASTRO, P. R. C.; SENA, J. O. A.; KLUGE, R. A. M. Introdução à fisiologia do desenvolvimento vegetal. Maringá: Eduem, 2002. p.79-104.

WEAVER, R. J. Plant growth substances in agriculture. San Francisco: W.H. Freeman and Company, 1972. p.594.

\section{COPYRIGTH}

Direitos autorais: Os autores são os únicos responsáveis pelo material incluído no artigo.

Submetido em: 30/08/2019 Aprovado em: 17/09/2019 


\section{Área: Ciências Exatas e Engenharias}

\begin{tabular}{|c|c|}
\hline $1-3$ & $\begin{array}{l}\text { GERENCIAMENTO DE PUBLICIDADES NA PLATAFORMA } \\
\text { SOCIAIS DE ACORDO COM CATEGORIAS DE CONTEÚDO } \\
\text { ADVERTISING MANAGEMENT ON SOCIAL NETWORKS PLATFORMS } \\
\text { ACCORDING TO CONTENT CATEGORIES } \\
\text { Gustavo Nogueira De Sousa; Isabelle Da Silva Guimarães; Antonio Fernando } \\
\text { Lavareda Jacob; Fábio Manoel França Lobato }\end{array}$ \\
\hline $3-4$ & $\begin{array}{l}\text { DINÂMICA E CONTROLE VETORIAL DE UM MOTOR DE INDUÇÃO TRIFÁSICO } \\
\text { DYNAMIC AND VECTOR CONTROL OF THREE-PHASE INDUCTION MOTOR } \\
\text { Maxwell Diógenes Bandeira De Melo; Ivan Ney Alvizuri Romani; Sérgio Manuel } \\
\text { Rivera Sanhueza }\end{array}$ \\
\hline $3-4$ & $\begin{array}{l}\text { ANÁLISE DE VIABILIDADE FINANCEIRA DE UM PROJETO DE GERAÇÃO DE } \\
\text { ENERGIA FOTOVOLTAICA CONSIDERANDO DIFERENTES CENARIOS E } \\
\text { LOCALIDADES BRASILEIRAS } \\
\text { FINANCIAL FEASIBILITY ANALYSIS OF A PHOTOVOLTAIC GENERATION } \\
\text { PROJECT CONSIDERING DIFFERENT BRAZILIAN SCENARIOS AND } \\
\text { LOCATIONS } \\
\text { Sang Koo Monomi; Thyago Carvalho Marques; Sandrerley Ramos Pires }\end{array}$ \\
\hline $3-7$ & $\begin{array}{l}\text { VIABILIDADE PARA A IMPLEMENTAÇÃO DE UMA USINA DE RECICLAGEM } \\
\text { DE RESIDUOS DA CONSTRUÇÃO CIVIL NA REGIÃO METROPOLITANA DE } \\
\text { GOIÂNIA } \\
\text { VIABILITY FOR THE IMPLEMENTATION OF A CIVIL CONSTRUCTION WASTE } \\
\text { RECYCLING COMPANY IN THE METROPOLITAN REGION OF GOIÂNIA } \\
\text { Gabriel De Faria Feris; Thyago Carvalho Marques }\end{array}$ \\
\hline $3-8$ & $\begin{array}{l}\text { MELHORIA NO FLUXO EM UMA TRANSPORTADORA DE VALORES: UM } \\
\text { ESTUDO DE CASO } \\
\text { IMPROVEMENT FLOW IN A CASH TRUCK: CASE STUDY } \\
\text { Richele Querino; Arcione Ferreira Viagi; Hamzagic Miroslava; Jose Carlos Borges } \\
\text { De Paula }\end{array}$ \\
\hline $3-12$ & $\begin{array}{l}\text { DETECÇÃO DE FALHAS NO PROCESSO DE COMUNICAÇÃO E ANÁLISE DOS } \\
\text { IMPACTOS SOBRE A SEGURANÇA DE VÔO PELO CONTROLE DE TRÁFEGO } \\
\text { AÉREO } \\
\text { DETECTION OF FAILURES IN THE COMMUNICATION PROCESS AND } \\
\text { ANALYSIS OF IMPACTS ON FLIGHT SECURITY BY AIR TRAFFIC CONTROL } \\
\text { Robervandro Silva De Lima; Clauderino Da Silva Batista }\end{array}$ \\
\hline
\end{tabular}




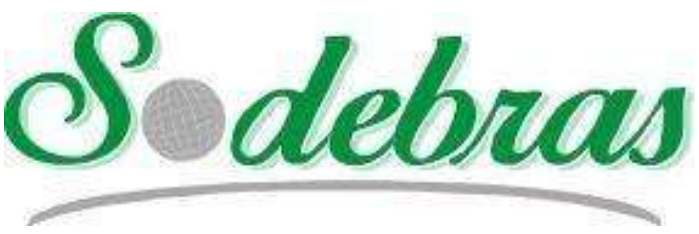

\author{
Revista SODEBRAS - Volume 14 \\ $\mathrm{N}^{\circ} 166$ - OUTUBRO/ 2019
}

\title{
GERENCIAMENTO DE PUBLICIDADES NA PLATAFORMA DAS REDES SOCIAIS DE ACORDO COM CATEGORIAS DE CONTEÚDO
}

\author{
ADVERTISING MANAGEMENT ON SOCIAL NETWORKS PLATFORMS \\ ACCORDING TO CONTENT CATEGORIES
}

\author{
GUSTAVO NOGUEIRA DE SOUSA ${ }^{1,3}$; ISABELLE DA SILVA GUIMARÃES ${ }^{2}$; ANTONIO FERNANDO \\ LAVAREDA JACOB JR $^{1}$; FÁBIO MANOEL FRANÇA LOBATO ${ }^{2}$ \\ 1 - UNIVERSIDADE ESTADUAL DO MARANHÃO (UEMA); 2 -UNIVERSIDADE FEDERAL DO OESTE \\ DO PARÁ (UFOPA); 3 - SOCIAL CRM RESEARCH CENTER (SCRC) \\ sougusta@gmail.com;isabelle.guimaraes2@gmail.com;jacobjr@engcomp.uema.br; \\ fabio.lobato@ufopa.edu.br
}

\begin{abstract}
Resumo - O uso de mídias sociais está se expandindo por diferentes setores da sociedade, consequentemente, uma grande quantidade de conteúdos gerados pelos usuários é produzida todos os dias. Devido aos diferentes efeitos gerados nos usuários, a gestão de conteúdo é essencial para a publicidade comercial nessas plataformas. No entanto, o grande volume de dados faz com que os custos para a medição dos efeitos que os conteúdos têm sobre os usuários sejam elevados. Este artigo investiga o uso de técnicas de aprendizado de máquina para automatizar o processo de análise, aumentando a eficiência dos processos $e$ a confiabilidade dos resultados. Mais especificamente, avalia-se o uso de um classificador de texto para categorizar as publicações de acordo com o seu conteúdo, como estudo de caso, adotou-se publicações de empresas no Facebook. Os resultados mostram que o classificador obtido apresenta potencial para analisar uma quantidade significativa de conteúdo com eficiência. $O$ classificador tem implicações práticas, uma vez que permite uma extensa análise dos concorrentes e também é capaz de influenciar as campanhas de marketing em mídias sociais.
\end{abstract}

Palavras-chave: Rede Social. Propaganda. Engajamento de usuários. Aprendizado de Máquina. Tomada de Decisão Baseada em Dados.

Abstract - Social media usage is expanding in different sectors of society; consequently, a large amount of User-Generated-Content is produced every day. Due to its various effects on users, content management is essential for business advertising on these platforms. However, the massive social media's data volume, increase the costs for analyzing the content effects on users. This paper examines the use of machine learning techniques to reduce the cost and effort of this kind of analysis. More specifically, an automatic document classification to identify content categories is evaluated. As a case study, we adopted some Facebook companies' posts. The results show that the machine learning classifier obtained has the potential to analyze a significant amount of content. The classifier has practical implications since it allows an extensive competitor analysis to be conducted and is also able to influence social media campaigns.

Keywords: Social Network. Advertising. User Engagement. Machine Learning. Data-Driven Decision Making.

\section{INTRODUÇÃO}

O uso de mídias sociais está crescendo constantemente (BELLO-ORGAZ et al., 2016). Em 2019, estima-se que essas plataformas tenham cerca de 2,77 bilhões de usuários, com o Facebook como plataforma líder, com 2,3 bilhões de usuários (SHIAU et al., 2018). Além disso, outras plataformas apresentam um grande número de usuários, como o Youtube com 1,9 bilhão, o Twitter com 330 milhões e o Instagram com 1 bilhão (STATISTA, 2018). Devido à facilidade de uso, os usuários podem criar, interagir, colaborar e compartilhar conteúdo com outras pessoas por meio dessas mídias (MAIZ et al., 2016). Este fenômeno resultou em uma melhoria significativa na comunicação e interação social, impactando diretamente na relação entre as empresas e seus clientes (PRADIPTARINI, 2011; ALMEIDA et al., 2017; LOBATO et al., 2017; SOUSA et al., 2018).

Devido a facilidade para compartilhar informações nessas plataformas, iniciou-se um fenômeno chamado de Boca a Boca Virtual (electronic Word-of-Mouth - eWoM), que transformou os consumidores em atores ativos (BARRETO et al., 2015). O eWoM pode ser entendido como $\mathrm{o}$ ato de criar e compartilhar informações sobre marcas, produtos e serviços nas mídias digitais (SCHMÄH et al., 2017). Isso significa que a mídia social se tornou um importante meio para compartilhar esses tipos de conteúdo (AHMAD and LAROCHE, 2017), podendo representar uma importante fonte de informações sobre as preferências das pessoas (ROSSOW, 2019).

As informações derivadas do eWoM permitem uma comparação entre marcas, produtos ou serviços (HUSSAIN et al., 2018). Ao aplicar métodos de detecção de comunidades em dados de mídia social, é possível fornecer insights úteis sobre algumas das dinâmicas e fenômenos que ocorrem nesses sistemas (SILVA et al., 2017). Além disso, este fenômeno está diretamente relacionado ao setor de turismo, já que um grande número de turistas seleciona seu destino, hotel, passeios e restaurantes com o auxílio de conteúdos de eWoM, tais como fotos, vídeos, avaliações e feedbacks (HARRIGAN et al., 2017; OLIVEIRA \& CASAIS, 2019). Isso pode ser descrito como Turismo Inteligente, que é definido como atendimento ao cliente de forma onipresente por meio de informações turísticas relevantes, e é caracterizado pela provisão, gerenciamento e compartilhamento de serviços e experiências durante a jornada dos turistas (GRETZEL et al., 2015; LI et al., 2017). 
As transformações e mudanças trazidas pelo uso do Turismo Inteligente podem ser potencializadas através da integração de sistemas de CRM (Customer Relationship Management) e planejamento de estratégias de atuação nas mídias sociais (COLOMO-PALACIOS et al., 2017). Essa estratégia reduz os riscos envolvidos na tomada de decisões e leva à transparência e confiança nos contatos com os clientes (COLOMO-PALACIOS et al., 2017; VECCHIO et al., 2018).

Tendo em vista a importância do eWoM para o mercado, neste artigo focamos na Publicidade em Redes Sociais (PRS) no que diz respeito a: A) As formas de conteúdo que são criadas pelas marcas e disseminadas pelas mídias sociais; e B) o Engajamento em Conteúdo Digital (ECD), que pode ser definido como o estado psicológico induzido pelas interações com a identidade da marca em um ambiente digital. Sete categorias de conteúdo PRS e três níveis de ECD são definidos por (GAVILANES et al., 2018), que podem ser correlacionados pelos analistas de marketing para determinar sua eficácia. Dada a grande quantidade de conteúdo PRS nas mídias sociais, são necessários altos custos e um esforço considerável para avaliar seu impacto no ECD (LIU et al., 2017). Neste contexto, a seguinte questão de pesquisa foi definida:

- É possível a classificação automática de posts de acordo com as categorias de conteúdo de PRS apresentadas por (GAVILANES et al., 2018)?

Para responder a essa questão de pesquisa, testamos diversos métodos de aprendizado de máquina, a fim de desenvolver um classificador automático de conteúdo de PRS com base nas categorias supramencionadas. O método de classificação automática de dados foi desenvolvido e testado em publicações sobre turismo no Facebook. Além disso, os profissionais validaram o modelo e discutiram suas implicações práticas. Por exemplo, é possível usar o classificador na automação da análise de concorrentes, na implementação de estratégias de marketing, avaliando o conteúdo de PRS e seu engajamento. É possível também o desenvolvimento de um sistema de suporte à decisão para prever o engajamento do usuário com base no conteúdo da postagem.

O restante deste artigo está estruturado como segue. $\mathrm{Na}$ Seção 2 descreve-se a metodologia empregada no estudo. Os resultados são analisados e discutidos na Seção 3. Finalmente, as conclusões e sugestões de trabalhos futuros são apresentadas na Seção 4.

\section{METODOLOGIA}

Nesta seção, a questão de pesquisa é respondida por meio de uma descrição do conjunto de dados, seguida pelas categorias de PRS e níveis de ECD, e pelo estabelecimento da Estrutura Experimental.

\section{1 - Descrição do conjunto de dados}

Neste trabalho, usamos dados que foram extraídos de publicações no Facebook de diversas empresas do setor de turismo. Seguindo os seguintes critérios de seleção: i) as empresas precisavam ter perfil no Facebook; e ii) as empresas deveriam estar ativas nos últimos seis meses, em outras palavras, ter postagens no respectivo período. Esta abordagem foi adaptada de (NOGUEIRA DE SOUSA et al.,
2018). O Facebook foi escolhido devido à sua popularidade, grande número de usuários e consequente relevância mercadológica. A extração de dados foi realizada por meio da API oficial do Facebook de janeiro a junho de 2018.

Os critérios de seleção foram definidos com base em (MAIZ et al., 2016). No total, dados de 93 empresas foram coletados de uma ampla gama de empreendimentos correlatos ao turismo, como bares, restaurantes, hotéis, pousadas e afins. Ao todo, houve um total de 10.925 publicações durante o período de extração, sendo os dados para cada publicação estão descritos na Tabela 1.

Tabela 1 - Descrição dos dados extraídos.

\begin{tabular}{|c|c|c|}
\hline$\underline{\text { Dados }}$ & Formato & Descrição \\
\hline Post ID & Numérico & $\begin{array}{l}\text { Identificação de cada } \\
\text { publicação na rede social. }\end{array}$ \\
\hline Texto & String & $\begin{array}{l}\text { Conteúdo textual de cada } \\
\text { publicação. }\end{array}$ \\
\hline Tipo & String & $\begin{array}{l}\text { Tipo de publicação - "foto", } \\
\text { "vídeo", "status" e/ou "link". }\end{array}$ \\
\hline Link & $\mathrm{URL}^{1}$ & Link da publicação. \\
\hline \multicolumn{2}{|c|}{ Data da publicação Data } & $\begin{array}{l}\text { Data de publicação na rede } \\
\text { social. }\end{array}$ \\
\hline Reação & Emoticons & $\begin{array}{l}\text { As reações dos usuários no post } \\
\text { - essas reações são: "Curtir", } \\
\text { "hahas", "amei", "wows", } \\
\text { "Triste", "Raiva", "Especial". }\end{array}$ \\
\hline $\begin{array}{l}\text { Compartilha- } \\
\text { mento }\end{array}$ & Numérico & $\begin{array}{l}\text { Número de vezes que a } \\
\text { publicação foi compartilhada. }\end{array}$ \\
\hline
\end{tabular}

\section{2 - Categorias de PRS e níveis de ECD}

Este artigo foca na publicidade em redes sociais e nos níveis de engajamento de conteúdo digital descritos por (GAVILANES et al., 2018). A Tabela 2 mostra as categorias de conteúdo com suas respectivas descrições. Da mesma forma, Tabela 3 mostra os níveis de ECD com uma avaliação de seu grau de influência sobre sua eficácia e a descrição de cada nível.

\section{3 - Estrutura Experimental}

A estrutura experimental adotada para o estudo é descrita na Figura 1 e é composta das seguintes etapas: 1) Aquisição de dados (dados brutos); 2) Pré-processamento de dados; 3) Anotação manual de uma amostra significativa dos dados; 4) Classificação do restante das publicações por meio de um algoritmo de aprendizado de máquina; 5) medição da precisão e validação do classificador obtido no passo 4 ; 6) Correlação das categorias PRS com os níveis de ECD; 7) Validação dos resultados obtidos.

Tabela 2 - Categorias de PRS adotadas de (GAVILANES et al., 2018)

\begin{tabular}{|c|c|c|}
\hline Categoria & Rótulo & Descrição \\
\hline Nenhuma & - & $\begin{array}{l}\text { Publicações que não pertencem a } \\
\text { nenhuma das outras categorias }\end{array}$ \\
\hline \multicolumn{2}{|c|}{$\begin{array}{l}\text { Anúncio de novo NP } \\
\text { produto }\end{array}$} & $\begin{array}{l}\text { Publicações destacando o anúncio de } \\
\text { novos produtos e/ou serviços. }\end{array}$ \\
\hline
\end{tabular}

${ }^{1}$ Uniform Resource Locator

Volume 14 - n. 166 - Outubro/2019 
Exposição do $\mathrm{CP}$ produto corrente

Sorteios e SW
concursos

Vendas

Feedback do CF consumidor entretenimento

Marca da organização
Informação e IT

Publicações que destacam o produto atual ou o retorno de um produto.

Publicações com informações sobre sorteios, regras e regulamentos.

Publicações que anunciam vendas ou promoções de um produto, incluindo informações de descontos e vouchers.

Publicações solicitando que os clientes forneçam informações, como avaliação do produto, avaliação ou problemas.

Publicações que fornecem informações novas, úteis, educativas ou interessantes.

OB Publicações que destacam a organização ou marca (por meio de logotipos, legendas, informações gerais da empresa, atributos organizacionais, rede de lojas e funcionários).

Elaborado pelo Autor.

Tabela 3 - Categorias de ECD descritas por (GAVILANES et al., 2018)

\begin{tabular}{llll}
\hline Categoria & Grau & Descrição & Métricas \\
\hline $\begin{array}{l}\text { Filtragem } \\
\text { positiva }\end{array}$ & Moderado & $\begin{array}{l}\text { Resposta } \\
\text { mostrando } \\
\text { atitudes } \\
\text { emocionais } \\
\text { positivas em } \\
\text { relação ao } \\
\text { conteúdo }\end{array}$ & $\begin{array}{l}\text { Reações (Curtir, } \\
\text { amei, wows, } \\
\text { haha, tristes, } \\
\text { raiva, especial). }\end{array}$ \\
$\begin{array}{l}\text { Processa- } \\
\text { mento } \\
\text { cognitivo e } \\
\text { afetivo }\end{array}$ forte & $\begin{array}{l}\text { Co-criação no } \\
\text { ambiente da } \\
\text { marca }\end{array}$ & Comentário. \\
Apoio & Forte & $\begin{array}{l}\text { Forte } \\
\text { investimento } \\
\text { cognitivo e } \\
\text { emocional, co- } \\
\text { criação de valor, } \\
\text { publicação, auto- } \\
\text { expressão }\end{array}$ \\
\hline
\end{tabular}

Elaborado pelo Autor.

A primeira etapa, descrita na Figura 1, é a aquisição de dados, a qual foi realizada por meio da API do Facebook. O processo de classificação automatizado envolve preparar e anotar os dados para construir um modelo de classificação. A segunda etapa foi a aplicação de métodos de préprocessamento nos textos de cada publicação visando reduzir o ruído. Este passo seguiu o workflow descrito por Cirqueira (2017a). O ruído, neste contexto, era composto por URLs, palavras irrelevantes, números, acentuação, emoticons e caracteres especiais.

Figura 1 - Fluxo de trabalho dos experimentos

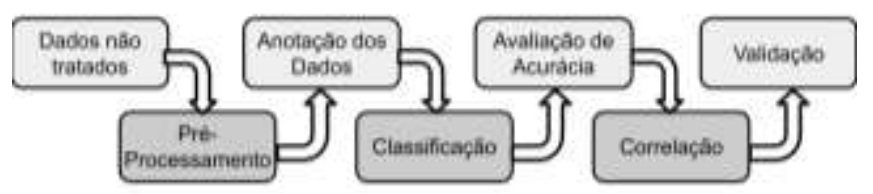

Elaborado pelo Autor.
A terceira etapa do fluxo de trabalho refere-se à anotação de dados manual de acordo com as categorias de PRS mencionadas anteriormente. A anotação foi realizada por dois avaliadores independentes utilizando-se de um sistema adaptado para tal (CIRQUEIRA et al., 2017b). A confiabilidade das anotações foi avaliada por meio do Coeficiente Kappa de Cohen e apenas os dados com concordância entre os anotadores foram retidos, em outras palavras, somente quando os dois avaliadores atribuíram o mesmo rótulo a uma publicação, a publicação era incluída ao conjunto de dados de treinamento.

Para o quarto passo do processo descrito na Figura 1, alguns algoritmos de aprendizado de máquina usados para classificação foram testados para responder às questões de pesquisa previamente definidas. Os algoritmos testados foram: K-Nearest Neighbors (KNN), Gaussian Nä̈ve-Bayes, Support-Vector Machine (SVM), Multinomial Nä̈ve-Bayes e Random Forest (RF). Esses algoritmos estão disponíveis no framework scikit-learn (PEDREGOSA et al., 2011). A parametrização do algoritmo foi realizada usando GridSearch para SVM, KNN e RF. Para os outros algoritmos os parâmetros padrão foram usados. Na Tabela 4 os algoritmos e parâmetros adotados são apresentados.

Tabela 4 - Lista de algoritmos e sua melhor parametrização considerando a precisão da classificação

\begin{tabular}{lll}
\hline Algoritmos & Parâmetros & Acurácia \\
\hline KNN & $\mathrm{k}=9$, distance $=$ 'cosine' & $73 \%$
\end{tabular}

Gaussian Naive Priors=None, Var_smoothing $=10^{\wedge} 9 \quad 71 \%$ Bayes

SVM

$$
\mathrm{C}=10000 \text {, Kernel='sigmoid' }
$$

$80 \%$

Multinomial Alpha $=1.0$, Class prior=None, Fit $68 \%$ Naive Bayes prior=True

Random Forest $\mathrm{n}$ estimators $=7$, min samples split $=9 \quad 79 \%$

Foram utilizadas as seguintes medidas de desempenho: Acurácia, Precisão, Recall e F1-measure (ponderada), e os dados foram estratificados por meio de validação cruzada (10 vezes). A F1-measure (ponderada) foi adotada em vez de micro / macro, uma vez que leva em conta o desequilíbrio do rótulo. À luz das melhores medições de desempenho, o algoritmo SVM foi adotado (Tabela 4).

A correlação das categorias de PRS com as métricas que determinam os níveis de ECD é realizada para determinar a eficácia do conteúdo. A validação foi realizada considerando um cenário real relacionado ao turismo inteligente, no qual dois profissionais que atuam nesse setor realizaram uma avaliação qualitativa dos resultados obtidos nas etapas anteriores.

O processo de avaliação consistiu em uma seleção aleatória de algumas publicações classificadas para serem usadas no processo de validação. Além disso, foi aplicado um algoritmo de modelagem de tópico para todo o conjunto de dados classificados, apresentando os resultados (por classe) para os profissionais. Eles analisaram se a correlação do tópico era consistente com as classes propostas. No entanto, devido a restrição no tamanho do artigo, a apresentação deste processo foi suprimida dos resultados. 


\section{RESULTADOS E DISCUSSÕES}

Neste trabalho foram coletados um total de 10.925 publicações de 93 empresas atuantes no setor de turismo, como bares, restaurantes, hotéis, pousadas e afins. Considerando a quantidade de publicações coletadas, foram necessárias 628 publicações para obter um intervalo de confiança de $99 \%$ com uma margem de erro de $5 \%$. No entanto, como era possível que os anotadores não correspondem ao mesmo rótulo para os mesmos dados, 1.020 publicações foram extraídas para anotação manual.

Como mencionado na Seção de Metodologia, as anotações foram avaliadas usando o coeficiente Kappa de Cohen e obtiveram o valor de 0,5 , o que significa que há um nível moderado de concordância entre as anotações. Esses dados inicialmente representavam $9 \%$ do número total de publicações, embora apenas os dados classificados com o mesmo rótulo fossem mantidos, o que resultou em 680 publicações, ou cerca de $6 \%$, mais do que o requerido pelo intervalo de confiança e erro previamente definido. Todos os dados foram extraídos, anotados e processados aleatoriamente.

Vários estágios de pré-processamento foram executados no conjunto de dados de treinamento, para limpar e remover todas as informações desnecessárias, por exemplo, URLs e palavras irrelevantes. No classificador SVM, as publicações que foram anotadas manualmente foram submetidas ao treinamento do algoritmo, e os resultados obtiveram uma Acurácia de 80,87\%, Precisão de $77,03 \%$, Recall de $80,87 \%$ e $F 1$-measure de $78,17 \%$. As medições de desempenho, também, podem ser observadas na Figura 2, que foi normalizada para fornecer uma melhor visualização de dados.

Como forma de provar que a classificação automática de publicações pode obter resultados semelhantes a uma classificação manual, o classificador treinado foi aplicado ao restante do conjunto de dados (cerca de $94 \%$ dos dados). Os resultados foram promissores, com a distribuição das categorias nos resultados observados na Figura 3 é possível observar que o uso de técnicas de aprendizado de máquina é uma maneira eficaz de reduzir o esforço da tarefa de rotulagem para medir a eficácia do PRS no ECD. Além disso, permite analisar grandes quantidades de dados e demonstrar como é a melhor envolver os usuários por meio de marketing em redes sociais(GAVILANES et al., 2018).
Figura 2 - Matriz de Confusão relacionada às categorias de ECD consideradas

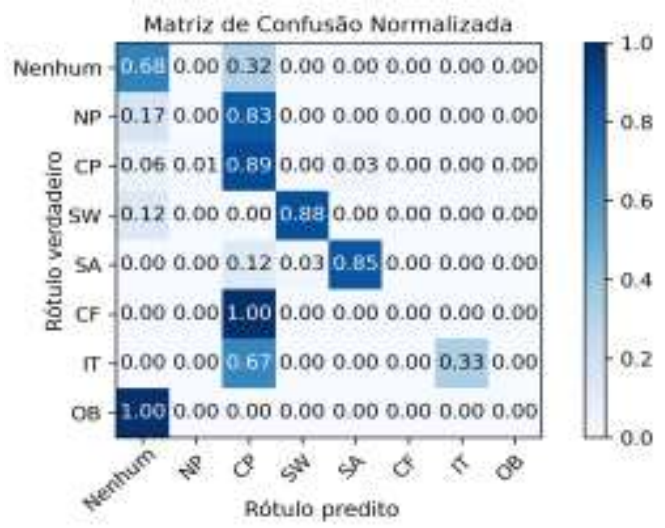

Elaborado pelo Autor.

A Tabela 5 foi montada com base nos resultados da classificação automática, e uma correlação pode ser observada entre as categorias de PRS e as métricas dos níveis de ECD propostas por (GAVILANES et al., 2018). Nestas, as categorias de Sorteios e Concursos têm um apelo maior ao ECD de acordo com a média de curtidas, comentários e compartilhamentos em cada publicação.

\section{CONCLUSÃO}

Esta pesquisa investigou o uso de técnicas de aprendizado de máquina para reduzir o custo e o esforço de avaliar estratégias de Publicidade em Redes Sociais. Para isso, adotamos as categorias de Engajamento de Conteúdo Digital propostas por (GAVILANES et al., 2018) e dados do Facebook. Com base em experimentos extensivos, avaliamos vários classificadores de aprendizado de máquina, a saber, K-Nearest Neighbors (KNN), Gaussian Naïve Bayes, Support Vector Machine (SVM), Multinomial Naïve Bayes e Random Forest (RF). Os resultados mostram que o classificador SVM tem um excelente potencial para realizar a classificação de conteúdo, a qual permite uma posterior correlação entre categorias e escala de engajamento. Sendo capaz de analisar uma grande quantidade de conteúdo com maior eficiência e menor custo/esforço. Assim, em termos proporcionais, o classificador automático pode alcançar resultados semelhantes aos obtidos pela anotação manual. No entanto, como é possível observar na Figura 2, algumas classes de conteúdo obtiveram uma classificação com erro inaceitável, a saber a NP, CF, IT e OB. Isto ocorreu devido ao desbalanceamento na quantidade de dados anotados manualmente para treino do classificador para estas classes, como exemplificado na Figura 3.

Tabela 5 - Relação do PRS com o ECD em posts do Facebook.

Nota: $\mathrm{AV}=$ Média e $\mathrm{F}=$ Frequência

\begin{tabular}{lrrrrrr}
\hline & \multicolumn{2}{c}{ Filtragem positiva } & \multicolumn{2}{c}{$\begin{array}{c}\text { Processamento cognitivo e } \\
\text { afetivo }\end{array}$} & \multicolumn{2}{c}{ Apoio } \\
\cline { 2 - 7 } & \multicolumn{1}{c}{ F } & Av & F & Av & F & Av \\
\hline Nenhum & 87,175 & 54,4 & 3820 & 2,3 & 5508 & 3,4 \\
Anúncio de novo produto & 23,523 & 36,7 & 947 & 5,5 & 472 & 1,7 \\
Exposição do produto corrente & 604,910 & 81,5 & 39367 & 5,3 & 26194 & 3,5 \\
Sorteios e concursos & 66,005 & 244,4 & 42617 & 157,8 & 7455 & 157,8 \\
Vendas & 128,148 & 100,9 & 3571 & 2,8 & 1742 & 1,3 \\
Feedback do consumidor & 331 & 16,5 & 27 & 1,35 & 4 & 0,2 \\
Informação e entretenimento & 1,977 & 34 & 160 & 2,75 & 99 & 1,7 \\
Marca da organização & 7,406 & 68,5 & 459 & 4,2 & 219 & 2 \\
\hline
\end{tabular}

Elaborado pelo Autor. 
Figura 3 - Os resultados fornecidos por anotações automáticas e manuais por categorias

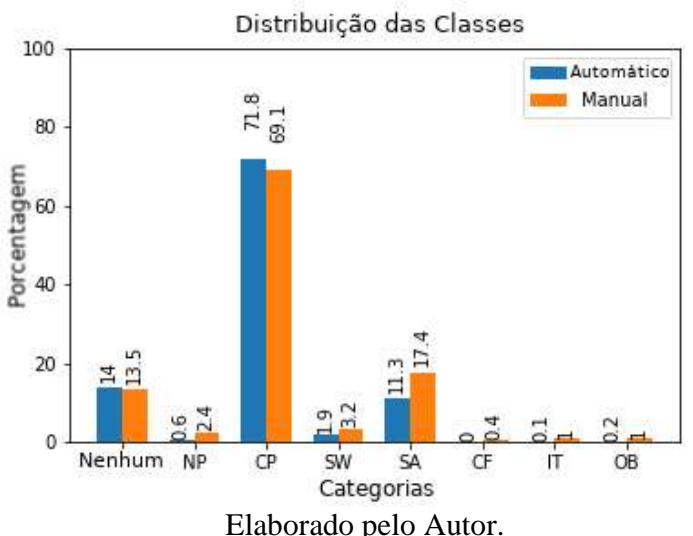

Os resultados do classificador foram avaliados $\mathrm{e}$ validados por profissionais. Com base nos resultados, algumas implicações práticas foram visualizadas: i) é possível acompanhar os concorrentes analisando automaticamente o conteúdo publicitário das mídias sociais; ii) o classificador pode ser incorporado em um sistema de suporte à decisão, auxiliando na mensuração do engajamento do usuário e no desenvolvimento de novas estratégias de marketing; iii) o classificador também pode apoiar a análise do engajamento do usuário de acordo com as demandas atuais do mercado por gerenciamento comunitário nos setores de energia e outros. Estes são serviços bem conhecidos fornecidos por agências de marketing digital (BARATA et al., 2018), que podem ser aprimorados pelo classificador obtido.

No entanto, existem algumas limitações em nosso estudo que precisam ser abordadas em estudos futuros. Primeiro, nosso conjunto de dados incluía apenas dados de turismo e, assim, resultou em um conjunto de dados desbalanceado. Em segundo lugar, como apenas dois anotadores foram usados, houve um baixo intervalo de confiança nos resultados. Em vista disso, em trabalhos futuros, gostaríamos de expandir nosso conjunto de dados para outros setores de mercado e incluir um terceiro anotador para melhorar a confiabilidade da pesquisa. Além disso, estamos planejando incluir técnicas que lidam com conjuntos de dados desbalanceados ou para melhorar o desempenho da classificação.

\section{AGRADECIMENTOS}

Os autores agradecem o apoio financeiro a essa pesquisa da Universidade Federal do Oeste do Pará (UFOPA), do Serviço Alemão de Intercâmbio Acadêmico (DAAD, SCRMSPECS) e Fundação de Amparo à Pesquisa e ao Desenvolvimento Científico e Tecnológico do Maranhão (FAPEMA).

\section{REFERÊNCIAS}

AHMAD, N.; LAROCHE, M. Analyzing electronic word of mouth: A social commerce construct. International Journal of Information Management. v. 37, n. 3, Junho/2017, p. 202-213.

ALMEIDA, G. R. T.; LOBATO F., CIRQUEIRA D. Improving Social CRM through electronic word-ofmouth: a case study of ReclameAqui. In: XIV Workshop de Trabalhos de Iniciação Científica (WTIC 2017), Gramado, Brasil. Anais do XXIII Simpósio Brasileiro de Sistemas
Multimídia e Web: Workshops e Pôsteres. Porto Alegre: Sociedade Brasileira de Computação, 2017.

BARATA, G. M.; VIANA J. A.; REINHOLD, O.; LOBATO F.; ALT, R. Social CRM in Digital Marketing Agencies: An Extensive Classification of Services. In: 2018 IEEE/WIC/ACM International Conference on Web Intelligence (WI), p. 750-753.

BARRETO, Ana Margarida. The Word-of-Mouth Phenomenon in the Social Media Era. International Journal of Market Research, v. 56, n. 5, p. 631-654, 2015.

BELLO-ORGAZ, G.; JUNG, J. J.; CAMACHO, D. Social big data: Recent achievements and new challenges. Information Fusion. v. 28, Março/2018, p. 45-59.

CIRQUEIRA, Douglas; VINÍCIUS, Lucas; et al. Opinion Label: A Gamified Crowdsourcing System for Sentiment Analysis Annotation. In: XVI Workshop de Ferramentas e Aplicações, p. 209-213, 2017a.

CIRQUEIRA, Douglas; JACOB JR, Antonio; et al. Performance Evaluation of Sentiment Analysis Methods for Brazilian Portuguese. In: Bus. Inf. Syst. Work. BIS 2016 Int. Work. Leipzig, Ger. July 6-8, 2016, Revis. Pap. [S.1.]: Springer, Cham, 2017b. p. 245-251.

COLOMO-PALACIOS, R.; GARCÍA-PEÑALVO, F. J.; STANTCHEV, V.; MISRA, S. Towards a social and contextaware mobile recommendation system for tourism. Pervasive and Mobile Computing, v. 38(2), Julho/2017, p. 505-515.

GAVILANES, J. M.; FLATTEN, T. C.; BRETTEL, M. Content Strategies for Digital Consumer Engagement in Social Networks: why advertising is an antecedent of engagement. Journal of Advertising. v. 47, 2018, p.4-23.

GRETZEL, U.; WERTHNER, H.; KOO, C.; LAMSFUS. C. Conceptual foundations for understanding smart tourism ecosystems. Computers in Human Behavior. v. 50, Setembro/2015, p. 558-563.

HAMILTON, J.; HOGAN, B.; LUCAS, K.; MAYNE, R. Conversations about conservation? Using social network analysis to understand energy practices. Energy Research \& Social Science. v. 49, Março/2019, p. 180-191.

HARRIGAN, P.; EVERS, U.; MILES, M.; DALY, T. Customer engagement with tourism social media brands. Tourism Management. v. 59, Abri/2017, p. 597-609.

HUSSAIN, S.; GUANGJU, W.; JAFAR, R. M. S.; ILYAS, Z.; MUSTAFA, G.; JIANZHOU, Y. Consumers' online information adoption behavior: Motives and antecedents of electronic word of mouth communications. Computers in Human Behavior. v. 80, Março/2018, p. 22-32.

LI, Y.; HU, C.; HUANG, C.; DUAN, L. The concept of smart tourism in the context of tourism information services. Tourism Management. v. 58, Fevereiro/2017, p. 293-300.

LIU, Bang et al. Growing story forest online from massive breaking news. In: International Conference on Information and Knowledge Management, Proceedings, v. Part F131841, p. 777-785, 2017.

LOBATO, F.; PINHEIRO, M.; JACOB JR, A.; REINHOLD, O.; SANTANA, Á. Social CRM: Biggest Challenges to Make it Work in the Real World. In: ABRAMOWICZ, W.; ALT, 
R.; FRANCZYK, B. (eds) Business Information Systems Workshops. BIS 2016. Lecture Notes in Business Information Processing, v. 263, 2017, p. 221-232.

LÓPEZ-DE-ARMENTIA，J.; CASADO-MANSILLA，D.; LÓPEZ-DE-IPIÑA, D. Making social networks a means to save energy. Journal of Network and Computer Applications. v. 59, Janeiro/2016, p. 237-46.

MAIZ, A.; ARRANZ, N.; JUAN. J. C. Factors affecting social interaction on social network sites: the Facebook case. Journal of Enterprise Information Management, v. 29 n. 5, 2016, p. 630-649.

OLIVEIRA, B.; CASAIS, B. The importance of usergenerated photos in restaurant selection. Journal of Hospitality and Tourism Technology, v. 10 n. 1, 2019, p. $2-14$.

PRADIPTARINI, C. Social Media Marketing: Measuring Its Effectiveness and Identifying the Target Market. Journal of Undergraduate Research, v. 14, 2011, p. 1-11.

ROSSOW, A. B. O uso do Big Data no estudo do Mercado consumidor, potencialidades para aplicação no Brasil. Revista Sodebras [on line] v.14, n.159, Dez./2019, p. 198202. ISSN 1809-3957. doi: https://doi.org/10.29367/issn.1809-3957.14.2019.159.203

SCHMÄH, M.; WILKE, T.; ROSSMANN, A. Electronic Word-of-Mouth: A Systematic Literature Analysis. In: Digital Enterprise Computing (DEC 2017), 2017, p. 147-158.

SHIAU, W. L.; DWIVEDI, Y. K.; LAI, H. H. Examining the core knowledge on facebook. International Journal of Information Management. v. 43, Dezembro/2018, p. 5263.

PEDREGOSA, F et al. Scikit-learn: Machine Learning in Python. Journal of Machine Learning Research, v. 12, p. 2825-2830, 2011.

SILVA, W.; SANTANA, Á.; LOBATO, F.; PINHEIRO, M. A methodology for community detection in Twitter. In: WI '17 Proceedings of the International Conference on Web Intelligence, 2017, p. 1006-1009.

SOUSA, G. N. de et al. Adoption of Social CRM in Micro and Small Enterprises: an Analysis of Santarém's Market. In: Proceedings of the 15th CONTECSI International Conference on Information Systems and Technology Management, v. 15, p. 0-2, 2018.

STATISTA. Facebook users worldwide. Disponível em: $<$ https://www.statista.com/statistics/264810/number-ofmonthly-active-facebook-users-worldwide/>. Acesso em 25 abr 2019.

VECCHIO, P. D.; MELE, G.; NDOU, V.; SECUNDO, G. Creating value from Social Big Data: Implications for Smart Tourism Destinations. Information Processing \& Management, v. 54, Setembro/2018, p. 847-860.

\section{COPYRIGHT}

Direitos autorais: Os autores são os únicos responsáveis pelo material incluído no artigo. 


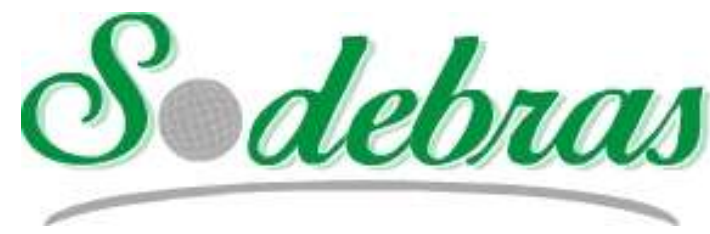

\author{
Revista SODEBRAS - Volume 14 \\ $\mathrm{N}^{\circ} 166$ - OUTUBRO/ 2019
}

\title{
DINÂMICA E CONTROLE VETORIAL DE UM MOTOR DE INDUÇÃO TRIFÁSICO
}

\author{
DYNAMIC AND VECTOR CONTROL \\ OF THREE-PHASE INDUCTION MOTOR
}

\author{
MAXWELL DIÓGENES BANDEIRA DE MELO ${ }^{1}$; IVAN NEY ALVIZURI ROMANI ${ }^{2}$; \\ SÉRGIO MANUEL RIVERA SANHUEZA ${ }^{3}$ \\ $1 ; 2 ; 3$ - UNIVERSIDADE FEDERAL DO TOCANTINS \\ maxwellmelo@uft.edu.br; ivanromani@uft.edu.br; sergiorivera@uft.edu.br
}

\begin{abstract}
Resumo - Neste trabalho, implementa-se a simulação da dinâmica de um Motor de Indução Trifásico (MIT) e, em seguida, simula-se o Controle Vetorial do MIT em dois testes básicos: primeiro, o de robustez e, em um segundo momento, o de inversão de velocidade. A técnica usada neste trabalho foi o controle vetorial conhecido como IUFOR (Indirect Universal Field Oriented Rotor) que tem como característica básica a estimativa do vetor fluxo rotórico e a orientação do sistema pela posição do mesmo. Os tempos de respostas obtidos neste trabalho tanto para o teste de inversão de velocidade quanto para o de robustez foram interessantes, e inferiores a um segundo.
\end{abstract}

Palavras-chave: Controle Vetorial. Motor de Indução. IUFOR.

Abstract - In this work, the simulation of the dynamics of a three-phase induction motor is implemented, and then the induction motor Vector Control is simulated in two basic tests: first, the robustness and, secondly, the of speed inversion. The technique used in this work was the vector control known as IUFOR (Indirect Universal Field Oriented Rotor), whose basic characteristic is the estimation of the rotor flux vector and the orientation of the system by its position. The response times obtained in this work for both the speed inversion test and the robustness test were interesting, and less than one second.

Keywords: Vector Control. Induction Motor. IUFOR.

\section{INTRODUÇÃO}

Os processos envolvendo controle de máquinas de Corrente Contínua (CC) são dominados há algum tempo, porém os processos referentes ao controle do MIT têm seu embrião no final da década de 1960 (LEONHARD, 1996). Começava assim uma etapa decisiva no que se refere ao controle da velocidade e do conjugado de um MIT com elevadas exigências de desempenho. Neste trabalho abordase o controle vetorial do MIT baseado numa orientação do sistema de referência (eixos $d$ e $q$ ) orientado pelo vetor fluxo rotórico (KABZINSKI, 2017; KRAUSE et al., 2013; QUANG e DITTRICH, 2015). Desta forma o eixo $d$ do sistema de coordenadas encontra-se em fase com o vetor fluxo rotórico.

As estratégias de controle vetorial baseadas na orientação pelo campo propiciam o controle desacoplado, ou quasi-desacoplado do fluxo e conjugado (LORENZ et al., 1997; FILADELFO, 2016). Sendo assim, tenta-se transformar o modelo do MIT em um modelo semelhante ao de um motor de $\mathrm{CC}$, que possui um desacoplamento natural entre essas grandezas. Vale lembrar que o desacoplamento entre fluxo e o conjugado nem sempre é um requisito necessário para o desempenho ótimo do sistema (SILVA, 1995). Os métodos de controle vetorial empregam variáveis de controle representadas por seus módulos e fases angulares. Com isso é possível efetuar um controle do MIT de maneira mais precisa, atendendo dessa forma, a certos critérios de desempenho. Os principais critérios de precisão são a rapidez e a exatidão na resposta das malhas de fluxo e de conjugado, custo do acionamento bem como a robustez (SILVA, 1995). Neste trabalho considera-se a rapidez da resposta e a robustez à aplicação de uma carga mecânica ao eixo do motor como figuras de méritos principais.

\section{MODELO DO MIT}

O termo Controle Vetorial, define uma série de técnicas de controle de máquinas elétricas cujas variáveis de controle e atuação são representadas por seus módulos e fases angulares ou por suas componentes em eixos ortogonais, possuindo, portanto, características vetoriais (SILVA, 1995; BOLDEIA e NASAR, 2017).

Existem diversas técnicas de controle vetorial, sendo que uma das técnicas usam os controladores UFO (Universal Field Oriented). Quando UFO é orientada segundo a componente de eixo direto do vetor fluxo rotórico é conhecida como UFOR (Universal Field Oriented Rotor) que por sua vez pode trabalhar no modo Direto (DUFOR) e Indireto (IUFOR) - (STOPA, 1997). Usa-se neste trabalho a técnica IUFOR.

Pode-se controlar o MIT de maneira direta ou indireta. Quando o vetor fluxo rotórico é medido através de sensores, estimadores ou observadores, diz-se que o controle vetorial é direto. Neste tipo de controle há uma vantagem clara, que é a robustez ante as variações paramétricas da máquina. No método indireto de orientação pelo campo, o vetor fluxo não é medido, mas calculado a partir dos parâmetros da máquina, este método é empregado devido a maior simplicidade de implementação (SILVA, 1995). O controlador a ser utilizado é o controlador universal orientado pelo vetor fluxo rotórico, calculado de maneira indireta (IUFOR). Um requerimento fundamental para a implementação desta técnica é definir corretamente o vetor 
fluxo rotórico. Orienta-se o eixo $d$ do sistema de coordenadas $d q$ de modo que sua fase coincida com o ângulo calculado para o vetor fluxo rotórico. Na Figura 1, baseada em (VAS, 1990), mostra-se a interação entre os principais vetores e o par $d q$.

Figura 1 - Disposição dos vetores envolvidos no controle vetorial

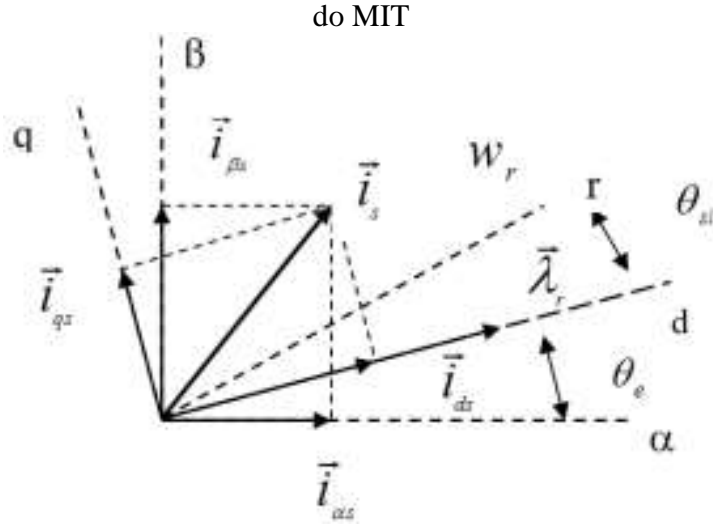

Fonte: Adaptado de (VAS, 1990) pelos autores.

Na Figura 1, os eixos $d$ e $q$ estão em uma velocidade angular de referência, estipulada por $w_{e}=\frac{d \theta_{e}}{d t} \operatorname{rad} . \mathrm{s}^{-1}$, que neste trabalho representa a velocidade do vetor fluxo rotórico. O eixo $d$ está em fase com o vetor fluxo rotórico $\left(\vec{\lambda}_{r}\right)$. Os eixos $\alpha$ e $\beta$ representam um sistema de eixos ortogonais estacionários. A corrente estatórica $\left(\vec{i}_{s}\right)$ é decomposta nos sistemas de coordenadas estacionário e de referência. $\mathrm{O}$ ângulo $\theta_{s l}$ refere-se à diferença de posição entre a velocidade do rotor e a do eixo $d$, e é chamado de ângulo de escorregamento.

O sistema da Figura 1 está orientado pelo vetor fluxo rotórico, pois percebe-se que o eixo $d$ está em fase com o mesmo.

O método indireto de controle vetorial é bastante sensível às variações paramétricas da máquina ou das aproximações feitas como, por exemplo, o comportamento não linear do fluxo magnético devido à saturação ou as variações da resistência do rotor com a temperatura ou o efeito pelicular. Com a orientação pelo campo têm-se uma significativa simplificação nas equações que regem o controle da máquina. Colocando-se as equações da máquina em um referencial síncrono com a posição do vetor fluxo rotórico, chega-se às seguintes equações de 1 a 14 (LORENZ et al., 1997):

$$
\begin{aligned}
& \vec{v}_{s}^{e}=r_{s} \vec{i}_{s}^{e}+p \vec{\lambda}_{s}^{e}+j w_{e} \vec{\lambda}_{s}^{e} \\
& \vec{v}_{r}^{e}=r_{r} \vec{i}_{r}^{e}+p \vec{\lambda}_{r}^{e}+j\left(w_{e}-w_{r}\right) \vec{\lambda}_{r}^{e}
\end{aligned}
$$

as equações 1 e 2 representam as tensões na forma vetorial,

$$
\begin{aligned}
& \vec{\lambda}_{s}^{e}=L_{s} \vec{i}_{s}^{e}+L_{m} \vec{i}_{r}^{e} \\
& \vec{\lambda}_{r}^{e}=L_{r} \vec{i}_{r}^{e}+L_{m} \vec{i}_{s}^{e}
\end{aligned}
$$

e as equações 3 e 4 representam o enlace de fluxo.

Novamente decompondo em termos de coordenadas $d$ e $q$ chega-se as seguintes equações:

$v_{q s}^{e}=r_{s} i_{q s}^{e}+p \lambda_{q s}^{e}+w_{e} \lambda_{d s}^{e}$

$v_{d s}^{e}=r_{s} i_{d s}^{e}+p \lambda_{d s}^{e}-w_{e} \lambda_{q s}^{e}$ $v_{q r}^{e}=r_{r} i_{q r}^{e}+p \lambda_{q r}^{e}+\left(w_{e}-w_{r}\right) \lambda_{d r}^{e}=0$

$v_{d r}^{e}=r_{r} i_{d r}^{e}+p \lambda_{d r}^{e}-\left(w_{e}-w_{r}\right) \lambda_{q r}^{e}=0$

Para as equações de enlace de fluxo tem-se:

$\lambda_{d s}^{e}=L_{s} i_{d s}^{e}+L_{m} i_{d r}^{e}$

$\lambda_{q s}^{e}=L_{s} i_{q s}^{e}+L_{m} i_{q r}^{e}$

$\lambda_{d r}^{e}=L_{r} i_{d r}^{e}+L_{m} i_{d s}^{e}$

$\lambda_{q r}^{e}=L_{r} i_{q r}^{e}+L_{m} i_{q s}^{e}$

As equações mecânicas do MIT são:

$J p\left(\frac{2}{P} w_{r}\right)=T_{e}-T_{L}-B\left(\frac{2}{P} w_{r}\right)$

$T_{e}=\frac{3}{2} \frac{P}{2} \frac{L_{m}}{L_{r}}\left(\lambda_{d r}^{e} i_{q s}^{e}-\lambda_{q r}^{e} i_{d s}^{e}\right)=\frac{3}{2} \frac{P}{2} L_{m}\left(i_{d r}^{e} i_{q s}^{e}-i_{q r}^{e} i_{d s}^{e}\right)$

Onde,

$p$ : Operador $d / d t$.

$\vec{v}_{s}^{e}$ : Tensão estatórica representada em vetores complexos em um referencial síncrono com a posição do vetor fluxo rotórico;

$\vec{i}_{s}^{e}$ : Corrente estatórica representada em vetores complexos em um referencial síncrono com a posição do vetor fluxo rotórico;

$\vec{\lambda}_{s}^{e}$ : Fluxo estatórico representado em vetores complexos em um referencial síncrono com a posição do vetor fluxo rotórico;

$\vec{v}_{r}^{e}$ : Tensão rotórica representada em vetores complexos em um referencial síncrono com a posição do vetor fluxo rotórico;

$\vec{i}_{r}^{e}$ : Corrente rotórica representada em vetores complexos em um referencial síncrono com a posição do vetor fluxo rotórico;

$\vec{\lambda}_{r}^{e}$ : Fluxo rotórico representado em vetores complexos em um referencial síncrono com a posição do vetor fluxo rotórico;

$v_{d s}^{e}$ : Tensão estatórica de eixo $d$ em um referencial síncrono com a posição do vetor fluxo rotórico;

$v_{q s}^{e}$ : Tensão estatórica de eixo $q$ em um referencial síncrono com a posição do vetor fluxo rotórico;

$i_{q s}^{e}$ : Corrente estatórica de eixo $q$ em um referencial síncrono com a posição do vetor fluxo rotórico;

$i_{d s}^{e}$ : Corrente estatórica de eixo $d$ em um referencial síncrono com a posição do vetor fluxo rotórico; $\lambda_{q s}^{e}$ : Fluxo estatórico de eixo $q$ em um referencial síncrono com a posição do vetor fluxo rotórico;

$\lambda_{d s}^{e}$ : Fluxo estatórico de eixo $d$ em um referencial síncrono com a posição do vetor fluxo rotórico;

$i_{q r}^{e}$ : Corrente rotórica de eixo $q$ em um referencial síncrono com a posição do vetor fluxo rotórico;

$i_{d r}^{e}$ : Corrente rotórica de eixo $d$ em um referencial síncrono com a posição do vetor fluxo rotórico; 
$\lambda_{q r}^{e}$ : Fluxo rotórico de eixo $q$ em um referencial síncrono com a posição do vetor fluxo rotórico;

$\lambda_{d r}^{e}$ : Fluxo rotórico eixo $q$ em um referencial síncrono com a posição do vetor fluxo rotórico;

$v_{q r}^{e}$ : Tensão rotórico de eixo $d$ em um referencial síncrono com a posição do vetor fluxo rotórico;

$v_{d r}^{e}$ : Tensão rotórico eixo $d$ em um referencial síncrono com a posição do vetor fluxo rotórico;

$J$ : Momento de inércia; $T_{e}$ : Torque eletromagnético; $T_{L}$ : Torque de carga; P: Número de polos; B: Coeficiente de atrito viscoso.

Antes de simular o Controle Vetorial do MIT é interessante obter resultados da sua dinâmica, para isso as equações de 1 a 14 são simuladas num referencial arbitrário. $\mathrm{O}$ sistema em diagrama de blocos a ser simulado pode ser apreciado na Figura 2. Onde Fonte é a alimentação do sistema por correntes trifásicas balanceadas transformadas para os eixos d e q, o bloco Conj. de Carga simula a carga mecânica do motor, Ids* é a corrente estatórica de referência para o eixo $d$, We é a velocidade de referência para o eixo d, que passa por um integrador para gerar um ângulo de referência $\theta_{\mathrm{e}}$, o MIT é um motor modelado com as equações de 1 a $14 \mathrm{e}$ os outros subsistemas são blocos de aquisição de sinais do MIT. O MIT simulado possui os seguintes parâmetros: Potência $=2 \mathrm{hp} ; \mathrm{P}=4$; Tensão $=220 / 380 \mathrm{~V}$; Corrente $=6,5$ / 3,8 A; Velocidade $=1720 \mathrm{rpm} ; J=0,018 \mathrm{Kg} \cdot \mathrm{m}^{2} ; \mathrm{B}=0,002$ N.m.s; Resistências $R_{s}=4,08 \Omega$ e $R_{r}=4,87 \Omega$; Indutâncias $L_{m}$ $=305 \mathrm{mH} ; L_{l s}=10,4 \mathrm{mH} ; L_{l r}=18,5 \mathrm{mH}$ (Parâmetros gentilmente cedidos pelo professor Selênio Silva).

Figura 2 - Sistema que simula a dinâmica de um MIT, em diagrama de blocos, no SIMULINK (MATLAB)

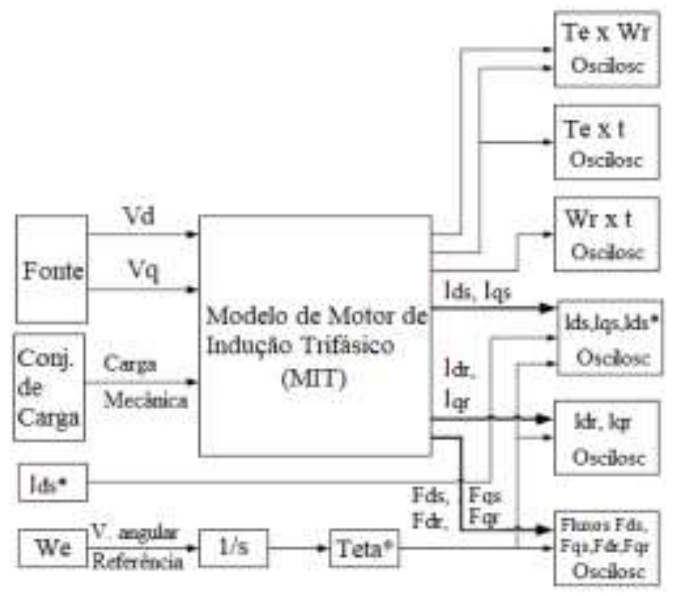

Fonte: Os autores.

\section{1- Resultados de simulação da dinâmica do MIT}

Nesta seção, serão vislumbradas as características mais importantes do MIT para uma simulação computacional, a qual que tem como principais figuras de mérito a partida em vazio do MIT e uma posterior aplicação de uma carga no motor, de valor igual á metade da carga nominal, em $t=1,25 \mathrm{~s}$ e a retirada da mesma em $t=2,25 \mathrm{~s}$. As simulações têm por objetivo principal mostrar como a velocidade do eixo do rotor do motor de indução sofre uma redução quando se aplica uma carga sobre este.

Na Figura 3 pode-se observar a forma ondulatória do conjugado eletromagnético da máquina em função da velocidade do rotor. Percebe-se que o torque eletromagnético tende a zero na velocidade de regime, e que oscila entre 0 e 4 N.m quando da aplicação e retirada da carga mecânica.

Figura 3 - Conjugado eletromagnético por velocidade angular rotórica

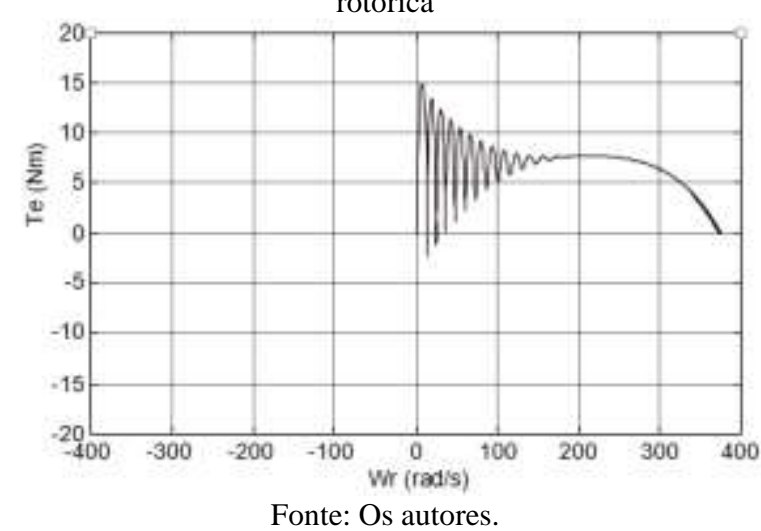

Na Figura 4 mostra-se o comportamento do MIT desde a partida até a aplicação de uma carga mecânica no valor de $4 \mathrm{Nm}$. Neste momento, verifica-se que a máquina responde a força contrária e, então, o conjugado eletromagnético tende a igualar-se ao conjugado de carga depois de uma constante de tempo que depende da inércia rotacional do eixo.

Figura 4 - Conjugado eletromagnético em função do tempo

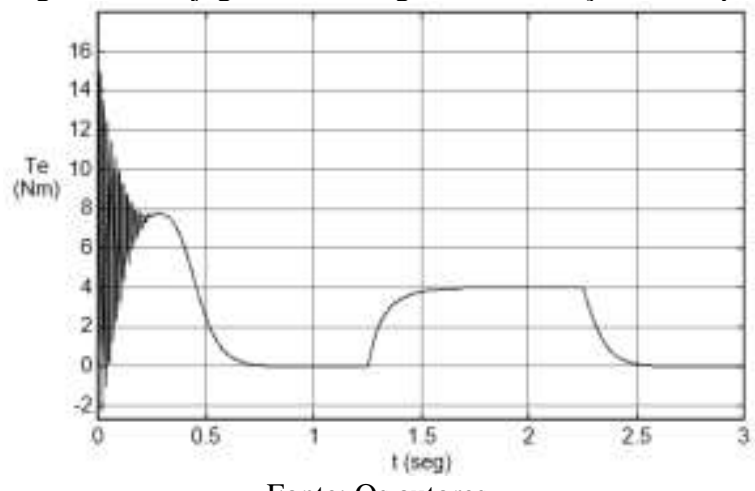

Fonte: Os autores.

Na Figura 5 observa-se a velocidade rotórica do MIT em regime que tende a $377 \mathrm{rad} . \mathrm{s}^{-1}$.

Figura 5 - Velocidade angular do rotor em radianos elétricos por segundo

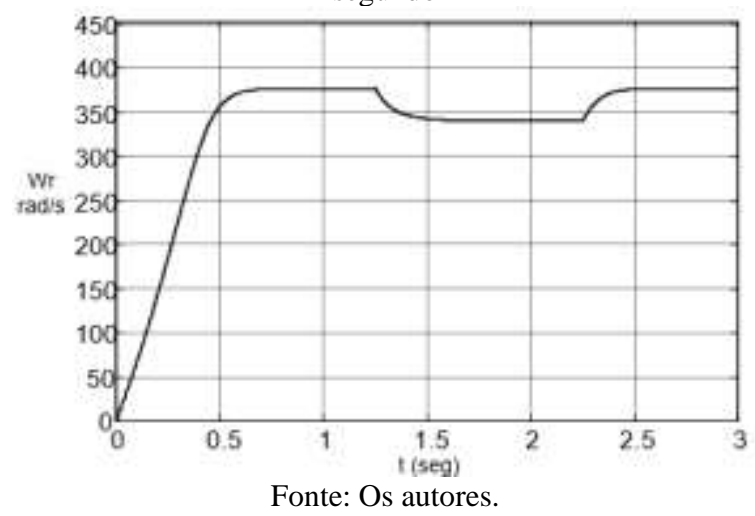

A redução de velocidade na Figura 5 ocorre porque foi aplicada uma carga no eixo, provocando um aumento da corrente requerida e consequentemente do conjugado 
eletromagnético. Em $t=1,25 \mathrm{~s}$ o conjugado de carga $\left(T_{l}\right)$ é maior que o conjugado eletromagnético $\left(T_{e}\right)$ pois, $T_{e}$ tende a zero neste instante. De acordo com a equação 13 pode-se constatar que $T_{e}$ tende a se estabilizar em outro valor, igual a $T_{l}$, zerando a aceleração.

Na Figura 6 observa-se a corrente estatórica do MIT para a fase "a". A partir de $\mathrm{t}=1,25 \mathrm{~s}$ a corrente estatórica sofre um aumento e retorna a corrente nominal depois da retirada da carga em $\mathrm{t}=2,25 \mathrm{~s}$.

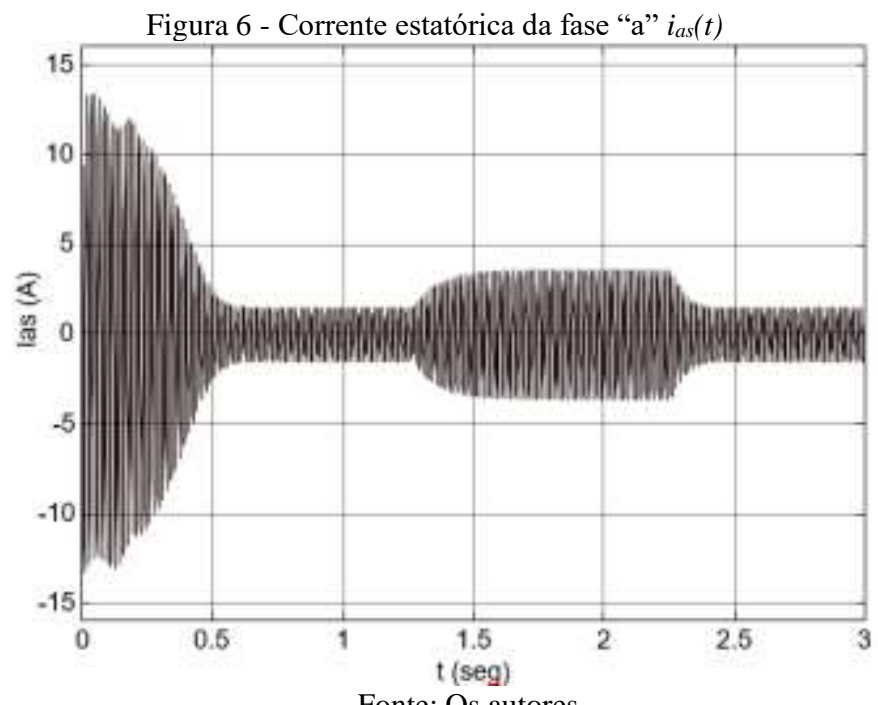

Fonte: Os autores.

\section{ESTRATÉGIAS DE CONTROLE}

A estratégia de controle utilizada neste trabalho é a IUFOR. Com o eixo $d$ do sistema $d q$ de coordenadas orientado pelo vetor fluxo rotórico chega-se ao conjunto de equações capazes de controlar de maneira eficaz o MIT. Definindo o vetor fluxo rotórico em termos de variáveis $d q$ :

$\vec{\lambda}_{r}=\lambda_{d r}+j \lambda_{q r}$

Pela Figura 1, conclui-se que $\lambda_{q r}=0$, pois não existe componente no eixo $q$ do sistema de coordenadas. $\operatorname{Logo} \vec{\lambda}_{r}=\lambda_{d r}$. Assim a Equação 14 pode ser reescrita da seguinte forma:

$T_{e}=\frac{3}{2} \frac{P}{2} \frac{L_{m}}{L_{r}} \lambda_{d r}^{e} i_{q s}^{e}$

Observa-se que se o fluxo rotórico pode ser controlado independentemente da corrente de estator de eixo em quadratura, e o conjugado ficará totalmente controlado pela componente de eixo $q$ da corrente estatórica. Assim, obtémse um controle desacoplado da máquina de indução, fazendo com que esta se assemelhe a um motor $\mathrm{CC}$, no qual fluxo e corrente de armadura estão fisicamente desacoplados. Em um sistema de acionamento sob orientação pelo fluxo magnético do rotor, a determinação da posição e do módulo do fluxo é geralmente realizada com base nos valores de referência $i_{d s}^{e^{*}}$ e $i_{q s}^{e^{*}}$ (o asterisco significa variável de referência), que são as referências dentro das quais se quer que o sistema trabalhe.

Da Equação 8 têm-se $r_{r} i_{d r}^{e}+p \lambda_{d r}^{e}=0$ logo,

$i_{d r}^{e}=-\frac{1}{r_{r}} p \lambda_{d r}^{e}$
Substituindo 17 em 11 obtêm-se,

$\lambda_{d r}^{e}=L_{r}\left(-\frac{1}{r_{r}} p \lambda_{d r}^{e}\right)+L_{m} i_{d s}^{e}$

$\lambda_{d r}^{e}\left(1+\frac{L_{r}}{r_{r}} p\right)=L_{m} i_{d s}^{e}$

Logo,

$\lambda_{d r}^{e}=\frac{L_{m} i_{d s}^{e}}{1+\tau_{r} p}$

Onde $\tau_{r}=\frac{L_{r}}{r_{r}}$, representa a constante de tempo rotórica.

A equação 18 representa o módulo do vetor fluxo rotórico. A posição deste vetor pode ser obtida utilizando-se a equação 7. Assim: $r_{r} i_{q r}^{e}+\left(w_{e}-w_{r}\right) \lambda_{d r}^{e}=0, \log$,

$w_{e}-w_{r}=-\frac{r_{r} i_{q r}^{e}}{\lambda_{d r}^{e}}$

Porém de 12 chega-se a seguinte equação,

$i_{q r}^{e}=-\frac{L_{m}}{L_{r}} i_{q s}^{e}$

de 18 e 20 em 19 obtém-se

$w_{e}-w_{r}=\frac{-r_{r}\left(-\frac{L_{m}}{L_{r}} i_{q s}^{e}\right)}{\left(\frac{L_{m} i_{d s}^{e}}{1+\tau_{r} p}\right)}$

Simplificando obtemos,

$w_{e}-w_{r}=\frac{\frac{1}{\tau_{r}} i_{q s}^{e}}{\frac{1}{1+\tau_{r} p} i_{d s}^{e}}$ ou $w_{e}-w_{r}=\frac{\frac{L_{m}}{\tau_{r}} i_{q s}^{e}}{\lambda_{d r}^{e}}$ ou $w_{e}=w_{r}+\frac{\frac{L_{m}}{\tau_{r}} i_{q s}^{e}}{\lambda_{d r}^{e}}$,

que define a velocidade angular do vetor fluxo rotórico como função das correntes estatóricas em quadratura e do fluxo rotórico em eixo direto do MIT. A posição do vetor fluxo rotórico é conseguida integrando no tempo a Equação 22 para $w_{e}$. Assim, definido o módulo e a posição do vetor fluxo rotórico, parte-se agora para o cálculo dos controladores de corrente. As equações 18 e 22 são a essência do controle vetorial indireto com orientação pelo campo. Na Figura 7 é mostrado um típico sistema de controle vetorial para um MIT.

Figura 7 - Sistema básico do controle vetorial de um MIT

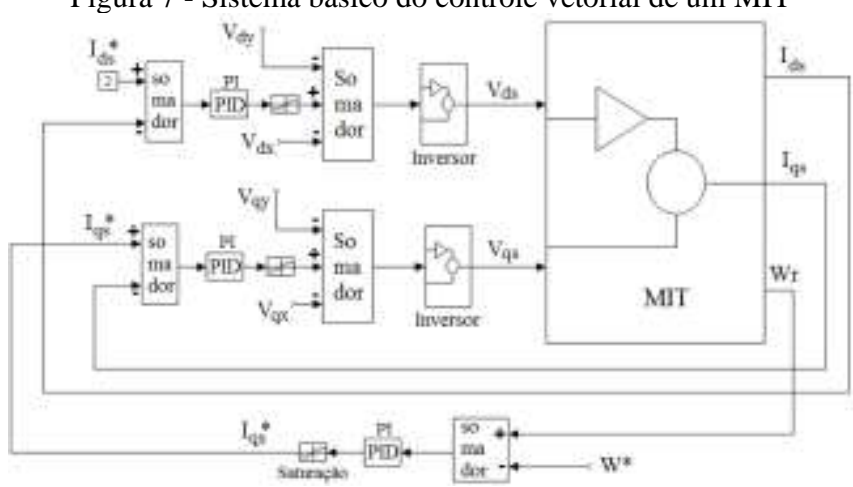

Fonte: Os autores.

Basicamente existem três malhas de realimentação, uma de velocidade e outras duas para as correntes. Como se trabalha com o modelo $d q$ do MIT, não há a necessidade de 
preocupar-se com as variáveis no sistema $a b c$, mesmo porque para obter essas variáveis, simplesmente aplica-se uma transformada de eixo $(d q / a b c)$. Nota-se na Figura 7 que existem três ganhos de controladores PI (proporcional e integral). Um ganho para a malha de corrente de eixo $d$, outro ganho para a malha de corrente de eixo $q$, e finalmente, um ganho para a malha de velocidade. Os termos $V d x$ e $V d y$ são tensões de compensações. A obtenção desses ganhos e das compensações é discutida em (STOPA, 1997). Para conseguir controlar o MIT eficientemente é necessário calcular os controladores responsáveis pelo gerenciamento das variáveis do processo. Pode-se encontrar esses ganhos por via matemática ou por métodos empíricos. Os controladores empregados são do tipo PI. O projeto dos ganhos proporcional e integral dos controladores foi realizado de modo a se cancelar o polo dominante e impor um amortecimento de 0,707. Com essa estratégia, conseguese oscilações consideravelmente amortecidas e respostas razoavelmente rápidas. O projeto desses controladores é mostrado em MELO, 1998.

\section{CONTROLE VETORIAL DO MIT: O SISTEMA E RESULTADOS DAS SIMULAÇÕES}

Essencialmente o sistema de controle digital de um MIT tem que executar o processo mostrado na Figura 8. É necessário fazer a aquisição das variáveis de controle do MIT, a saber: $i_{a}(t), i_{b}(t), i_{c}(t)$ e $w_{r}$. Logo após realiza-se o algoritmo de controle sob a técnica IUFOR, cujo objetivo é o cálculo dos novos valores de referência, que são comparados com as grandezas reais do MIT. Dessa comparação obtém-se um erro que, após passar por controladores PI, geram as tensões necessárias para que o MIT mantenha a velocidade de referência. Neste trabalho o PWM e o inversor são representados apenas como um atraso nas tensões $v_{d s}$ e $v_{q s}$. Serão mostrados agora os resultados nos testes de inversão de velocidade e de robustez.

Figura 8 - Sistema de controle do MIT sob a técnica IUFOR

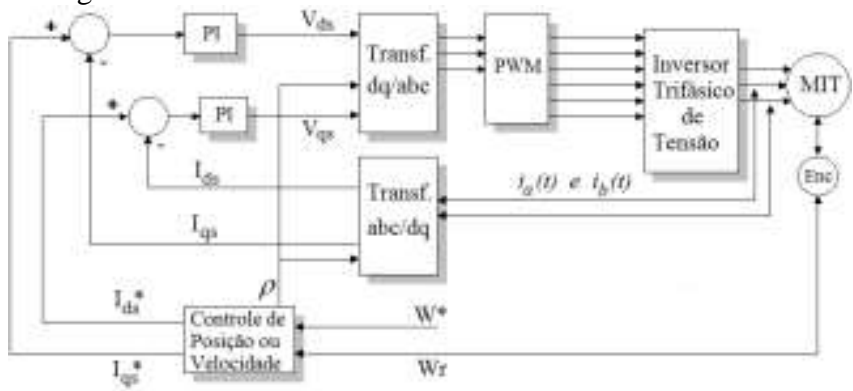

Fonte: Os autores.

\section{1- Teste de Inversão de Velocidade}

Na Figura 9, a referência de velocidade muda de 200 rad. $\mathrm{s}^{-1}$, em $t=1,5 \mathrm{~s}$, para $-200 \mathrm{rad} . \mathrm{s}^{-1}$. Logo após, inverte-se a referência novamente para $200 \mathrm{rad} . \mathrm{s}^{-1}$, em $t=3,5 \mathrm{~s}$, fazendo com que o MIT retorne à velocidade requerida que, neste caso, é $w^{*}=200 \mathrm{rad} . \mathrm{s}^{-1}$ (valor de referência). Percebe-se que o MIT segue a inversão de velocidade que, na prática, significa uma inversão em duas das três fases que alimenta o MIT.

O erro em regime é nulo com um atraso de aproximadamente de $0,8 s$ na resposta, ou seja, o MIT leva este tempo para chegar na velocidade de referência. Esse resultado está de acordo com SZOKE et al., 2014, em que obteve um valor de $0,75 \mathrm{~s}$ para um motor semelhante ao deste trabalho.

Figura 9 - Velocidade de referência (vermelho) e a velocidade do eixo do rotor (azul) em rad.s $\mathrm{s}^{-1}$

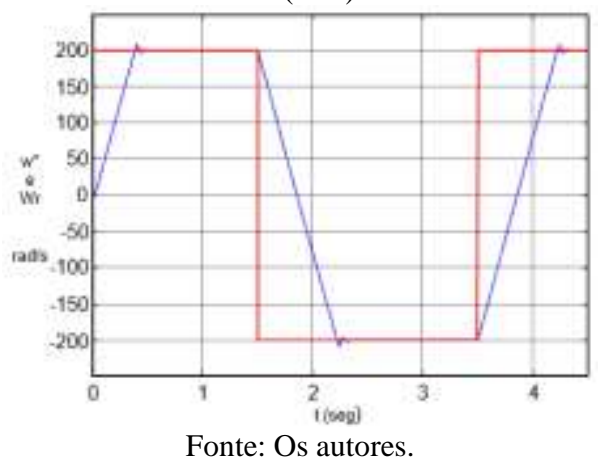

A rapidez da resposta pode ser ajustada através do valor de referência do conjugado eletromagnético na malha de velocidade. Na Figura 10 pode-se observar o plano de fase $T_{e} \quad x \quad w_{r}$. Nota-se que o torque eletromagnético se mantém aproximadamente constante exceto para os momentos de inversão de velocidade.

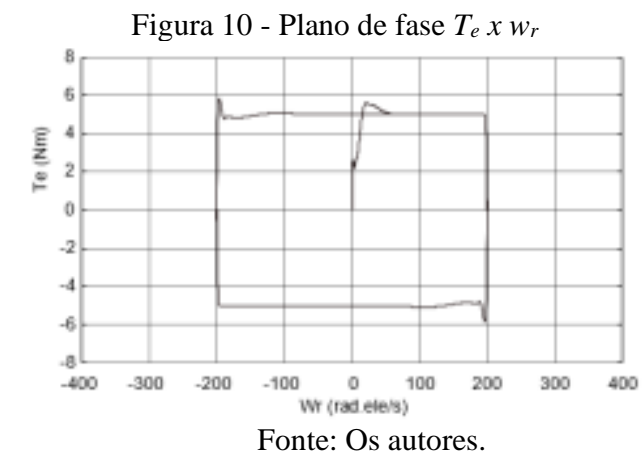

A corrente estatórica da fase "a" do MIT, para este teste, pode ser vista na Figura 11.

Figura 11 - Corrente estatórica de fase "a" requerida pelo MIT para a simulação de inversão de fase

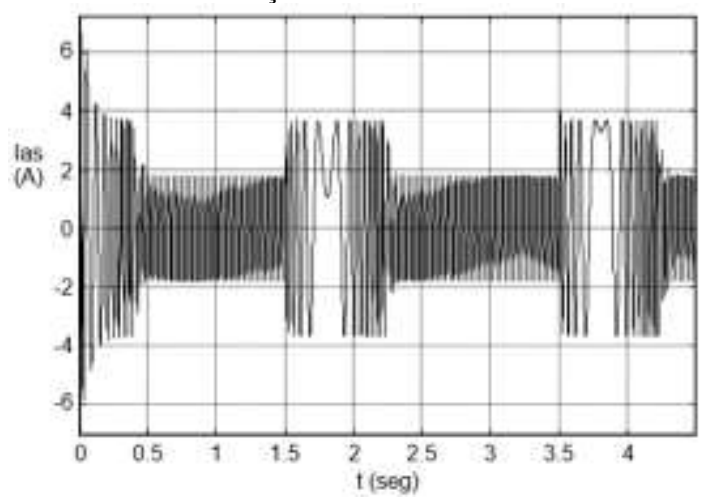

Fonte: Os autores.

\section{2- Teste de Robustez}

Na Figura 12 foi aplicada uma carga mecânica no eixo do rotor em $t=1,5 \mathrm{~s}$ e, logo após, esta carga é retirada em $t=3,5 s$. O módulo do conjugado de carga é de metade do conjugado nominal. Notar a diferença entre Figura 12 e a Figura 5, nesta, a velocidade do rotor, sofre uma queda devido á carga aplicada ao eixo e volta a velocidade de regime apenas quando a carga é retirada. Na Figura 12 a velocidade do rotor retorna a velocidade de referência 
independentemente da carga. A velocidade rotórica retorna para a referência em um tempo inferior a $0,4 \mathrm{~s}$, e isto é um bom resultado e compatível com FILADELFO, 2016, que obteve aproximadamente $2 \mathrm{~s}$ para um teste semelhante. A corrente estatórica da fase "a" do MIT, pode ser vista na Figura 13 para este teste.

Figura 12 - Velocidade de referência (azul) e velocidade do eixo do rotor (vermelho) em rad.s ${ }^{-1}$

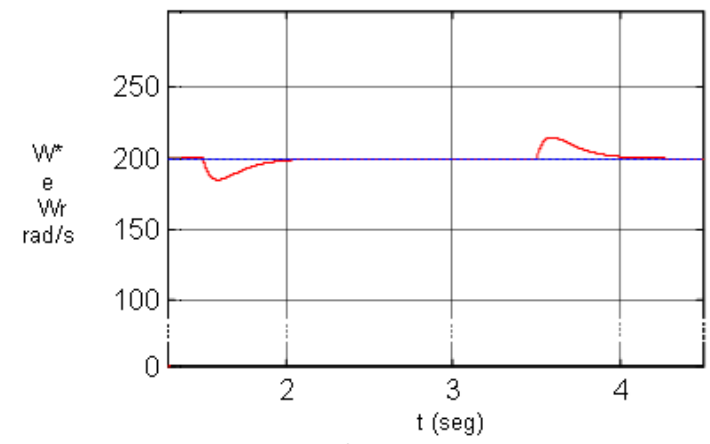

Fonte: Os autores.

Figura 13 - Corrente estatórica de fase "a" requerida pelo MIT para a simulação de uma aplicação e retirada de uma carga mecânica ao eixo do MIT

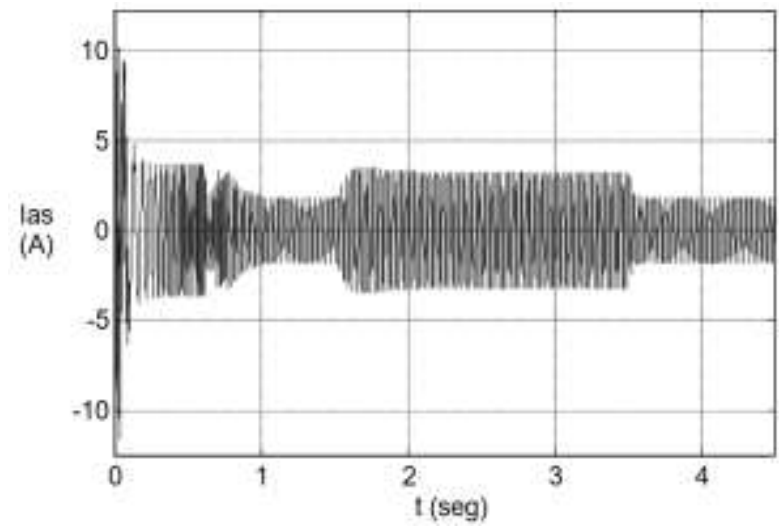

Fonte: Os autores.

Nessas simulações o controlador universal orientado pelo vetor fluxo rotórico mantém o MIT em uma velocidade de referência preestabelecida, suportando impactos de carga mecânica bastante consideráveis. Os testes de inversão de velocidade e de robustez são amplamente usados para medir a performance de um MIT e possuem aplicações na indústria em esteiras mecânicas, bombas, compressores, ventiladores, bombas de pistão e laminadores dentre outras aplicações.

\section{CONCLUSÕES}

O método de controle vetorial Indireto Orientado pelo Vetor Fluxo Rotórico (IUFOR), no teste de inversão de velocidade, apresenta um atraso na resposta de aproximadamente de $0,8 \mathrm{~s}$, que é um resultado bastante promissor quando comparados com outras pesquisas.

No teste de robustez, verificou-se resultados interessantes mesmo quando comparados com motores de menor inercia rotacional.

Os resultados tanto para a dinâmica quanto para o controle vetorial do MIT mostram a eficácia da metodologia empregada.

\section{AGRADECIMENTOS}

Aos professores Francisco de Assis dos Santos Neves e Selênio Rocha Silva in memoriam, pelos diversos esclarecimentos e orientações para realização deste trabalho.

\section{REFERÊNCIAS}

BOLDEIA, I., NASAR, S.A. Vector Control of AC Drives, CRC Press, 2017.

FILADELFO, F. R. Modelagem de controle vetorial orientado pelo fluxo do estator de motor de indução trifásico aplicado em um sistema de propulsão veicular. Tese (doutorado) - Universidade Estadual Paulista, Faculdade de Engenharia de Guaratinguetá, 2016.

KABZINSKI, J. (Ed.). Advanced Control of Electrical Drives and Power Electronic Converters, Springer, 2017.

KRAUSE, P., WASYNCZUK, O., SUDHOFF, S., PEKAREK, S. Analysis of Electric Machinery and Drive Systems, third edition, Wiley, 2013.

LEONHARD, W. Control of Eletrical Drives, $2^{\mathrm{a}}$ ed Springer Verlag, Berlim Heidelberg, 1996.

LORENZ, R.D., LIPO, T.A., NOVOTNY, D.W. Motion Control with Induction Motors, In: Bimal K. Bose (Ed.), Power Electronics and Variable Frequency Drives, IEEE Press, NJ-USA, 1997.

MELO, M. D. B. Simulação da Dinâmica e do Controle Vetorial Indireto com Orientação pelo Vetor Fluxo Rotórico de um Motor de Indução Trifásico. Dissertação de Mestrado - Universidade de Brasília. Faculdade de Tecnologia. Departamento de Engenharia Elétrica, 1998.

QUANG, N.P., DITTRICH, J.A. Vector Control of ThreeFase AC Machine: System development in the practice, Second edition, Springer, 2015.

SILVA, S.R. Sistemas Elétricos de Alto Desempenho à Velocidade Variável: Estratégias e Controle e Aplicações. Tese para Concurso de Professor Titular, Escola de Engenharia da UFMG, p. 157, 1995.

STOPA, M.M. Controle por Orientação pelo Campo: Uma Implementação Utilizando um Conversor CA/CC/CA com Retificador Chaveado. Dissertação de Mestrado, Escola de Engenharia da UFMG, Belo Horizonte, 1997.

SZOKE, E., SZABO, C., IMECS, M., INCZE, I.I. Double Field Oriented Sensorless Control of Cage Induction Motor, 15th IEEE International Symposium on Computational Intelligence and Informatics, p. 19-21, 2014.

VAS, P. Vector Control of Induction Machines, In: P. Hammond e R.L. Grimsdale (Eds.), Vector Control of AC Machines, Clarendon Press, Oxford-Inglaterra, p. 331, 1990.

\section{COPYRIGTH}

Direitos autorais: Os autores são os únicos responsáveis pelo material incluído no artigo.

Submetido em: 28/08/2019 Aprovado em: 18/09/2019 


\title{
Revista SODEBRAS - Volume 14 \\ $\mathrm{N}^{\circ} 166-$ OUTUBRO/ 2019
}

\section{Sodebras}

\section{ANÁLISE DE VIABILIDADE FINANCEIRA DE UM PROJETO DE GERAÇÃO DE ENERGIA FOTOVOLTAICA CONSIDERANDO DIFERENTES CENÁRIOS E LOCALIDADES BRASILEIRAS}

\section{FINANCIAL FEASIBILITY ANALYSIS OF A PHOTOVOLTAIC GENERATION PROJECT CONSIDERING DIFFERENT BRAZILIAN SCENARIOS AND LOCATIONS}

\author{
SANG KOO MONOMI ${ }^{1}$; THYAGO CARVALHO MARQUES ${ }^{2}$; SANDRERLEY RAMOS PIRES ${ }^{3}$ \\ $1 ; 2 ; 3$ - UNIVERSIDADE FEDERAL DE GOIÁS \\ thyago@ufg.br
}

\begin{abstract}
Resumo - O trabalho tem como objetivo apresentar um estudo de viabilidade financeira da geração de energia elétrica através de um sistema de geração fotovoltaica a ser implementado em uma empresa de saneamento básico considerando o limite da isenção do ICMS. Os resultados e benefícios são mostrados através de um conjunto de indicadores financeiros, facilitando o processo de tomada de decisões de investimentos da empresa. Um conjunto de análises de sensibilidades foram desenvolvidas, demonstrando que há viabilidade no sistema de geração fotovoltaica em suas diferentes configurações, mesmo se instalada em todas unidades Federativas Brasileiras, considerando suas características particulares como irradiação e preço de tarifa de energia, inclusive quando não se considera a isenção do ICMS. Nessa última situação, para que haja viabilidade de implementação do sistema, deveria ter uma capacidade instalada da ordem $3 \mathrm{MW}$.
\end{abstract}

Palavras-chave: Viabilidade Financeira. Engenharia Econômica e Financeira. Energia Fotovoltaica.

\begin{abstract}
The objective of this paper is to present a financial feasibility study of electric power generation through a photovoltaic system to be implemented in a sanitation company considering the ICMS exemption limit. Results and benefits are shown through a set of financial indicators, facilitating the company's investment decision making process. A set of sensitivity analyzes have been developed, showing that the photovoltaic generation system is viable in its different configurations, even if installed in all Brazilian Federative Units, considering its particular characteristics such as irradiation and energy tariff price, even when not considered. ICMS exemption. In the latter situation, for system implementation to be feasible, it should have an installed capacity of the order of $3 \mathrm{MW}$.
\end{abstract}

Keywords: Financial Viability. Economic and Financial Engineering. Photovoltaics.

\section{INTRODUÇÃO}

$\mathrm{O}$ alto crescimento da utilização de sistemas fotovoltaicos $(\mathrm{FV})$ para a geração de energia elétrica originase das constantes inovações na indústria que tem permitido a viabilidade destes sistemas. Segundo ABINEE (2012), as tecnologias disponíveis comercialmente vêm reduzindo os custos aumentando a eficiência destes sistemas, por meio de novos produtos e processos de produção, disposição, financiamento e instalação.

A Resolução Normativa no 482 de 2012 da ANEEL, autoriza os consumidores a gerar sua energia elétrica para consumo a partir de fontes renováveis e fornecer o excedente de energia gerado a rede de distribuição da concessionária local, obtendo créditos em energia para serem utilizados em faturas de consumo de energia subsequentes. Não abatendo ao custo de disponibilidade (grupo B), e a demanda contratada (grupo A).

Em 2015 o Conselho Nacional de Política Fazendária (CONFAZ), publicou o Convênio ICMS 16, que possibilita a isenção de ICMS incidente sobre a energia elétrica injetada na rede de distribuição da concessionária nas operações internas de circulação de energia elétrica. Como a compensação de ICMS da energia elétrica produzida é aplicada à microgeração e a minigeração, o incentivo se dá até o limite de sistemas com potência instalada de até $1 \mathrm{MW}$, incentivando consumidores menores e minigeradores.

O benefício da geração da energia FV desta modalidade pode ser bem aproveitado, a exemplo de uma determinada empresa de saneamento localizada no estado de Goiás, que possui custos elevados com energia elétrica.

O objetivo deste trabalho é desenvolver um estudo de viabilidade financeira da geração de energia elétrica através de um sistema de geração fotovoltaica a ser implementado em uma empresa de saneamento básico considerando o limite da isenção do ICMS. Os resultados e benefícios serão mostrados através de um conjunto de indicadores financeiros, e de analises de sensibilidade, que visa demonstrar que há viabilidade no sistema de geração fotovoltaica em suas diferentes configurações, mesmo se instalada em todas unidades Federativas Brasileiras, considerando suas características particulares como irradiação e preço de tarifa de energia, inclusive quando não se considera a isenção do ICMS.

\section{MÉTODO, MODELAGEM E IMPLEMENTAÇÃO DO SISTEMA FOTOVOLTAICO}

Nos sistemas FV de geração distribuída, há maior frequência de sistemas onde a geração ocorre na mesma 
localidade do consumo e abatimento do custo energético. Mas como a tarifa de consumo é menor, em locais onde a potência/carga instalada é maior, os benefícios do abatimento do custo energético são mais baixos. Desta forma, no projeto para a usina fotovoltaica foi definido utilizar a energia gerada na modalidade de autoconsumo remoto, possibilitando selecionar o local onde a tarifa de consumo é mais alta para trazer maior benefício.

\section{1 - Dimensionamento e Geração do Sistema}

Como se trata de sistema de energia FV via Geração Distribuída, no qual os créditos da geração de energia irão abater os custos do consumo, é necessário que a geração de energia esteja ajustada à demanda do local.

$\mathrm{O}$ dimensionamento do sistema de geração FV através da energia pretendida (ou consumida) pode ser calculada pela equação (1) demonstrada em Pinho et al. (2014):

$\mathrm{Pf}=\mathrm{E} /(\mathrm{PR} * \mathrm{HSP})$

Onde:

Pf = Potência de pico do painel FV (Watt-pico)

$\mathrm{E}=$ Consumo diário médio anual $(\mathrm{Wh} / \mathrm{dia})$

$\mathrm{PR}=$ Performance Ratio (adimensional)

HSP = Média Diária anual das HSP incidente no plano do painel FV ( $\mathrm{kWh} / \mathrm{m}^{2}$.dia $)$

A Performance Ratio (PR) representa a relação percentual entre o rendimento real e o rendimento esperado do sistema fotovoltaico (SMA, 2011). É uma medida para avaliação da eficiência de um sistema fotovoltaico por considerar todas as perdas do sistema (aquecimento dos módulos, queda de tensão, sombreamento, entre outras).

Além de ser utilizada para estimar a quantidade de energia que será gerada pelo sistema, a PR é uma medida de eficiência do sistema que pode ser usada para comparar sistemas de energia FV de outras localidades. Geralmente os sistemas fotovoltaicos conectados a rede apresentam uma PR de $70 \%$ até $80 \%$.

A HSP (horas de sol pleno) reflete o número de horas em que a irradiância solar deve permanecer constante e igual a $1 \mathrm{~kW} / \mathrm{m}^{2}$, de forma que a energia resultante seja equivalente à energia disponibilizada pelo sol no local em questão (PINHO; GALDINO, 2014). De forma usual, a HSP representa um índice de irradiância solar do local que será implantado o sistema.

Conforme Nakabayashi (2014), a geração de energia do sistema FV pode ser simplificada pela seguinte equação:

$\mathrm{E}=\mathrm{Po} * \mathrm{FC} *(\mathrm{~T} 2-\mathrm{T} 1)$

Onde:

$\mathrm{E}=$ Energia gerada (Watt-hora)

Po $=$ Potência de pico do painel FV (Watt-pico)

$\mathrm{FC}=$ Fator de Capacidade (adimensional)

O Fator de Capacidade (FC) é a relação entre a energia gerada em determinado período e a energia potencial caso o sistema operasse na potência nominal no tempo todo. É calculada pela seguinte equação:

$\mathrm{FC}=(\mathrm{HSP} * \mathrm{PR}) /(\mathrm{T} 2-\mathrm{T} 1)$

Dada a equação (3), o Fator de capacidade depende tanto da eficiência do sistema (PR) quanto da irradiação média do local, sendo também um indicador utilizado para comparar o potencial de geração de energia de diferentes sistemas FV.

\section{2 - Viabilidade Financeira}

O principal método quantitativo de avaliação de projetos é o Valor Presente Líquido (VPL). Lemes et al. (2010) conceitua que o Valor Presente Líquido é o valor presente do fluxo de caixa operacional do projeto, descontado ao custo de capital da empresa e o investimento. Por considerar o valor do dinheiro no tempo descontado a uma taxa de juros, o VPL reflete quanto determinado projeto agrega de riqueza em valores atuais ao longo do tempo definido.

Neste projeto de investimento da empresa, a taxa de desconto a ser utilizada no cálculo do VPL, é o Custo Médio Ponderado de Capital (CMPC). Para Lemes et al. (2010) o custo de capital da empresa é a remuneração dos acionistas (donos), dos credores e investidores. Ao utilizar o CMPC nos projetos estaria se valendo do princípio de equilíbrio entre endividamento e capital próprio. A taxa de desconto utilizada nos métodos de avaliação financeira representa a Taxa Mínima de Atratividade (TMA), que seria a taxa mínima aceitável do projeto para remunerar investimento.

Outro método muito utilizado é a Taxa Interna de Retorno (TIR). De acordo com Lemes et al. (2010) a TIR é o retorno médio anualizado que o investidor obtém no período do projeto sobre os investimentos do projeto. Para o projeto ser economicamente atraente a TIR deve ser maior que a taxa de desconto considerada (TMA), tornando o VPL positivo.

Por fim, temos Payback Descontado que é o período de tempo necessário para recuperar o investimento inicial considerando os fluxos de caixa descontados. Para Lemes et al. (2010) é muito utilizado nas decisões de investimento de longo prazo, indicando maior risco quanto maior for o período de recuperação do investimento.

Os parâmetros podem variar e os resultados do projeto podem não ser alcançados conforme projetado. A análise de sensibilidade permite avaliar os impactos que as variáveis causam no resultado do projeto.

Assaf (2008) descreve da seguinte forma:

"Análise de Sensibilidade é uma metodologia de avaliação do risco que revela em quanto o resultado econômico (VPL) de um investimento se modificará diante de alterações em variáveis estimadas dos fluxos de caixa."

Dessa forma, é importante estimar e demonstrar as diferentes possibilidades dos resultados possíveis, pois possibilita gerenciar melhor os recursos, além de perceber outras alternativas do investimento, ampliando a capacidade de tomada de decisão. Em Marques et al. (2016) e Marques et al. (2018) realizaram estudos de viabilidade financeira que facilitaram claramente o processo de tomada de decisão, indicando a viabilidade financeira. Esses estudos foram elaborados através de um conjunto de indicadores de riscos e retornos, diante do fluxo de caixa determinado de acordo com o objetivo do projeto.

\section{INVESTIMENTOS, RECEITAS E DESPESAS}

Em EPE (2012) para estimar os investimentos iniciais do sistema FV é considerado o custo médio de instalação dos sistemas em $\mathrm{R} \$ / \mathrm{kW}$. Para obter os valores mais atuais, neste trabalho será utilizado o levantamento de preços médios de 
mercado realizado trimestralmente pela Greener, demonstrado em EE (2018), que é apresentado na Tabela 1.

Tabela 1 - Preços para o cliente final

$\begin{array}{cc}\text { Potência }(\mathbf{k W p}) & \text { Média }(\mathbf{R} \mathbf{\$} \mathbf{k W p}) \\ 75 & 4.800 \\ 150 & 4.530 \\ 300 & 4.380 \\ 500 & 4.230 \\ 1.000 & 4.150 \\ 3.000 & 3.960 \\ 5.000 & 3.900\end{array}$

Fonte: Mercado Fotovoltaico de Geração Distribuída, $2^{\circ}$ Semestre 2018 - Greener.

O custo unitário do kWp é menor em sistemas maiores, ou seja, há ganhos de escala no custo para implementação do sistema. Assim, os sistemas maiores tendem a serem mais viáveis financeiramente, porém os ganhos de escala são cada vez menores na medida que os sistemas FV apresentam maiores dimensões como também observado em EPE (2012). Isto pode ser observado na Figura 1. abaixo:

Figura 1 - Preço Médio (R\$/Wp) vs. Potência do Sistema FV $(\mathrm{kWp})$

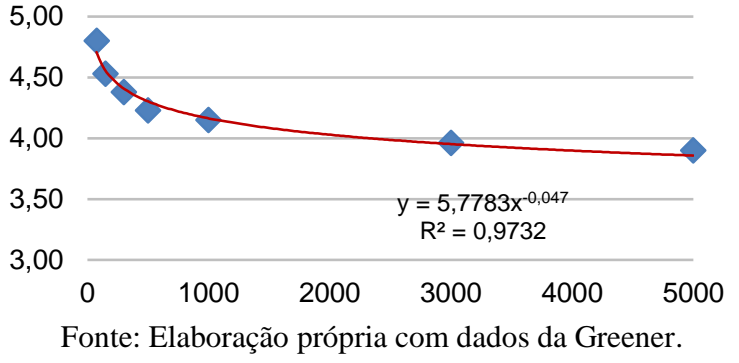

Entretanto, além do alto volume de investimento em sistemas maiores, exige-se também uma maior capacidade técnica e mais especializada.

O local para a implantação do sistema de energia solar FV fica na Estação de Tratamento de Esgoto situado no município de Goianésia-GO. O motivo do local escolhido foi a área disponível e a menor tarifa de demanda, dada a modalidade A4 $(2,3$ a $25 \mathrm{kV})$ a tarifa verde é menor em relação as outras. No local selecionado a carga instalada é baixa, portanto, a energia gerada no sistema FV será utilizada na modalidade de autoconsumo remoto, que possibilita o abatimento de conta de energia em outras estações e unidades da empresa.

Apesar deste modelo não ser o mais utilizado, esta modalidade de geração possibilita a empresa escolher o local onde a tarifa de energia é maior e gerar a energia em locais onde a empresa possui disponibilidade de área dado o tamanho do sistema e a necessidade de potência. Neste estudo, visando obter o maior crédito, o abatimento de consumo de energia ocorrerá nas faturas da tarifa do subgrupo B1 residencial, seguindo a constatação do projeto.

De acordo com dados disponibilizados pelo LABREN (Laboratório de Modelagem e Estudos de Recursos Renováveis de Energia) (LABREN, 2019), a média anual da irradiação solar no plano inclinado no município de Goianésia foi de $5,424 \mathrm{kWh} / \mathrm{m}^{2}$ dia, sendo este o valor a ser adotado em HSP.

\section{1 - Investimentos Iniciais}

Para o projeto de implantação da usina é proposto um sistema fotovoltaico de aproximadamente $1 \mathrm{MW}$ de potência com o objetivo de usufruir do benefício de isenção tributária de ICMS, dado o limite da legislação.

Para estimar a potência do sistema pela equação (1), utilizou-se o valor energético nominal de $5.424 \mathrm{kWh}$ considerando a potência nominal pretendida $(1.000 \mathrm{~kW})$ e a média anual das HSP $\left(5,424 \mathrm{kWh} / \mathrm{m}^{2}\right)$. A Performance Ratio (PR) na equação (1) é o valor potencial médio de $80 \%$ que os sistemas FV convencionais podem atingir. Desta forma, a potência da usina de minigeração de energia $\mathrm{FV}$ foi dimensionado em $1.250 \mathrm{kWp}$.

De acordo com as estimativas de preço por potência, ilustrado anteriormente, foi considerado o valor médio de 4.132,81 R \$/Wp, portanto o investimento inicial é de $\mathrm{R} \$$ 5.166.011,02.

A potência do modelo de placa adotado é de $335 \mathrm{Wp}$ com tamanho de $3,34 \mathrm{~m}^{2}$, sendo assim necessário 3.731 placas para atingir a potência de $1.250 \mathrm{kWp}$ e uma área aproximada de $12.460 \mathrm{~m}^{2}$.

Para a projeção anual de geração de energia foi considerado alguns parâmetros adotados em ABINEE (2012). Entre eles é a perda de eficiência dos painéis de $0,75 \%$ ao ano sobre a geração do primeiro ano. A Performance Ratio (PR) para a geração de energia será de 75\%, valor adotado em EPE (2012).

\section{2 - Receitas}

Além da energia produzida, a projeção de receita (benefícios) do projeto (proveniente do abatimento do consumo energético), também dependerá da tarifa de energia cobrada pela concessionária. Em média todo ano as tarifas de energia sofrem reajustes que influenciam nos resultados financeiros obtidos na geração de energia.

Devido à inflação na economia o nível geral de preços aumenta com o tempo, sendo necessário deflacionar os reajustes da tarifa de energia para obter a variação real do período. Os dados históricos da tarifa média de energia em Goiás (Celg/ENEL) têm sido maiores que a inflação (IPCA), ilustrado na Tabela 2 abaixo:

Tabela 2 - Evolução das Tarifas Médias de Goiás e IPCA

\begin{tabular}{ccc} 
Período & $\begin{array}{c}\text { Tarifa Média } \\
(\mathbf{R} \$ \mathbf{k W h})\end{array}$ & $\begin{array}{c}\text { Número Índice } \\
\text { (IPCA) }\end{array}$ \\
\hline jan/08 & 0,3246 & 707,77 \\
nov/17 & 0,7447 & $1.261,49$ \\
Var. Acumulada & $129,41 \%$ & $78,23 \%$ \\
\hline
\end{tabular}

Fonte: Dados da ANEEL (2008) e IBGE (2019).

Descontando o IPCA, de janeiro de 2008 a novembro de 2017, o aumento real da tarifa média de energia foi de $28,71 \%$, que calculado pela média geométrica indica um reajuste real anual de $2,5 \%$ no período. Sendo este valor a ser considerado para o cenário base para o reajuste anual das tarifas. A tarifa de consumo utilizada no modelo é a tarifa do grupo B, subgrupo B1, na classe residencial, cobrada no mês de abril de 2019 , que foi $\mathrm{R} \$ 0,78$ por $\mathrm{kWh}$.

\section{3 - Despesas}

Dado que a Geração Distribuída adotada para este estudo, utiliza a rede da companhia distribuidora para backup do sistema, há o custo fixo do contrato de demanda de 
potência. Como informado anteriormente, este é um valor que não será abatido pelo sistema de compensação energético.

A maior parte dos estudos financeiros para sistema FV de Geração Distribuída não consideram este custo de demanda de potência, pois nesses sistemas o local de implantação também é onde ocorre o consumo e abatimento, isto é, onde possui carga instalada para o sistema e já é realizado pagamento da tarifa de demanda de potência. Assim, a implantação do sistema não incrementaria este custo de demanda de potência.

Porém neste trabalho, como a utilização dos créditos é em outra localidade da empresa, na modalidade de autoconsumo remoto, haverá um novo contrato de demanda e assim será incrementado o custo de demanda de potência. A tarifa mensal de demanda de potência a ser utilizada é a do grupo A, subgrupo A4, na modalidade verde que em maio de 2019 foi de $\mathrm{R} \$ 24,20$ por $\mathrm{kW}$.

Em relação aos custos anuais de operação e manutenção é utilizado $1 \%$ sobre o valor do investimento inicial, tal valor já considera o valor da troca de inversores que possuem vida útil de dez anos.

\section{FLUXO DE CAIXA}

Assim sendo, o benefício monetário obtido com a geração de energia pode ser determinado pela quantidade de energia gerada pelo sistema proposto multiplicado pela tarifa de energia. O tempo de vida útil do sistema é de 20 anos, valor adotado em EPE (2012). A Tabela 3 apresenta a projeção de geração de energia produzida, calculado pelas equações (2) e (3) e seu benefício anual:

Tabela 3 - Projeção de Energia em 20 anos

\begin{tabular}{ccccc}
\hline Ano & $\begin{array}{c}\text { Eficiência } \\
\text { relativa }\end{array}$ & $\begin{array}{c}\text { Energia } \\
\text { Produzida } \\
\text { (MWh) }\end{array}$ & $\begin{array}{c}\text { Tarifa } \\
(\mathbf{R} \$)\end{array}$ & $\begin{array}{c}\text { Benefício } \\
(\mathbf{E m ~ m i l ~} \\
\mathbf{R} \$)\end{array}$ \\
\hline 1 & $100,00 \%$ & $1.856,03$ & 0,78 & $1.447,70$ \\
2 & $99,30 \%$ & $1.842,10$ & 0,80 & $1.472,76$ \\
3 & $98,50 \%$ & $1.828,18$ & 0,82 & $1.498,17$ \\
4 & $97,80 \%$ & $1.814,26$ & 0,84 & $1.523,94$ \\
5 & $97,00 \%$ & $1.800,34$ & 0,86 & $1.550,05$ \\
$\ldots$ & $\ldots$ & $\ldots$ & $\ldots$ & $\ldots$ \\
20 & $85,80 \%$ & $1.591,54$ & 1,25 & $1.984,57$ \\
\hline \multicolumn{5}{c}{ Fonte: Elaborado pelo autor. }
\end{tabular}

Conforme os dados da Tabela 3 é esperado uma geração de energia no primeiro ano de $1.856 .025 \mathrm{kWh}$, que irá diminuir ao longo dos anos devido a perca de eficiência dos módulos FV. No entanto, considerando um incremento real das tarifas de energia (acima da inflação) espera-se que o benefício da geração de energia aumente com o passar dos anos.

Considerando o contrato de demanda de $1 \mathrm{MW}$, o valor a ser pago à concessionária de energia corresponde a $\mathrm{R} \$$ $24.200,00$ por mês equivalendo a $\mathrm{R} \$ 290.400,00$ por ano. $\mathrm{Na}$ projeção dos fluxos de caixa, esta tarifa também é corrigida pelo reajuste real de $2,5 \%$ ao ano. A Tabela 4 apresenta o fluxo de caixa projetado para o período de 20 anos:
Tabela 4 - Fluxo de Caixa do projeto em 20 anos (Em mil R\$)

\begin{tabular}{ccccc} 
Ano & $\begin{array}{c}\text { Benefícios } \\
(\mathbf{R} \text { \$) }\end{array}$ & $\begin{array}{c}\text { Operação e } \\
\text { Manutenção } \\
(\mathbf{R} \$)\end{array}$ & $\begin{array}{c}\text { Demanda de } \\
\text { Potência } \\
(\mathbf{R} \$)\end{array}$ & $\begin{array}{c}\text { Fluxo de } \\
\text { Caixa }(\mathbf{R} \$)\end{array}$ \\
\hline 0 & - & - & - & $-5.166,01$ \\
1 & $1.447,70$ & $-51,66$ & $-290,40$ & $1.105,64$ \\
2 & $1.472,76$ & $-51,66$ & $-297,66$ & $1.123,44$ \\
3 & $1.498,17$ & $-51,66$ & $-305,10$ & $1.141,41$ \\
4 & $1.523,94$ & $-51,66$ & $-312,73$ & $1.159,55$ \\
5 & $1.550,05$ & $-51,66$ & $-320,55$ & $1.177,84$ \\
$\ldots$ & $\ldots$ & $\ldots$ & $\ldots$ & $\ldots$ \\
20 & $1.984,57$ & $-51,66$ & $-464,25$ & $1.468,66$ \\
\hline & & &
\end{tabular}

Fonte: Elaborado pelo autor.

A taxa de desconto a ser utilizada no cálculo do VPL e do Payback Descontado deste cenário, é de $9,11 \%$ ao ano, que foi determinada pelo Custo Médio Ponderado de Capital.

Portanto, dada as premissas consideradas neste trabalho, no cenário padrão o VPL resultou em R \$ 5.981.594,52 no período de 20 anos. Demonstrando a viabilidade financeira da implantação do sistema de geração de energia FV proposto. Logo, o valor da TIR apresentou-se muito superior à taxa de desconto, em 22,46\%. O Payback Descontado indicou que o investimento pode ser recuperado em seis anos.

\section{ANÁLISE DE SENSIBILIDADE}

Apresentado o cenário padrão, foi realizado simulações para analisar o impacto nos resultados através da modificação de algumas variáveis, mantendo as demais variáveis constantes.

Na Figura 2, é apresentado o VPL em função da potência do sistema, considerando que em uma usina maior que $1.000 \mathrm{~kW}$ não há a isenção do ICMS (sendo o valor de $29 \%$ sobre o benefício financeiro da energia gerada).

Figura 2 - VPL (mil R\$) em função da potência do sistema

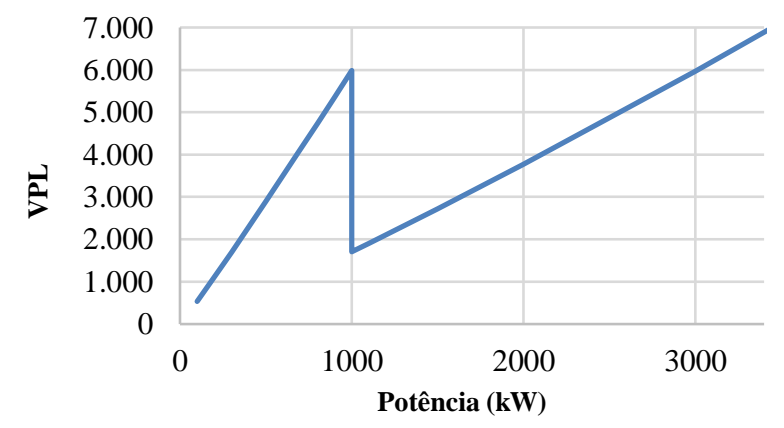

Fonte: Elaborado pelo autor.

Com a potência do sistema acima dos $1.000 \mathrm{~kW}$ o VPL cai drasticamente devido a perda do benefício do ICMS. No entanto, em virtude dos ganhos de escala sobre o tamanho dos sistemas, o VPL é maior a partir de sistemas de $3.009 \mathrm{~kW}$, ponto de equilíbrio onde o VPL se iguala ao sistema de 1.000 kW. Os dados da Figura 2 podem ser observados na Tabela 5. 
Tabela 5 - Resultados em função da potência do sistema

\begin{tabular}{cccc}
$\begin{array}{c}\text { Potência } \\
(\mathbf{k W})\end{array}$ & $\begin{array}{c}\text { Custo Médio } \\
(\mathbf{R} \mathbf{\$} \mathbf{k W})\end{array}$ & $\begin{array}{c}\text { Investimento } \\
(\mathbf{R} \mathbf{})\end{array}$ & VPL (R\$) \\
\hline 200 & $4.457,56$ & 1.114 .389 & 1.107 .778 \\
400 & $4.314,68$ & 2.157 .340 & 2.293 .466 \\
600 & $4.233,23$ & 3.174 .925 & 3.506 .816 \\
800 & $4.176,38$ & 4.176 .381 & 4.737 .757 \\
1000 & $4.132,81$ & 5.166 .011 & 5.981 .595 \\
1100 & $4.114,34$ & 5.657 .213 & 1.902 .208 \\
1500 & $4.054,80$ & 7.602 .743 & 2.715 .670 \\
2000 & $4.000,34$ & 10.000 .850 & 3.769 .365 \\
3000 & $3.924,83$ & 14.718 .105 & 5.962 .866 \\
5000 & $3.831,72$ & 23.948 .248 & 10.572 .744 \\
\hline \multicolumn{4}{c}{ Fonte: Elaborado pelo autor. }
\end{tabular}

Neste modelo, com as premissas consideradas, não seria vantajoso implantar sistemas entre $1 \mathrm{MW}$ a $3 \mathrm{MW}$ de potência por apresentarem menor retorno.

Na Figura 3 o ponto de eficiência do sistema em que o VPL é igual a zero é de 44,6\%. De acordo com a equação da reta o aumento de um ponto percentual na eficiência, ocasiona um aumento de $\mathrm{R} \$ 196.666,48$ no VPL do projeto.

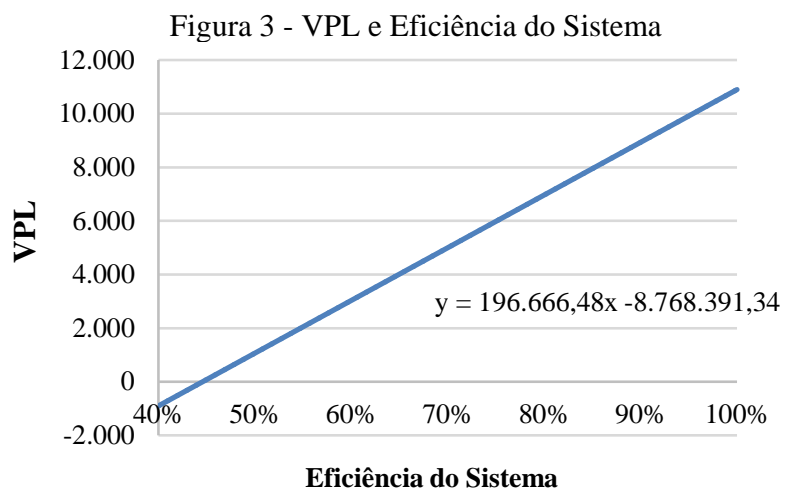

Fonte: Elaboração própria.

Mantendo as demais variáveis constantes (não considerando a temperatura, por exemplo, que também influência na eficiência), a variável HSP tem alto impacto nos resultados do projeto. Regiões com HSP acima de 6,5 podem apresentar VPL cerca de $80 \%$ maior que as regiões de HSP de valor 5. A variação de 0,1 nas HSP da localidade selecionada ocasiona na variação de R $\$ 271.939,27$ no VPL, conforme apresentado na Figura 4.

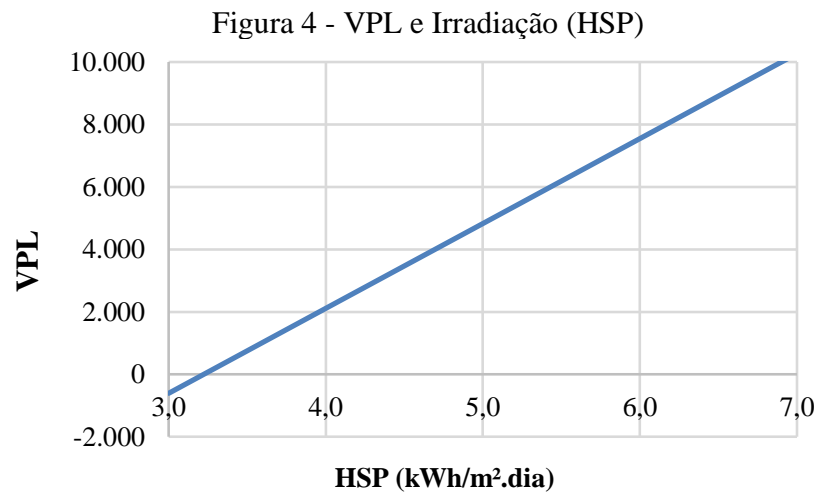

Fonte: Elaboração própria.
A equação da reta da Figura 5 demonstra que um aumento de $\mathrm{R} \$ 0,10$ na tarifa ocasiona num aumento de $\mathrm{R} \$$ $1.891 .023,83$ no VPL do projeto. O ponto de equilíbrio da tarifa, ou seja, o valor da tarifa onde o VPL iguala a zero é R\$ 0,464 , que representa a tarifa mínima para que o projeto seja minimamente viável.

Figura 5 - VPL e Tarifa de Consumo

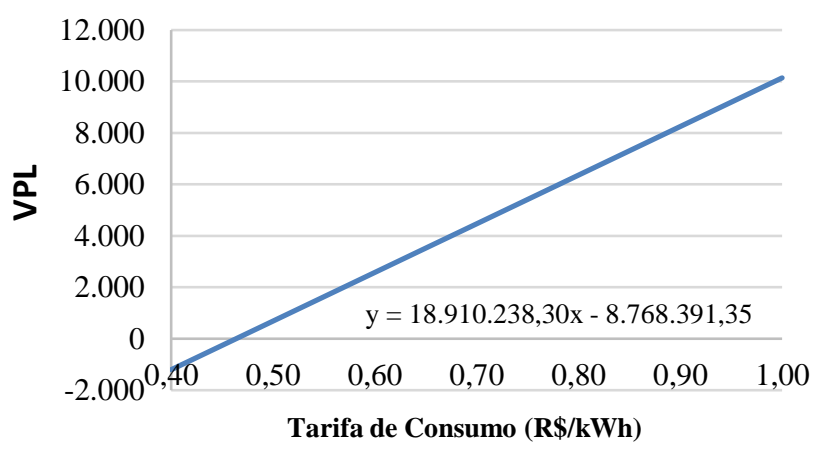

Fonte: Elaboração própria.

\section{1 - Análise de Cenários}

Além do cenário padrão do modelo, foram calculados mais dois cenários, um pessimista e outro otimista no intuito de verificar o impacto da combinação das variáveis: Performance Ratio, Fator de Capacidade, reajuste tarifário e taxa de desconto.

Os dois cenários foram estabelecidos com valores possíveis de ocorrer de forma negativa e positiva aos resultados do projeto.

\begin{tabular}{lcccc}
\hline \multicolumn{4}{c}{ Quadro 1 } & Resultado dos Cenários \\
\hline \multirow{2}{*}{ Fatores do Sistema FV } & Pessimista & Realista & Otimista \\
\hline \multirow{2}{*}{ Operacional } & PR & $70 \%$ & $75 \%$ & $80 \%$ \\
& HSP & 5,424 & 5,424 & 5,424 \\
\hline \multirow{2}{*}{ Econômico } & FC & $15,82 \%$ & $16,95 \%$ & $18,08 \%$ \\
\hline \multirow{4}{*}{ Reajuste Tar. } & $0 \%$ & $2,50 \%$ & $4 \%$ \\
& TMA & $11 \%$ & $9,11 \%$ & $7 \%$ \\
\hline \multirow{4}{*}{ Payback D. } & 8,35 & 6,06 & 4,93 \\
& TIR & $17,90 \%$ & $22,46 \%$ & $25,97 \%$ \\
\hline
\end{tabular}

Verifica-se que pequenas alterações conjuntas das variáveis acarretam em alto impacto nos resultados do projeto, pois os efeitos das variáveis combinadas são multiplicados. Essa alta variação nos resultados ocorre nos projetos dado a quantidade de fatores, no entanto dentro dos cenários escolhidos é esperado um retorno positivo. E também o risco operacional dos sistemas de geração FV é considerado baixo.

\section{2 - Aplicação do Modelo nos Estados Brasileiros}

Além dos cenários propostos, foi analisado a viabilidade do sistema de energia FV proposto nos estados brasileiros de acordo com a média de irradiação e as tarifas das principais concessionárias destes estados. 
A média anual de irradiação solar no plano inclinado (HSP em $\mathrm{kWh} / \mathrm{m}^{2}$ dia) dos estados foi calculada com a base de dados de 72.272 registros do LABREN.

As tarifas de demanda e de consumo (TE e TUSD) foram obtidas pelas resoluções tarifárias das concessionárias de energia homologadas pela ANEEL.

Os valores obtidos para cada concessionária seguem no Tabela 6 abaixo:

Tabela 6 - Irradiação média dos estados e tarifas das concessionárias

\begin{tabular}{|c|c|c|c|c|}
\hline UF & $\begin{array}{l}\text { Concessionária } \\
\text { de Energia }\end{array}$ & $\begin{array}{c}\text { Irradiação } \\
\text { Média } \\
\left(\mathbf{k W h} / \mathbf{m}^{2} . \text { dia }\right)\end{array}$ & $\begin{array}{c}\text { Tarifa de } \\
\text { Demanda } \\
(\mathrm{R} \$ / \mathrm{kW})\end{array}$ & $\begin{array}{l}\text { Tarifa de } \\
\text { Consumo } \\
(\mathrm{R} \$ / \mathrm{kWh})\end{array}$ \\
\hline $\mathbf{A C}$ & ELETROACRE & 4,648 & 17,08 & 0,868 \\
\hline $\mathbf{A L}$ & $C E A L$ & 5,350 & 22,48 & 0,758 \\
\hline $\mathbf{A M}$ & $A M E$ & 4,497 & 23,51 & 0,999 \\
\hline $\mathbf{A P}$ & $C E A$ & 4,642 & 23,64 & 0,802 \\
\hline $\mathbf{B A}$ & COELBA & 5,523 & 35,26 & 0,782 \\
\hline $\mathbf{C E}$ & ENEL CE & 5,704 & 21,53 & 0,750 \\
\hline DF & $C E B D$ & 5,516 & 11,53 & 0,789 \\
\hline ES & EDP ES & 4,982 & 26,81 & 0,796 \\
\hline GO & $C E L G-D$ & 5,474 & 24,68 & 0,796 \\
\hline MA & CEMAR & 5,229 & 32,33 & 0,929 \\
\hline MG & CEMIG & 5,367 & 19,76 & 0,890 \\
\hline MS & E.M.S & 5,221 & 27,86 & 0,862 \\
\hline MT & $E M T$ & 5,094 & 23,84 & 0,888 \\
\hline PA & CELPA & 4,700 & 35,82 & 0,950 \\
\hline PB & $E P B$ & 5,708 & 27,11 & 0,810 \\
\hline PE & CELPE & 5,585 & 21,02 & 0,778 \\
\hline PI & CEPISA & 5,738 & 17,89 & 0,719 \\
\hline PR & COPEL & 4,880 & 19,47 & 0,733 \\
\hline RJ & $L I G H T$ & 4,918 & 17,89 & 0,719 \\
\hline $\mathbf{R N}$ & COSERN & 5,776 & 25,25 & 0,716 \\
\hline RO & CERON & 4,651 & 15,15 & 0,823 \\
\hline $\mathbf{R R}$ & $R E$ & 4,818 & 22,25 & 0,899 \\
\hline RS & CEEE & 4,799 & 23,99 & 0,776 \\
\hline SC & CELESC & 4,500 & 17,42 & 0,737 \\
\hline SE & ESE & 5,324 & 24,85 & 0,752 \\
\hline $\mathbf{S P}$ & ELETROPAULO & 5,090 & 18,35 & 0,730 \\
\hline TO & ETO & 5,344 & 40,43 & 0,850 \\
\hline
\end{tabular}
LABREN (2019).

O valor da tarifa a ser utilizado é a tarifa final que o consumidor paga, desta maneira é adicionado o PIS, COFINS e ICMS, tributos calculados "por dentro". A tarifa final de consumo e de demanda foi calculada de acordo com a fórmula:

Tarifa Final $=$ Tarifa Homologada $/$ (1- (PIS+COFINS+ICMS)

Assim sendo, foi simulado a viabilidade com os valores médios para cada estado considerando o cenário padrão do modelo, que pode ser ilustrado na Tabela 7 abaixo em ordem do retorno:

Tabela 7 - Ranking dos estados brasileiros com a tarifa de demanda

\begin{tabular}{ccccc}
\hline UF & $\begin{array}{c}\text { Ponto de } \\
\text { Equilíbrio } \\
(\mathbf{k W})\end{array}$ & $\begin{array}{c}\text { Payback } \\
\text { Desc. }\end{array}$ & TIR & $\begin{array}{c}\text { VPL (Em } \\
\text { mil R\$) }\end{array}$ \\
\hline MG & 2.206 & 4,77 & $27,4 \%$ & 8.458 \\
DF & 2.096 & 4,96 & $26,5 \%$ & 8.048 \\
MA & 2.873 & 5,37 & $24,8 \%$ & 7.116 \\
MT & 2.591 & 5,43 & $24,6 \%$ & 7.044 \\
AM & 2.602 & 5,46 & $24,5 \%$ & 6.999 \\
PB & 2.727 & 5,46 & $24,5 \%$ & 6.971 \\
PE & 2.570 & 5,58 & $24,1 \%$ & 6.792 \\
RR & 2.678 & 5,70 & $23,7 \%$ & 6.581
\end{tabular}

\begin{tabular}{ccccc} 
CE & 2.682 & 5,75 & $23,5 \%$ & 6.489 \\
MS & 2.961 & 5,76 & $23,4 \%$ & 6.448 \\
PI & 2.570 & 5,80 & $23,3 \%$ & 6.423 \\
GO & 2.861 & 5,83 & $23,2 \%$ & 6.351 \\
AC & 2.604 & 5,93 & $22,9 \%$ & 6.220 \\
RO & 2.691 & 6,26 & $21,9 \%$ & 5.753 \\
AL & 3.129 & 6,35 & $21,7 \%$ & 5.594 \\
RN & 3.354 & 6,40 & $21,5 \%$ & 5.514 \\
PA & 4.534 & 6,53 & $21,1 \%$ & 5.298 \\
SE & 3.796 & 6,73 & $20,7 \%$ & 5.099 \\
TO & 6.002 & 6,78 & $20,5 \%$ & 4.964 \\
SP & 3.304 & 6,88 & $20,3 \%$ & 4.947 \\
BA & 5.313 & 6,89 & $20,2 \%$ & 4.854 \\
ES & 4.336 & 7,04 & $19,9 \%$ & 4.726 \\
RJ & 3.830 & 7,43 & $19,1 \%$ & 4.369 \\
PR & 4.075 & 7,48 & $19,0 \%$ & 4.316 \\
AP & 4.680 & 7,49 & $19,0 \%$ & 4.287 \\
RS & 4.841 & 7,54 & $18,8 \%$ & 4.236 \\
SC & 5.021 & 8,22 & $17,6 \%$ & 3.674 \\
\hline & \multicolumn{5}{c}{ Fonte: Elaboração própria. } \\
\hline
\end{tabular}

Observou-se alta variação nos resultados obtidos em função do nível de irradiação solar dado a vasta extensão do país e as tarifas de energia de cada concessionária. De modo que escolha do local onde será implantada a usina é um fator muito determinante nos resultados do projeto. Neste modelo o estado de Minas Gerais apresentou os maiores indicadores de retorno e o DF apresentou o menor ponto de equilíbrio.

\section{CONCLUSÃO}

Este artigo teve como objetivo avaliar e apresentar a viabilidade de um sistema de geração de energia elétrica fotovoltaica para uma empresa de saneamento através da geração distribuída na modalidade de autoconsumo remoto.

Os valores obtidos nas análises de sensibilidade demonstraram a relevância das variáveis operacionais nos resultados frente às variáveis econômicas. Isto ocorre devido ao maior impacto e a facilidade de manusear estas variáveis operacionais. A tarifa de energia, como variável econômica, apresenta alto impacto nos resultados, no entanto ela depende muito das empresas e políticas regulatórias do setor.

Reforçando que os fatores técnicos do projeto são cruciais na implantação dos sistemas. Como por exemplo a seleção do local onde há maiores níveis de irradiação solar, a utilização de tecnologias e soluções eficientes.

Nos cenários avaliados, o projeto se mostra financeiramente viável no cenário pessimista apresentado, onde a TIR pode atingir $16 \%$. No entanto, a recuperação do investimento inicial é lenta neste cenário.

$\mathrm{Na}$ simulação deste modelo por estado, em que há pagamento da tarifa de potência, todos os estados apresentaram viabilidade financeira.

\section{REFERÊNCIAS}

MARQUES, et al. Um Estudo de Viabilidade Financeira de Sistemas Automatizados para Estacionamento em Shopping, Revista Sodebras [on line]. v. 13, n.150. Jun./2018 p. 25-30. ISSN 1809-3957. Disponível em: <http://www.sodebras.com.br/edicoes/N150.pdf $>$. Acesso em 26 ago. 2019.

ABINEE - Associação Brasileira da Indústria Elétrica e Eletrônica. Propostas para inserção da energia solar fotovoltaica na matriz elétrica brasileira. 2012. 
ANEEL - Agência Nacional de Energia Elétrica. Atlas de energia elétrica do Brasil. $3^{\mathrm{a}}$ Ed. Brasília - DF. 2008.

IBGE - Instituto Brasileiro de Geografia e Estatística. Índice Nacional de Preços ao Consumidor Amplo IPCA. < https://www.ibge.gov.br/> Acesso em 26 ago. 2019.

ASSAF, Alexandre; LIMA, Fabiano Guasti. Curso de Administração Financeira. São Paulo: Atlas, 2009.

EE - Estudo Estratégico. Mercado Fotovoltaico de Geração Distribuída. $2^{\circ}$ Semestre 2018. Greener, 2018.

EPE - Empresa de Pesquisa Energética. Análise da inserção da geração solar na matriz elétrica brasileira. Rio de Janeiro: EPE, 2012.

LEMES JUNIOR, Antônio Barbosa; RIGO, Cláudio Miessa; CHEROBIM, Ana Paula Mussi Szabo. Administração Financeira: Princípios, Fundamentos e Práticas Brasileiras. Rio de Janeiro: Elsevier, 2010.

LOURES, et al. Iluminação de LED e Eficiência Energética com Consideração sobre Normas e Aspectos Técnicos de Qualidade de Energia. Revista Sodebras [on line]. v. 13, n. 155, Nov./2018, p.64-69. ISSN 1809-3957. https://doi.org/10.29367/issn.1809-3957.13.2018.155.64.

MARQUES, et al. Uma Análise de Viabilidade Econômica para Implementação de Sistemas Geotérmicos em Instalações Industriais. Revista Sodebras [on line]. v. 11, n. 132, Dez./ 2016 p. 248-252. ISSN 1809-3957. Disponível em: <http://www.sodebras.com.br/edicoes/N132.pdf>. Acesso em 26 ago. 2019.

NAKABAYASHI, Rennyo. Microgeração Fotovoltaica no Brasil: Condições Atuais e Perspectivas Futuras. Universidade de São Paulo, São Paulo, 2014.

PINHO, João Tavares. GALDINO, Marco Antonio. Manual de Engenharia para Sistemas Fotovoltaicos. Rio de Janeiro, 2014.

SMA - Informações técnica. Performance Ratio - fator de qualidade para sistema fotovoltaico. 2011.

LABREN - Laboratório de Modelagem e Estudos de Recursos Renováveis de Energia. < http://labren.ccst.inpe.br/> Acesso em 09 outubro. 2019.

\section{COPYRIGTH}

Direitos autorais: Os autores são os únicos responsáveis pelo material incluído no artigo.

Submetido em: 30/08/2019

Aprovado em: 21/09/2019 


\author{
Revista SODEBRAS - Volume 14 \\ $\mathrm{N}^{\circ} 166$ - OUTUBRO/ 2019
}

\title{
VIABILIDADE PARA A IMPLEMENTAÇÃO DE UMA USINA DE RECICLAGEM DE RESIDUOS DA CONSTRUÇÃO CIVIL NA REGIÃO METROPOLITANA DE GOIÂNIA
}

\author{
VIABILITY FOR THE IMPLEMENTATION OF A CIVIL CONSTRUCTION \\ WASTE RECYCLING COMPANY IN THE METROPOLITAN REGION OF \\ GOIÂNIA
}

\author{
GABRIEL DE FARIA FERIS; THYAGO CARVALHO MARQUES \\ $1 ; 2$ - UNIVERSIDADE FEDERAL DE GOIÁS \\ thyago@ufg.br
}

\begin{abstract}
Resumo - O objetivo deste trabalho é apresentar um estudo de viabilidade para a implantação de uma usina de reciclagem para a indústria da construção na região metropolitana de Goiânia-GO, devido ao alto impacto gerado por esses resíduos no meio ambiente e na saúde pública, uma vez que esses resíduos quando descartados em uma maneira ambientalmente inadequada pode servir como um local para a proliferação de vetores, impactando diretamente a saúde da população. Além disso, é mostrar que a maior parte dos resíduos dispostos em aterros, lixões, taludes $e$ terrenos baldios poderiam ser reutilizados como matéria-prima para a construção civil, uma das atividades que mais demandam recursos como: areia, cascalho, materiais recicláveis. Como resultado, esse projeto apresentou tanto uma viabilidade financeira atrativa quanto uma percepção clara de um aumento na vida útil dos aterros, redução da quantidade de resíduos descartados em um local inadequado, podendo com isso, criar novos empregos e fortalecer o compromisso com a sustentabilidade.
\end{abstract}

Palavras-chave: Reciclagem de Resíduos. Viabilidade. Sustentabilidade.

Abstract - The aim of this paper is to present a feasibility study for the implementation of a recycling plant for the construction industry in the metropolitan region of Goiânia-GO, due to the high impact generated by these residues on the environment and public health, a Since this waste when disposed of in an environmentally inappropriate manner can serve as a site for vector proliferation, directly impacting the health of the population. Moreover, it is to show that most of the waste disposed in landfills, dumps, slopes and vacant land could be reused as raw material for construction, one of the most demanding activities such as sand, gravel, recyclable materials. As a result, this project has both an attractive financial viability and a clear perception of an increase in landfill life, a reduction in the amount of waste disposed of in an inappropriate location, which can create new jobs and strengthen the commitment to sustainability.

Keywords: Recycling. Construction Waste. Sustainability.

\section{INTRODUÇÃO}

O desenvolvimento econômico iniciado na revolução industrial trouxe um elevado crescimento populacional para os centros urbanos. Esse aumento no número de habitantes impulsionou de forma significativa diversos setores da economia nas cidades, com destaque para a construção civil, resultando em um forte impacto sobre a extração de madeira, areia e britas, principalmente. Nos países emergentes, principalmente nos denominados BRICS (Brasil, Rússia, Índia, China e África do Sul), teve-se um considerável investimento realizado no setor econômico nos últimos 20 anos, o que acelerou de forma significativa investimentos no setor de infraestruturas, para a construção de hospitais, estradas, prédios, casas, fazendo assim com que a economia se mantivesse aquecida e gerando empregos (LIMA; CABRAL, 2013).

No Brasil, a resolução n 307 do Conselho Nacional do Meio Ambiente (CONAMA, 2002) foi o primeiro documento a estabelecer normas gerais para a gestão dos RCC (Resíduo da Construção Civil) no país. Segundo a referida resolução, nos planos de gerenciamento de resíduos da construção civil elaborados pelos geradores deve constar o incentivo à reinserção dos resíduos reutilizáveis ou reciclados no ciclo produtivo.

De acordo com estimativas apresentadas no Plano Estadual de Resíduos Sólidos do Estado de Goiás (PERS/GO), a região metropolitana de Goiânia é responsável por mais de $39 \%$ dos RCC gerados no estado (GOIÁS, 2017). Apesar do grande potencial existente para a reciclagem desses resíduos, trabalho desenvolvido por Sacho (2015) concluiu que a reciclagem dos RCC classe A gerados na região metropolitana de Goiânia, área de estudo desse trabalho, não era economicamente viável. Um dos motivos apresentados pela autora foi que o aterro sanitário da capital recebia gratuitamente os RCC. Esta realidade foi modificada em 07 de junho de 2016, com a assinatura da resolução n ${ }^{\circ} 20$ da Companhia de Urbanização de Goiânia (COMURG) que estabeleceu, a partir de então, a cobrança pela entrada desses resíduos no aterro sanitário.

\section{DIMENSIONAMENTO DE USINA RECICLAGEM DE RESIDUOS CLASSE A}

Para dimensionar uma usina de reciclagem de resíduos da construção civil é necessário monitorar a quantidade de resíduos classe A coletados na região metropolitana de 
Goiânia, local onde será implementada a usina, para isso foram utilizados dados coletados no Plano Estadual de Resíduos Sólidos do Estado de Goiás (PERS/GO) indicam que a geração média per capita de RCC no estado é de 1,45 $\mathrm{kg} / \mathrm{hab}$.dia, o que resultou em aproximadamente $7.860 \mathrm{t} / \mathrm{dia}$ no ano de 2015. As regiões administrativas com maior geração desses resíduos são a Metropolitana de Goiânia $(39,3 \%)$ como ilustrado na Tabela 2.1 .

Tabela 2.1 - Coleta de resíduos classe A na região metropolitana de

\begin{tabular}{cc}
\multicolumn{2}{c}{ Goiânia } \\
\hline Região & $\begin{array}{c}\text { Geração estimada de } \\
\text { RCC (t/dia) }\end{array}$ \\
\hline Metropolitana de & $3.088,61$ \\
Goiânia & $1.362,18$ \\
Entorno do Distrito & 817,08 \\
Federal & 719,78 \\
Centro Goiano & 515,53 \\
Sudoeste Goiano & 386,84 \\
Sul & 351,98 \\
Oeste Goiano & 296,41 \\
Norte Goiano & 161,47 \\
Sudeste Goiano & 159,89 \\
Nordeste Goiano & $7.859,77$ \\
Noroeste Goiano & \\
\hline Total & Fonte: GOIÁS $(2017)$.
\end{tabular}

Isso mostra que há uma grande geração de resíduos na região metropolitana de Goiânia e estes necessitam de tratamento adequado, sendo um indicativo que existe a viabilidade para a implantação de uma usina de reciclagem na região. Quando se analisa a geração mensal estimada chega-se ao número 92.658,3 toneladas/mês $(3.088,61 * 30$ dias), valor este que poderia ser reciclado, transformando resíduos em matéria prima.

No estado de Goiás, embora os RCC sejam, em sua maioria, de baixa periculosidade, a principal destinação dada a esses resíduos ainda é o lixão (GOIÁS, 2017). Por esse motivo, os RCC oferecem riscos significativos à saúde pública já que favorecerem a proliferação de vetores (ratos, mosquitos, baratas, moscas, etc.), assoreiam os cursos d'água e estimula a disposição incorreta de outros resíduos, o que onera os custos públicos.

Em trabalho desenvolvido na cidade de Goiânia, Oliveira et al. (2013) identificaram 187 pontos de descarte clandestinos. Destes, 55 foram classificados como pontos de relevância devido a grande quantidade de entulho encontrada e a constância do descarte inadequado. Os principais pontos de descarte identificados pelos autores são apresentados na Figura 2.1. Os pontos amarelos indicam resíduos dispostos em logradouros e os pontos vermelhos representam descarte em áreas de preservação permanente.

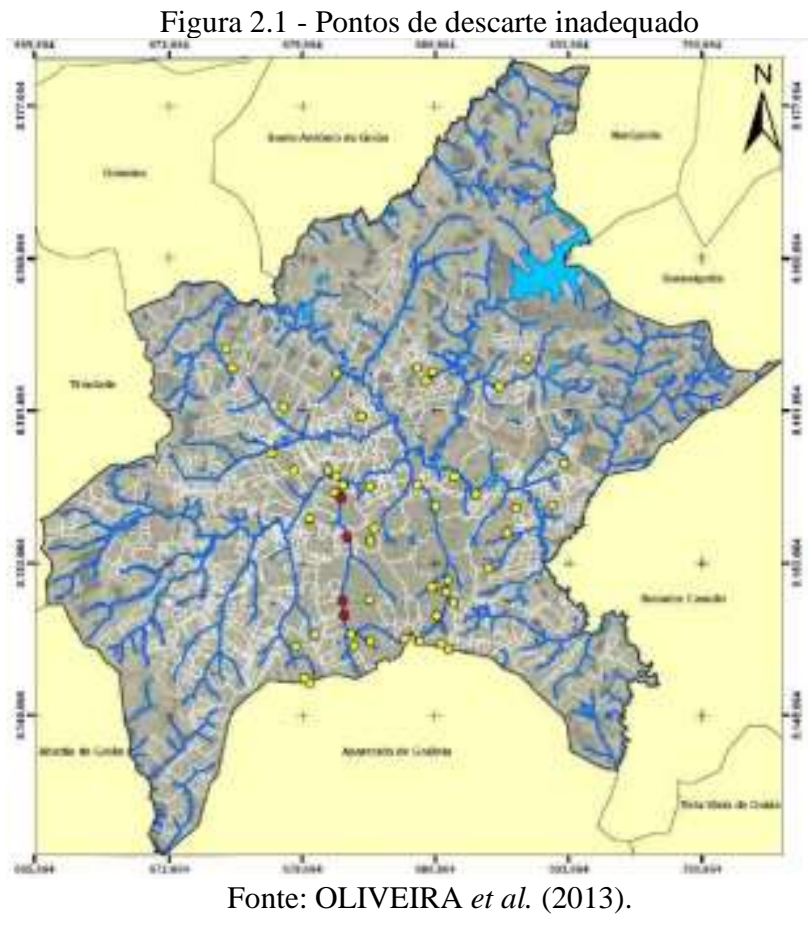

Apesar dos lançamentos clandestinos, muitos geradores encaminham seus RCC para o aterro sanitário de Goiânia. Segundo levantamento realizado por Sacho (2015), em 2015, $45 \%$ dos resíduos destinados ao aterro eram resíduos da construção civil. Atualmente, o aterro de Goiânia ainda recebe os RCC classes A e C que são utilizados como subbase dos pátios de manobra, reforma de estradas internas e como parte da camada de cobertura dos resíduos domiciliares. No entanto, com a publicação da resolução COMURG n ${ }^{\circ}$ 20, a prefeitura de Goiânia passou a cobrar para o recebimento destes resíduos no local os seguintes valores em 2016:

\section{- $\quad$ RCC classe A "limpo": R\$ 67,00 para cada 6 m³; \\ _ $\quad$ RCC "misturado": R\$ 98,00 para cada 6 m³ $^{3}$ \\ Figura 1.2 -Entrada de RCC Classe A no Aterro Sanitário de Goiânia}

Entrada de RCC Classe A no Aterro de Goiânia

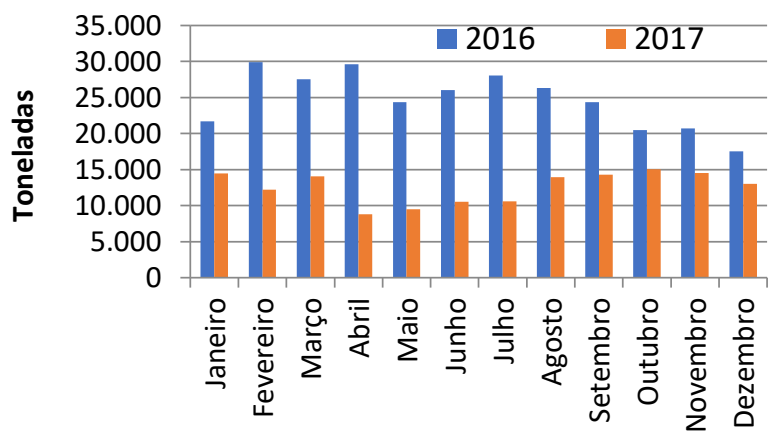

Fonte: Próprio Autor.

Mesmo quando o aterro começou a cobrar pelo recebimento de RCC o volume ainda se apresenta alto, com baixo potencial de reaproveitamento, fator que poderia ser melhor explorado, uma vez que estes resíduos podem servir como matéria prima. 
Quando se analisa o valor cobrado pelo recebimento de $\mathrm{RCC}$ por uma usina de reciclagem $\left(\mathrm{R} \$ 10,00 / \mathrm{m}^{3}\right)$ com o valor cobrado pelo aterro é possível observar que o valor da usina é menor, sendo um atrativo para empresários e pequenos geradores.

Outro fator que deve ser levado em conta é que na região metropolitana de Goiânia, os aterros de outras cidades como: Aparecida de Goiânia e Senador Canedo não recebem RCC, já os aterros de Anápolis, Bela Vista de Goiás, Hidrolândia, Trindade recebem, mas devido à distância do centro de Goiânia o valor pago pelo transporte pode tornar essa operação inviável, além da necessidade de cadastro prévio junto a secretaria municipal para o descarte.

Outras formas de destino como o Coprocessamento, utilização dos RCC como combustível para a fabricação de cimento, também são muito caras, segundo cotação com empresas que trabalham na região o valor pago para este tipo de destinação é $\mathrm{R} \$ 200,00$ de frete e $\mathrm{R} \$ 0,40 / \mathrm{kg}$ do resíduo.

Foi cotado com um aterro particular também é chegouse ao valor final de $R \$ 240,00$ para a coleta de $6 \mathrm{~m}^{3}$, juntamente com a disposição final e o transporte dos resíduos, valor muito superior quando comparado ao de uma usina de reciclagem, sendo está a forma mais acessível quando comparada com as demais formas de descarte ambientalmente adequado.

Há uma pedreira que recebe estes resíduos, e que para o descarte desses é cobrado uma taxa de $\mathrm{R} \$ 60,00 / 6 \mathrm{~m}^{3}$ limpo e $\mathrm{R} \$ 90,00 / 6 \mathrm{~m}^{3}$ misturado.

\section{COMPOSIÇÃO DO INVESTIMENTO INCIAL}

$\mathrm{Na}$ composição do investimento necessário para a implantação da usina de reciclagem de entulhos levantou-se os seguintes aspectos: terreno de instalação; licenças ambientais; equipamentos para a reciclagem; compra de caminhões; obras civis; e aquisição de moveis.

$\mathrm{O}$ preço do equipamento necessário para a reciclagem dos resíduos classe A foi obtido junto a empresa CODATO (Codato, 2019).

Segundo o próprio fabricante para atender a demanda da região metropolitana seria necessário um equipamento com capacidade para processar até 30ton/hora, com isso o equipamento adquirido encontra-se nas Figuras 3.1 e 3.2 abaixo:

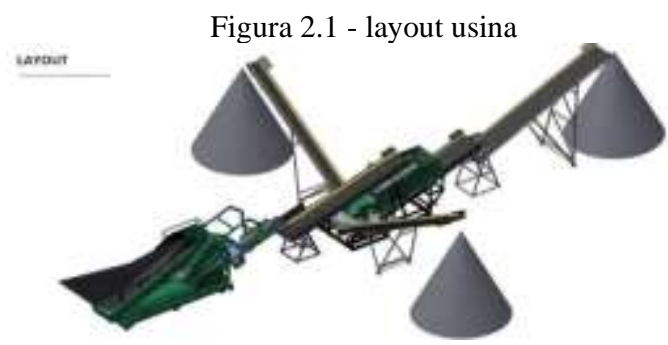

Fonte: O fabricante.
Figura 3.2- Planta Usina

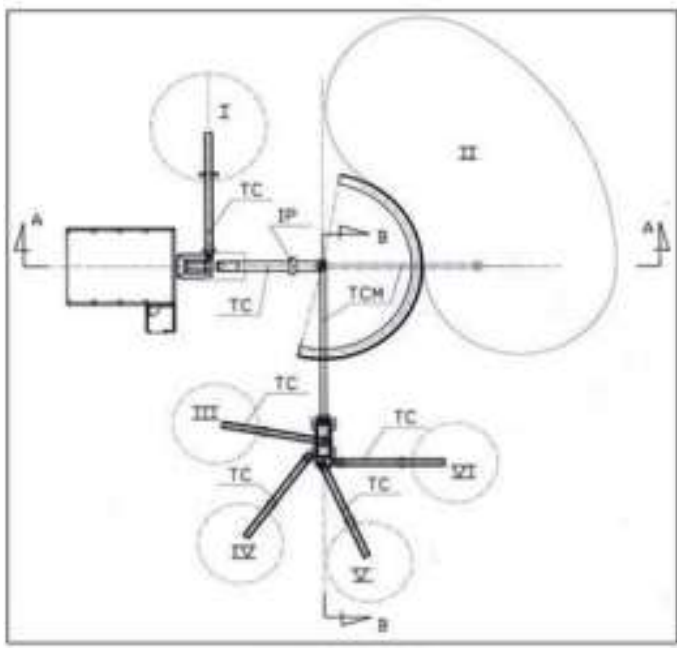

Fonte: O fabricante (Condato, 2019).

Para a composição do preço do terreno foi considerado o local onde seria possível a instalação deste terreno no município de Aparecida de Goiânia, para isso consultou o seu plano diretor e o tamanho do terreno.

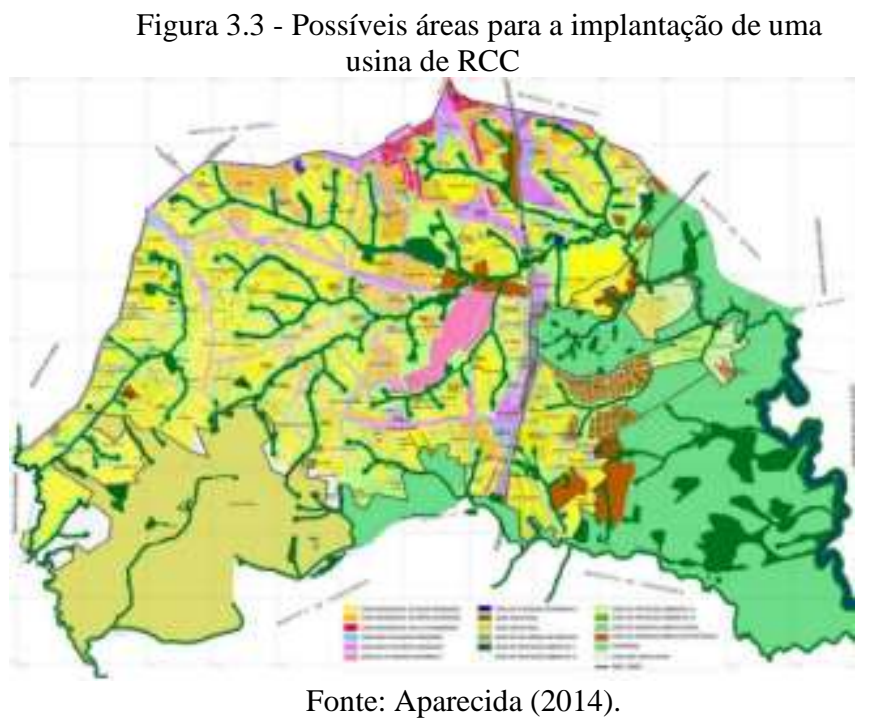

O valor das licenças ambientais: previa, instalação e de operação foi conseguido junto a Secretaria Municipal do Meio Ambiente (SEMMA) de aparecida de Goiânia, para a composição do preço foi necessário obter o CNAE (Classificação Nacional de Atividades Econômicas) da atividade juntamente com o porte da usina, aproximadamente $18.000 \mathrm{~m}^{2}$, esse seria o tamanho necessário para comportar todos os equipamento além das obras civis e pátio para carga e descarga, como área de estoque.

De acordo com a Figura 3.3, as possíveis áreas seriam as pintadas em marrom, sendo assim foi escolhido como local sede o setor Vale do Sol, e um terreno de aproximadamente $18.000 \mathrm{~m}^{2}$.

Já para o valor dos equipamentos foi levado em consideração a presença de 5 computadores da marca Asus, moveis de escritório, 1 impressora da marca HP, 7 cadeiras Mobly, 4 telefones da marca Intelbras, 2 ar condicionados de 12000 btus da marca Electrolux, 1 geladeira $300 \mathrm{~L}$ da marca Consul, 1 fogão 4 bocas da marca Consul e 1 micro-ondas $31 \mathrm{~L}$ da marca Electrolux, todos os preços foram cotados via 
internet, todos os dados encontrados estão dispostos na Tabela 3.1 abaixo:

Tabela 3.1- Equipamentos adquiridos para a usina

\begin{tabular}{cccc}
\hline Equipamento & Quantidade & Preço $(\mathrm{R} \$)$ & Custo $(\mathrm{R} \$)$ \\
\hline Moveis & & & $20.000,00$ \\
Microondas & 1 & 449,10 & 449,10 \\
Fogão & 1 & 404,91 & 404,91 \\
Cadeira & 7 & 230,00 & $1.610,00$ \\
Geladeira & 1 & $1.439,10$ & $1.439,10$ \\
Telefone & 4 & 39,90 & 159,60 \\
Ar & 2 & $1.369,00$ & $2.738,00$ \\
condicionado & 5 & $2.469,05$ & $12.345,25$ \\
Computador & 5 & 479,34 & 479,34 \\
Impressora & 1 & & $\mathbf{4 0 . 0 0 0 , 0 0}$ \\
\hline Total & & &
\end{tabular}

Fonte: $\mathrm{O}$ autor.

Para o preço do caminhão, pá carregadeira e da retroescavadeira foram escolhidos os seguintes modelos respectivamente: caminhão toco da marca Scania, modelo R500, uma pá carregadeira da marca Volvo, modelo L60F e uma retroescavadeira da marca CASE, modelo $580 \mathrm{~N}$, todos os preços obtidos foram através de fornecedores especializados, em que foram considerados impostos, fretes, etc. .

E para as obras civis foram consideradas os seguintes cômodos no local: Administração e sala de reunião $60 \mathrm{~m}^{2}$; vestiário com banheiro $16 \mathrm{~m}^{2}$; copa $16 \mathrm{~m}^{2}$, portaria $4 \mathrm{~m}^{2}$. para a composição do valor foi utilizado como base a tabela base do (SINDUSCON, 2019) com os valores atualizado para o mês de Janeiro de 2019.

Tabela 3.2 - Composição do investimento para implementação

\begin{tabular}{cc}
\hline Atividade & Custo $(\mathbf{R} \mathbf{\$})$ \\
\hline Equipamentos & $1.500 .000,00$ \\
Terreno & $500.000,00$ \\
Moveis & $40.000,00$ \\
Licença Ambiental & $6.000,00$ \\
Obras civis & $113.280,00$ \\
Caminhões & $610.000,00$ \\
\hline Total & $2.769 .280,00$ \\
\hline
\end{tabular}

Fonte: $\mathrm{O}$ autor.

Com isso encontra-se um investimento inicial igual a $\mathrm{R} \$$ 2.769.280,00.

\section{ANÁLISE DAS DESPESAS DO PROCESSO}

Para a análise das despesas do processo foi levantado junto a uma usina existente na região metropolitana de Goiânia, todos os possíveis gastos envolvidos no processo são: gastos com energia elétrica, óleo diesel, funcionários, custo com Equipamento de Proteção Individual (EPI), água, manutenção dos equipamentos e impostos.

Para a composição dos gastos levou-se em conta os seguintes aspectos representados abaixo:

\section{Custo com salários}

Utilizando os valores encontrados por Nicolau (2018), estimou-se o valor pago para cada funcionário da empresa, juntamente com os impostos (Férias, FGTS, INSS) além do valor pago pelo $13^{\circ}$ salário. Segundo Nicolau (2018) o valor pago para as Férias corresponde a 1/3 do salário mensal, já o valor pago no Fundo de Garantia do Tempo de Serviço (FGTS) corresponde a $8 \%$ do salário anual e o Instituto Nacional do Seguro Social (INSS) apresenta uma contribuição social da seguinte forma: $8 \%$ para salários até R\$ 1.693,72; 9\% para salários entre R\$ $1.693,73$ a R\$ $2.822,90$ e $11 \%$ para salários entre $\mathrm{R} \$ 2.822,90$ até $\mathrm{R} \$$ $5.645,80$.

\section{Custos com Equipamentos de Proteção Individual}

Os custos com EPI foram citados pelo gerente da usina como um dos gastos para a composição dos gastos mensais, tal fato também foi apresentado por Nicolau (2018) como um dos gastos mensais de uma usina. Para a definição da quantidade e tempo de duração dos EPI's foi levado em consideração o número de funcionários que necessitam do EPI e o tipo de trabalho realizado por cada um, sabendo disso é possível definir que trabalhos manuais tais como ajudantes de triagem necessitam de uma troca e reposição mais rápida dos equipamentos do que trabalhos administrativos.

\section{Custo com energia}

Para a estimativa dos gastos relacionados com o consumo de energia elétrica estimou-se os seguintes equipamentos presente na usina de reciclagem: um alimentador vibratório de triagem; uma esteira transportadora; um britador de mandíbula; duas correias de areia e brita; uma peneira vibratória e um painel de controle elétrico. Para os cálculos utilizou-se os valores encontrados por Jadovisk (2005), obtidas juntamente com os fabricantes do equipamento, para isso utilizou-se a seguinte tabela criada por Jadovisk, mostrada na Figura 4.1.

Figura 4.1 - Potência dos equipamentos de uma usina de RCC

\begin{tabular}{|c|c|c|c|c|c|c|c|c|c|c|}
\hline \multirow[b]{2}{*}{ 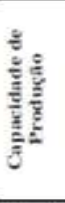 } & \multirow[b]{2}{*}{ 彭 } & \multirow[b]{2}{*}{ 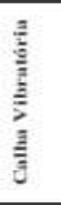 } & \multirow[b]{2}{*}{ 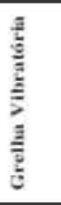 } & \multirow[b]{2}{*}{ 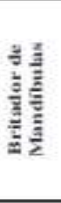 } & \multirow[b]{2}{*}{ 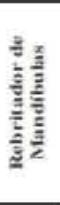 } & \multirow[b]{2}{*}{ 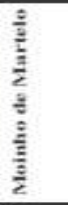 } & \multirow[b]{2}{*}{ 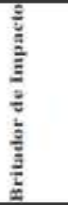 } & \multirow[b]{2}{*}{$\frac{2}{2}$} & \multicolumn{2}{|c|}{ Correis } \\
\hline & & & & & & & & & 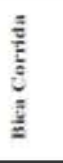 & $\begin{array}{l}\frac{a}{2} \\
\frac{\partial}{2} \\
\frac{a}{2} \\
\frac{a}{2}\end{array}$ \\
\hline (thon/h) & & & & & & W) & & & & \\
\hline 20 & 2.94 & 1,47 & & 19,61 & 15,00 & 49,0 & 22,07 & 3.68 & 2,94 & 11,03 \\
\hline 30 & 3.79 & 1.84 & & 19,42 & 18.39 & 44.13 & 29,42 & 5.52 & 2,94 & 13,24 \\
\hline 40 & 3,79 & 2,20 & & 35.00 & 2759 & 73,55 & 3678 & 736 & 3,68 & 13,24 \\
\hline 50 & 5,51 & 2,41 & 7.35 & 42,00 & 36,78 & 91,50 & 44,13 & 9,20 & 4,41 & 36,48 \\
\hline 75 & 1113 & 294 & 7,35 & 58.60 & 45.97 & 110,00 & 7355 & 11,03 & 9.19 & 27,58 \\
\hline 100 & 14,71 & 4,40 & 735 & 75,00 & 45,97 & 110,90 & 110,90 & 12.86 & 11013 & 30,16 \\
\hline
\end{tabular}

Fonte: Jadovisk (2005).

Na composição do gasto o valor do kwh foi obtido no site da companhia de distribuição de energia (ENEEL, 2019) com base na tarifa de maio de 2019. Neste valor já estão incluídos os impostos (ICMS+PIS+COFINS), contudo não foi considerado, neste trabalho, a sazonalidade das taxas adicionais de bandeira amarela e vermelha, adicionando um valor extra ao $\mathrm{kwh} / \mathrm{hora}$ a mais utilizado.

\section{Custo com óleo diesel}

Para a estimativa do consumo de óleo diesel, foram considerados 3 veículos utilizados na empresa, sendo eles: um caminhão toco da marca Scania, modelo R500, uma pá carregadeira da marca Volvo, modelo L60F e uma retroescavadeira da marca CASE, modelo $580 \mathrm{~N}$, adotou-se tais maquinas afim de facilitar o cálculo, contudo todos os veículos foram vistos em loco.

Para o caminhão foi adotado uma distância média percorrida de $10.410 \mathrm{~km}$ por mês (347 viagens de $30 \mathrm{~km}$ ) isso porque sabe-se que são reciclados 60 mil toneladas por ano na usina, isso dá um valor de 5 mil toneladas por mês, 
transformando esse valor de tonelada para metro cúbico temos a massa especifica igual a $1.200 \mathrm{~kg} / \mathrm{m}^{3}$, então temos um valor igual a $4.166,7 \mathrm{~m}^{3}$, conforme especificação técnica do veículo (Scania, 2019). Além disso, esse caminhão toco consegue transportar em média $12 \mathrm{~m}^{3}$, sendo assim tem-se um total de 347 viagens para o escoamento total da produção, com um consumo médio de 24,9 $1 / 100 \mathrm{~km}$ rodado para o caminhão Scania R500, encontrando um valor igual a 846 litros utilizados durante um mês.

Sabendo desta informação, e que o preço atualizado do óleo diesel para o mês de março de 2019 foi de R \$2,37 segundo o site da Agência Nacional de Petróleo (ANP, 2019) é possível encontrar o valor gasto com óleo diesel.

Para o consumo da pá carregadeira e retroescavadeira foram utilizados os valores sugeridos por Jadovisk (2005), onde segundo ele o valor de consumo médio para a pá carregadeira é de $16 \mathrm{l} / \mathrm{h}$ e para a retroescavadeira é de $8 \mathrm{l} / \mathrm{h}$ com isso é possível realizar os cálculos.

Além disso, foi adotado um valor seguindo Jadovisk (2005) de $\mathrm{R} \$ 1.000,00$ para gastos com licenciamento do caminhão.

\section{Custo com consumo de água}

Para o consumo de água foi realizado de acordo com a equação proposta por Jadovski (2005) (Eq. 2) onde:

Consumo de água $=$ Capacidade de produção $* 0,08 *$ valor unitário da água $/ \mathrm{m}^{3}$

Também, segundo a resolução normativa 0125/2018 da Saneago (2019) deve-se considerar como a tarifa básica cobrada para indústrias o valor de $\mathrm{R} \$ 12,71 / \mathrm{m}^{3}$ para os cálculos.

\section{Custo com manutenção}

Para fins de cálculo foi arbitrado um valor igual a 5\% do valor total gasto da usina mensalmente, tal fato leva em consideração os fatores mostrados por Jadovski (2005) nos quais podem ser citados: manutenção corretiva de máquinas e equipamentos; manutenção de obras civis; manutenção preventiva de máquinas e equipamentos.

\section{Custos com impostos}

Os impostos incidentes sobre este tipo de atividade foram mostrados por Jadovski (2005) onde pode-se citar os seguintes impostos: PIS/COFINS e o imposto de renda. O valor cobrado pelo PIS/COFINS segundo a Lei 10.637/2002 é de 3,65\% da receita bruta e o valor cobrado pelo imposto de renda é igual $15 \%$ do lucro, caso obtenha-se lucro superior a $\mathrm{R} \$ 20.000,00$ deve-se acrescentar 10\%, segundo Lei 9.430/1996.

Sabendo disto é possível construir a Tabela 4.1 a seguir com todos os valores encontrados:

Tabela 4.1- Quadro de gastos da usina

\begin{tabular}{cc}
\hline EPI mensal & $\mathrm{R} \$ 287,20$ \\
\hline Salários & $\mathrm{R} \$ 21.924,60$ \\
Energia & $\mathrm{R} \$ 5.982,59$ \\
Água & $\mathrm{R} \$ 4.236,00$ \\
Gasto com Automóveis & $\mathrm{R} \$ 19.153,92$ \\
PIS/COFINS & $\mathrm{R} \$ 5.969,26$ \\
Valor dos Gastos & $\mathrm{R} \$ 57.553,57$ \\
Manutenção & $\mathrm{R} \$ 2.877,68$ \\
\hline Valor Total Mensal & $\mathrm{R} \$ 60.431,25$ \\
\hline
\end{tabular}

Fonte: $\mathrm{O}$ autor.

\section{RECEITAS DA USINA}

Em uma usina de reciclagem de RCC tem-se uma receita em duas partes do processo, ou seja, na entrada dos resíduos para sua transformação em material agregado e na sua venda, como agregado reciclado.

Com intuito de observar a receita gerada por uma usina, foi utilizado dados de uma usina existente na cidade de Aparecida de Goiânia, sendo assim possível encontrar o benefício gerado com o processo.

Primeiramente foi solicitada ao empreendedor a quantidade de materiais agregados vendidos em um ano, segundo ele, por mês são vendidas 5.000 toneladas de agregados reciclados, transformando este para $\mathrm{m}^{3}$, tem-se um total de 4.166,6 $\mathrm{m}^{3}$ de agregados vendidos no mês.

Também foi fornecido que deste total, $30 \%$ é vendido com rachão, $25 \%$ como pedrisco, $25 \%$ como brita e $20 \%$ como areia.

Além disto, o valor cobrado para a venda de agregados foi fornecido um valor igual a $\mathrm{R} \$ 24,00 / \mathrm{m}^{3}$ para todos os agregados, analisando a situação de mercado chega até a Tabela 5.1.

Tabela 5.1 - Comparação da venda de agregados

\begin{tabular}{|c|c|c|c|c|}
\hline Empresas & Produto & Valor & Unidade & $\begin{array}{l}\text { Frete por } \\
\text { tonelada }\end{array}$ \\
\hline \multirow{3}{*}{ Pedreira A } & Brita 0 & $\mathrm{R} \$ 43,00$ & Ton & \multirow{3}{*}{$\mathrm{R} \$ 13,00$} \\
\hline & Brita 1 & $\mathrm{R} \$ 35,00$ & Ton & \\
\hline & Areia fina & $\mathrm{R} \$ 50,00$ & Ton & \\
\hline \multirow{3}{*}{ Pedreira B } & Brita 0 & $\mathrm{R} \$ 42,00$ & Ton & \multirow{3}{*}{$\mathrm{R} \$ 15,00$} \\
\hline & Brita 1 & $\mathrm{R} \$ 33,00$ & Ton & \\
\hline & Areia & - & Ton & \\
\hline \multirow{3}{*}{ Pedreira C } & Brita 0 & $\mathrm{R} \$ 43,00$ & Ton & \multirow{3}{*}{$\mathrm{R} \$ 15,00$} \\
\hline & Brita 1 & $\mathrm{R} \$ 35,00$ & Ton & \\
\hline & Areia & $\mathrm{R} \$ 26,00$ & Ton & \\
\hline \multirow{3}{*}{ Pedreira D } & Brita 0 & $\mathrm{R} \$ 61,00$ & Ton & \multirow{3}{*}{$\mathrm{R} \$ 13,00$} \\
\hline & Brita 1 & $\mathrm{R} \$ 51,00$ & Ton & \\
\hline & Areia & $\mathrm{R} \$ 42,00$ & Ton & \\
\hline
\end{tabular}

$\mathrm{Na}$ entrada dos resíduos também é cobrada uma taxa para o recebimento deste, sendo o valor de $\mathrm{R} \$ 10,00 / \mathrm{m}^{3}$, caso o resíduos apresente materiais que não podem ser utilizados no processo, o gerador paga uma quantia de $\mathrm{R} \$ 15,00 / \mathrm{m}^{3}$, com isso é possível construir a seguinte Tabela 5.2.

Tabela 5.2- Valor recebido pela entrada de resíduos na usina

\begin{tabular}{ccccc}
\hline $\begin{array}{c}\text { Total de resíduos } \\
\text { recebidos }\end{array}$ & 5.000 & ton/mês & $4.166,7$ & $\mathrm{~m} / \mathrm{mês}$ \\
\hline $\begin{array}{c}\text { Valor recebido pelo } \\
\text { recebimento dos } \\
\text { resíduos (RCC) }\end{array}$ & - & - & $\mathrm{R} \$ 39.583,33$ & $\mathrm{R} \$ / \mathrm{m}^{3}$ \\
$\begin{array}{c}\text { Valor recebido pelo } \\
\text { recebimento dos } \\
\text { resíduos (RCB) }\end{array}$ & - & - & $\mathrm{R} \$ 3.125,00$ & $\mathrm{R} \$ / \mathrm{m}^{3}$ \\
$\begin{array}{c}\text { Valor recebido pelo } \\
\text { recebimento dos } \\
\text { resíduos (Estoque }\end{array}$ & - & - & $\mathrm{R} \$ 2.083,33$ & $\mathrm{R} \$ / \mathrm{m}^{3}$ \\
$\begin{array}{c}5 \% \text { a mais de RCC } \\
\text { por mês) }\end{array}$ & & & & \\
\hline & Fonte: O autor. & & \\
\end{tabular}

Sabendo que do total que entra no processo apenas $95 \%$ é reutilizado no processo, conclui-se que 5\% de tudo é destinado ao aterro sanitário mais próximo, no caso analisado 
o aterro é o de Aparecida de Goiânia que possui um custo para o descarte de rejeitos de $\mathrm{R} \$ 96,00$, com isso é possível descobrir qual a receita da entrada de resíduos no local, apresentado na Tabela 5.3.

Tabela 5.3- Resultado \$ de resíduos na usina

\begin{tabular}{|c|c|c|c|c|}
\hline $\begin{array}{l}\text { Valor total } \\
\text { recebido pelo } \\
\text { recebimento de } \\
\text { resíduos }\end{array}$ & - & - & $\mathrm{R} \$ 44.791,67$ & $\mathrm{R} \$$ \\
\hline $\begin{array}{l}\text { Valor cobrado } \\
\text { pelo aterro para } \\
\text { recebimento } \\
\text { dos resíduos } \\
\text { Classe B }\end{array}$ & 96 & $\mathrm{R} \$ /$ ton & & - \\
\hline $\begin{array}{c}\text { Valor gasto } \\
\text { com o descarte } \\
\text { de resíduos para } \\
\text { o aterro de } \\
\text { aparecida de } \\
\text { Goiânia }\end{array}$ & $\mathrm{R} \$ 24.000,00$ & $\mathrm{R} \$$ & - & - \\
\hline $\begin{array}{l}\text { Valor total } \\
\text { recebido pelo } \\
\text { recebimento de } \\
\text { resíduos e o } \\
\text { descarte dos } \\
\text { rejeitos }\end{array}$ & $\mathrm{R} \$ 20.791,67$ & $\mathrm{R} \$$ & & \\
\hline
\end{tabular}

Fonte: $\mathrm{O}$ autor.

Para o recebimento de resíduos teve-se um benefício total de $\mathrm{R} \$ 20.791,67$.

Para a venda de agregados foi possível construir a seguinte Tabela 5.4.

Tabela 5.4- Lucro com a venda de agregados

\begin{tabular}{ccc}
\hline Vende & 4166,7 & $\mathrm{~m}^{3} / \mathrm{mês}$ \\
\hline Brita vendida & $25 \%$ & $\% / \mathrm{mês}$ \\
Areia vendida & $20 \%$ & $\% / \mathrm{mês}$ \\
Rachão vendido & $30 \%$ & $\% / \mathrm{mês}$ \\
Pedrisco vendido & $25 \%$ & $\% / \mathrm{mês}$ \\
Valor ganho de Brita 1 & $\mathrm{R} \$ 29.687,50$ & $\mathrm{R} \$ / \mathrm{mês}$ \\
Valor ganho areia & $\mathrm{R} \$ 23.750,00$ & $\mathrm{R} \$ / \mathrm{mês}$ \\
Valor ganho pedrisco & $\mathrm{R} \$ 35.625,00$ & $\mathrm{R} \$ / \mathrm{mês}$ \\
Valor ganho rachão & $\mathrm{R} \$ 29.687,50$ & $\mathrm{R} \$ / \mathrm{mês}$ \\
\hline Valor total ganho com & $\mathrm{R} \$ 118.750,00$ & $\mathrm{R} \$ / \mathrm{mês}$ \\
a venda de agregados & \multicolumn{2}{c}{ Fonte: O autor. }
\end{tabular}

Sabendo disso o lucro total gerado pela empresa é de $\mathrm{R} \$ 139.541,67$.

\section{ANÁLISE DOS INDICADORES FINANCEIROS}

Estimar e demonstrar as diferentes possibilidades dos resultados possíveis, possibilita gerenciar melhor os recursos, além de perceber outras alternativas do investimento, ampliando a capacidade de tomada de decisão. Em Marques et al. (2016) e Marques et al. (2018) realizaram estudos de viabilidade financeira que facilitaram claramente o processo de tomada de decisão, indicando a viabilidade financeira. Esses estudos foram elaborados através de um conjunto de indicadores de riscos e retornos, diante do fluxo de caixa determinado de acordo com o objetivo do projeto.

Para a análise dos indicadores financeiros foi utilizado o mesmo método de Sobralv (2012), onde o autor fez a analise através do método do valor presente líquido (VPL), segundo Sobralv (2012) essa constitui-se de uma técnica que considera todos os valores esperados para um fluxo de caixa da data zero utilizando como taxa de desconto a taxa mínima atrativo ou TMA, sendo assim todos os benefícios adquiridos com o projeto são levados para o valor presente inicial.

Com todos os dados apresentados anteriormente, é possível construir um fluxo de caixa, assim como calcular os indicadores financeiros. É importante salientar que para os cálculos foram adotados uma taxa de desconto de $15 \%$, um período de 10 anos (tempo adotado pelo fabricante para uma manutenção e reposição mais intensa das peças). O fluxo é apresentado na Tabela 6.1 :

Tabela 6.1- representação do fluxo de caixa da usina

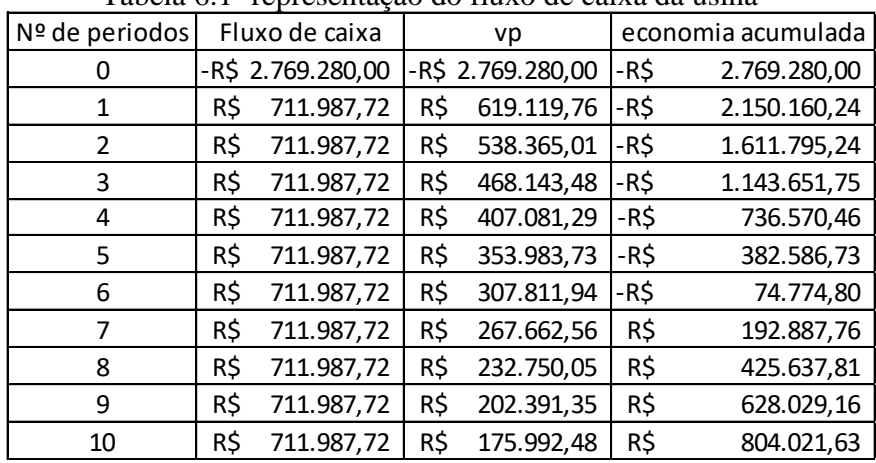
Fonte: $\mathrm{O}$ autor

Outra forma de representar o fluxo de caixa está representada na Figura 6.1.

Figura 6.1- Fluxo de caixa

Fluxo de caixa de uma usina de reciclagem de RCC

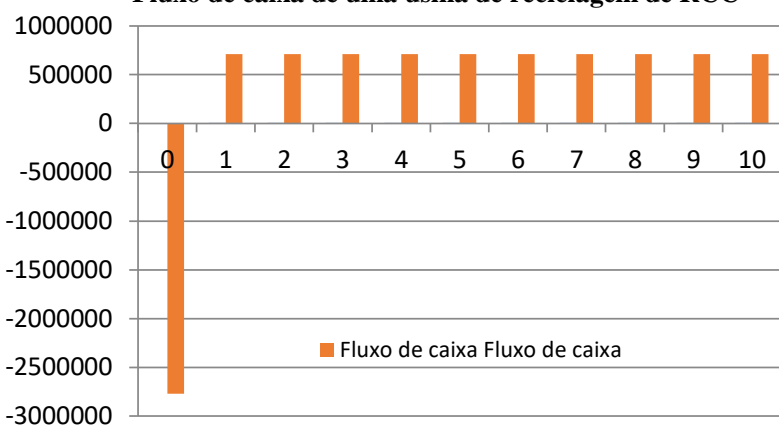

Fonte: $\mathrm{O}$ autor.

Juntamente com o fluxo de caixa é possível encontrar os indicadores, representados na Tabela 6.1.

\begin{tabular}{cc}
\multicolumn{2}{c}{ Tabela 6.1- Indicadores econômicos } \\
\hline VPL & $\mathrm{R} \$ 804.021,63$ \\
\hline VPLa & $\mathrm{R} \$ 123.875,46$ \\
IBC & 1,29 \\
ROIA & $3 \%$ \\
ROI & $18 \%$ \\
TIR & $22 \%$ \\
\hline PayBack & 6 e 7 ANOS \\
\hline \multicolumn{3}{c}{ Fonte: $\mathrm{O}$ autor. }
\end{tabular}

Destes pode-se retirar as seguintes informações: por ter um VPL positivo a atividade mostra-se viável, ou seja, o investidor consegue ter um retorno.

Quando se analisa o IBC observa-se que o valor é maior que 1 (um) e que, portanto, para cada unidade monetária investida no projeto o investidor recebera $\mathrm{R} \$ 0,29$ além do que foi investido.

O ROIA indica que o projeto gerará um total de $3 \%$ a.a de riqueza além da taxa de desconto considerada. 
A TIR representa tanto o retorno do investimento quanto uma percepção do nível de risco do projeto. Quanto mais próxima ela estiver da TMA maior será o risco do projeto e menos atrativo será. Nesse caso há uma distância da ordem de 7 pontos percentuais, o que indica que o projeto apresenta um baixo risco para o investidor.

O PayBack está entre 6 e 7 anos, e que em função do perfil do tomador de decisões, esse pode ser um tempo longo para retornar o capital investido.

\section{CONCLUSÃO}

O objetivo deste trabalho foi apresentar um estudo de viabilidade para a implantação de uma usina de reciclagem para a indústria da construção na região metropolitana de Goiânia-GO.

Observando e analisando os resultados apresentados na seção ANÁLISE DOS INDICADORES FINANCEIROS pode-se perceber a viabilidade financeira deste projeto. Além disso, foi possível mostrar que a maior parte dos resíduos dispostos em aterros, lixões, taludes e terrenos baldios pode ser reutilizada como matéria-prima para a construção civil. Além de uma percepção clara de um aumento na vida útil dos aterros, redução da quantidade de resíduos descartados em um local inadequado, podendo com isso, criar novos empregos e fortalecer o compromisso com a sustentabilidade.

\section{REFERÊNCIAS}

MARQUES, et al. Um Estudo de Viabilidade Financeira de Sistemas Automatizados para Estacionamento em Shopping, Revista Sodebras [on line]. v. 13, n.150. Jun./2018 p. 25-30. ISSN 1809-3957. Disponível em: 〈http://www.sodebras.com.br/edicoes/N150.pdf $>$. Acesso em 26 ago. 2019.

SOBRALV, Ricardo Franklin Cavalcanti. Viabilidade Econômica de Usina de Reciclagem de Resíduos da Construção Civil: Estudo de caso da USIBEM. Trabalho de conclusão de mestrado (Mestrado Profissionalizante em Engenharia) Universidade Federal da Paraíba. 2012.

CODATO, Empresa de Engenharia, Equipamentos e Manutenção. http://www.codato.ind.br/ <Acesso em 09/10/2019>

COMURG: Companhia de Urbanização de Goiânia. Resolução no 20 de 07 de junho de 2016. Goiânia, 2016.

CONAMA: CONSELHO NACIONAL DO MEIO AMBIENTE. Resolução $\mathbf{n}^{\circ} 307$, de 05 de julho de 2002. Brasília, 2002.

CONAMA: CONSELHO NACIONAL DO MEIO AMBIENTE. Resolução $\mathbf{n}^{\circ}$ 348, de 16 de agosto de 2004. Brasília, 2004.

CONAMA: CONSELHO NACIONAL DO MEIO AMBIENTE. Resolução $\mathbf{n}^{\circ} \mathbf{4 3 1}$, de 24 de maio de 2011. Brasília, 2011.

CONAMA: CONSELHO NACIONAL DO MEIO AMBIENTE. Resolução ${ }^{\circ}$ 448, de 18 de janeiro de 2012. Brasília, 2012.

CONAMA: CONSELHO NACIONAL DO MEIO AMBIENTE. Resolução $\mathbf{n}^{\circ} \mathbf{4 6 9}$, de 30 de julho de 2015. Brasília, 2015.
GOIÁS. Lei $\mathbf{n}^{\circ}$ 14.248, de 29 de julho de 2002. Goiânia, 2002.

ENEL, Distribuidora de Energia Elétrica no Estado de Goiás, https://www.enel.com.br. Acesso em 09/10/2019.

GOIÁS: SECRETARIA DE MEIO AMBIENTE, RECURSOS HIIDRICOS, INFRAESTRUTURA, CIDADES E ASSUNTOS METROPOLITANOS. Plano estadual de Resíduos Sólidos de Goiás. Goiânia, 2017.

JADOVSKI, Iuri. Diretrizes Técnicas e Econômicas para Usina de Reciclagem de Resíduos de Construção e Demolição. Trabalho de conclusão de mestrado (Mestrado Profissionalizante em Engenharia) - Escola de Engenharia da Universidade Federal do Rio Grande do Sul. Porto Alegre, 2005.

LIMA, Adriana Sampaio; CABRAL, Antonio Eduardo Bezerra. Caracterização e classificação dos resíduos de contrução civil de Fortaleza (CE). Eng. Sanit. Ambient. Fortaleza, v. 18 n.2, p. 169-176, 2013.

MARQUES, et al. Uma Análise de Viabilidade Econômica para Implementação de Sistemas Geotérmicos em Instalações Industriais. Revista Sodebras [on line]. v. 11, n. 132, Dez./ 2016 p. 248-252. ISSN 1809-3957. Disponível em: $\quad$ http://www.sodebras.com.br/edicoes/N132.pdf $>$. Acesso em 26 ago. 2019.

NICOLAU, Maiara Fuzatti. Estudo de Viabilidade Econômica com concepção de projeto de usina de reciclagem de RCC para municípios de pequeno porte. Trabalho para programa de Pós-Graduação (Pós-Graduação em Estrutura e Construção Civil) - Universidade Federal de São Carlos, São Carlos, 2018.

SINDUSCON-GO, Sindicato da Industria da Construção no Estado de Goiás, https://www.sinduscongoias.com.br/ Acesso em 09/10/2019.

JADOVSKI, Iuri. Diretrizes Técnicas e Econômicas para Usinas de Reciclagem de Resíduos de Construção e Demolição. 2005. 180 f. Tese (Mestrado em Engenharia) Universidade Federal do Rio Grande do Sul, RS.

APARECIDA, Prefeitura Municipal de Aparecida de Goiânia, http://www.aparecida.go.gov.br. Acesso em 2014.

SCANIA, Especificações Técnicas do Veículo, https://www.scania.com. Acesso em Out de 2019.

ANP, Agência Nacional do Petróleo, http://www.anp.gov.br/. Acesso em Out de 2019

SANEAGO, Empresa de Saneamento do Estado de Goiás, https://www.saneago.com.br/2016/arquivos/Res_Normativa _0125_2018.pdf. Acesso em Out de 2019.

\section{COPYRIGHT}

Direitos autorais: Os autores são os únicos responsáveis pelo material incluído no artigo.

Submetido em: 05/09/2019 Aprovado em: 25/09/2019 


\title{
Revista SODEBRAS - Volume 14 $\mathrm{N}^{\circ} 166$ - OUTUBRO/ 2019
}

\section{MELHORIA NO FLUXO EM UMA TRANSPORTADORA DE VALORES: UM ESTUDO DE CASO}

\author{
IMPROVEMENT FLOW IN A CASH TRUCK: CASE STUDY \\ RICHELE QUERINO'; ${ }^{1}$ ARCIONE FERREIRA VIAGI²; HAMZAGIC MIROSLAVA3; \\ JOSE CARLOS BORGES DE PAULA ${ }^{4}$ \\ $1 ; 2 ; 3 ; 4$ - UNIVERSIDADE DE TAUBATÉ \\ rityadm@bol.com.br; afviagi@gmail.com ; mira.unitau@gmail.com ; jcarlosborge@gmail.com
}

\begin{abstract}
Resumo - A Serolav (nome fictício) é uma empresa especializada no transporte de valores e foi criada em 2000. Objeto de estudo deste trabalho foi a identificação dos fatores que causavam ineficiência no fluxo de abastecimento dos caixas eletrônicos, devido a quebras constantes no controle de acesso realizado por meio de portões deslizantes automáticos na saída dos carros-fortes. O trabalho envolveu práticas de Manutenção Produtiva Total (TPM, Total Productive Maintenance), é o emprego das ferramentas da qualidade. A metodologia utilizada foi a de estudo de caso com a análise estáticas dos dados coletados. Uma vez identificados cada um dos problemas presentes na empresa, foram aplicadas as ferramentas da qualidade, como: Brainstorming, Histograma, Diagrama de Pareto, Diagrama de Causa e Efeito de Ishikawa e Fluxograma, entre outras. A partir da aplicação das ferramentas foram obtidos resultados promissores que permitiram eliminar ou reduzir os problemas, com a melhoria no fluxo de saída dos carrosfortes (CFs) e o não pagamento de multas. Ao final do trabalho foi proposto um plano de manutenção para ser seguido por meio de um CheckList sendo possivel registrar ganhos financeiros ao longo do período de manutenção do processo.
\end{abstract}

Palavras-chave: Manutenção. TPM. Controle de Acesso. qualidade

Abstract - Serolav (fictitious name) is a company that specializes in the transportation of securities and was created in 2000. The object of this study was to identify the factors that caused inefficiency in the cash flow of ATMs, due to constant breaks in access control performed. through automatic sliding gates at the exit of the cash truck. The work involved Total Productive Maintenance (TPM) practices, the use of quality tools. The methodology used was the case study with the static analysis of the collected data. Once each of the problems present in the company were identified, the quality tools were applied, such as: Brainstorming, Histogram, Pareto Diagram, Ishikawa Cause and Effect Diagram and Flowchart, among others. From the application of the tools promising results were obtained that allowed to eliminate or reduce the problems, with the improvement of the output flow of the strong cars (CFs) and the non-payment of fines. At the end of the work a maintenance plan was proposed to be followed through a CheckList and it was possible to record financial gains during the process maintenance period

Keywords: Maintenance. TPM. Access Control. Quality.

\section{INTRODUÇÃO}

\section{1 - Dados da empresa}

A Serolav (nome fictício) é uma empresa de segurança e transporte de valores fundada no ano 2000, que oferece soluções completas em logística, processamento de valores e informações personalizadas para Instituições financeiras
(IFs, sinônimo de um banco comercial) e do varejo, contribuindo assim, para a otimização do ciclo de numerários (dinheiro) no Brasil.

Os carros-fortes (CFs) transportam o dinheiro recolhido do varejo ou das IFs, realizando também, o abastecimento dos caixas eletrônicos (ATM, Automated Teller Machine). As equipes atuam sob os mais rígidos padrões de qualidade e segurança, utilizando tecnologia e a experiência da empresa para reduzir os riscos e assegurar uma operação contínua e eficaz.

O acordo de Nível do Serviço (SLA, Service Level Agreement) detalha todos os aspectos do tipo de serviço que será prestado, assim como os prazos contratuais, a qualidade do serviço e o preço a ser pago pelo trabalho.

$\mathrm{Na}$ análise do processo, observou-se que o tempo de controle de acesso da frota de carros-fortes, ou seja, a saída dos CFs da empresa, estava impactando no atendimento do abastecimento dos caixas eletrônicos gerando custos no resultado operacional e financeiro da empresa que foram alvo desta pesquisa. Em primeira análise, verificou-se falha na abertura e fechamento dos portões deslizantes automáticos do controle do acesso (BHAMU, 2014).

Foi então elaborado uma estratégia de trabalho para melhorar o fluxo e o processo de controle de acesso, conferindo maior agilidade na entrada e saída dos carrosfortes e, consequentemente, no abastecimento dos caixas eletrônicos, por meio da implementação das práticas de TPM.

\section{REVISÃO DA LITERATURA}

Uma das preocupações no setor operacional de qualquer organização é garantir que seu processo não tenha interrupções, pois as perdas podem ser significativas e comprometer todo o negócio. De acordo com o Lean Institute Brasil (2014) após o advento da "produção enxuta" (Tradução de: Lean Manufacturing), é utilizada para designar princípios e técnicas produtivas que visam a melhoria contínua, onde é importante considerar que desperdícios oriundos de qualquer atividade devem ser evitados a qualquer custo (OHNO, 2006). Ainda segundo o autor, garantir uma operação estável e ininterrupta resulta no planejamento robusto e bem organizado, com processos definidos e claros.

Conforme Tavares e Gomes (2015), é necessário que os gestores de manutenção possuam uma visão mais ampla e 
que comtemple todas as áreas, de forma sistêmica dentro de suas organizações e não apenas a manutenção. O papel deste setor não envolve apenas prever as quebras e falhas dos equipamentos, mas também, participar estrategicamente do negócio de qualquer área operacional (HASSAN, 2016).

Segundo Arslankaya e Atay (2015), o setor de manutenção tem como objetivo reduzir os custos operacionais, assegurar a continuidade da operação e a diminuição das paradas indesejadas.

Aplicar os conceitos de manutenção no setor de operação das empresas e no de serviços tem como finalidade eliminar os desperdícios de todo o processo, fazendo com que as operações aconteçam de forma linear e fluída (THANKI et al., 2016; ZHANG e CHEEN, 2016; MOSTAFA et al., 2015.)

De acordo com Viana (2002), os setores de manutenção passaram a ocupar um papel fundamental no planejamento das indústrias, devido a crescente necessidade de eficiência dos sistemas produtivos e de suas operações. Nesta perspectiva, estes não podem mais limitar-se apenas a atuar nas situações críticas, aguardando passivamente a parada do maquinário para intervenções corretivas ou então, deixando de acompanhar: indicadores de motivos das paradas, históricos de manutenção e análise do desempenho da equipe, entre outros. Na análise de Pinto e Xavier (2012), a manutenção além de ser eficiente deve se tornar eficaz, ou seja, não importa apenas o conserto do equipamento, mas deve manter sua disponibilidade o maior intervalo de tempo possível para a operação e reduzir os riscos de uma parada de operação não planejada. A manutenção deixa do estado de inércia e passa ser atuante com a visão voltada ao cliente externo, devendo focar na sua satisfação e nos resultados financeiros de qualquer organização.

Segundo a definição de Pinto e Xavier, (2012), o significado de manutenção é garantir a disponibilidade e o funcionamento pleno do equipamento para operar de forma contínua.

A Figura 1 apresenta como a manutenção pode ser classificada: corretiva, preventiva e preditiva. Contudo, está denominação depende do grau de risco que o equipamento traz para organização, por exemplo, se não for de grande importância e tiver baixo custo poderá ser classificado para ter a manutenção corretiva. Porém, equipamentos que trazem risco a uma operação e podem desencadear perdas financeiras, podem ser classificados para ter manutenções preventivas ou preditivas, havendo a necessidade de incluir: inspeção, monitoramento, operações de rotina, revisão e reparo nas atividades da manutenção (MOSTAFA et al., 2015).

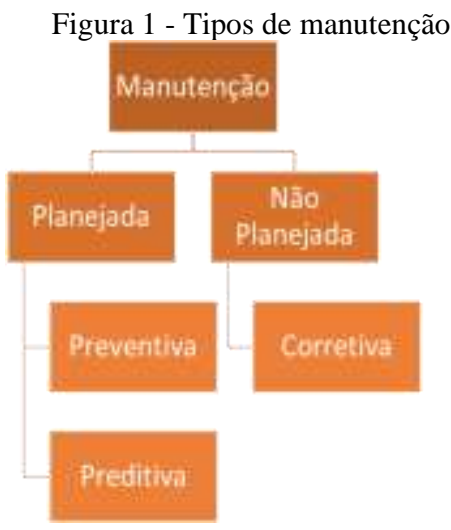

Fonte: Autoria Própria, 2019.
A manutenção corretiva segundo Pinto e Xavier (2012), atua na falha ou quebra do equipamento, ou seja, realiza a manutenção não planejada.

O objetivo da ferramenta TPM, é evitar que a máquina deixe de operar por problemas imprevistos decorrentes no processo. Para cumprir este requisito, a manutenção planejada conta principalmente com duas formas de atuação: primeiro em prevenir a interrupção da máquina por meio da gestão de seus sobressalentes e segundo em investigar, constante e periodicamente, indícios de qualquer anormalidade no processo, de modo que o combate seja posteriormente planejado (PINTO et al., 2012).

As práticas envolvidas na filosofia TPM têm como propósito primordial o aumento da disponibilidade e da eficácia dos equipamentos intrínsecos ao processo, por meio da melhoria em termos de manutenção (GUPTA; GARG, 2012). A implementação da filosofia TPM pode ocasionar maior nível de qualidade em todas as faces das operações da empresa (CHEN et al., 2015).

As ferramentas da qualidade visam trabalhar as causas e extinguir e coibir o aparecimento de problemas. Deste modo, as ferramentas básicas para a qualidade possuem o propósito de apoiar a direção na resolução de problemas (OLIVEIRA; ALLORA; SAKAMOTO, 2006).

\section{1 - Formulação do estudo}

O estudo de caso foi realizado em uma filial da empresa de transporte de valor denominada Serolav, localizada no estado de São Paulo, monitorada no período de janeiro a julho de 2019. A filial conta com uma frota de 7 carros-fortes e com quadro funcional total de 101 colaboradores: 66 para área operacional, 3 para área administrativa e 32 para área de segurança patrimonial.

$\mathrm{Na}$ Figura 2 está representado o fluxograma do processo de coleta dos malotes e de abastecimento dos caixas eletrônicos (ATM). As coletas de valores são realizadas no varejo ou nas Instituições Financeiras (IFs) por meio dos carros-fortes (CFs), sendo os numerários transportados para a filial. Duas atividades podem ser realizadas neste momento, que resultam em ganho financeiro e lucro para a empresa Serolav: processamento, que é a contagem física do numerário e, custódia, que é a guarda do numerário no cofre da própria empresa. Após esta etapa, os CFs se dirigem-se para o abastecimento do varejo, aproximadamente 108 ATM, no período de 22 dias úteis, no mês, cobrindo um raio de $70 \mathrm{~km}$ que correspondem a 2376 abastecimentos ao mês.

Figura 2 - Processo da coleta e distribuição dos numerários

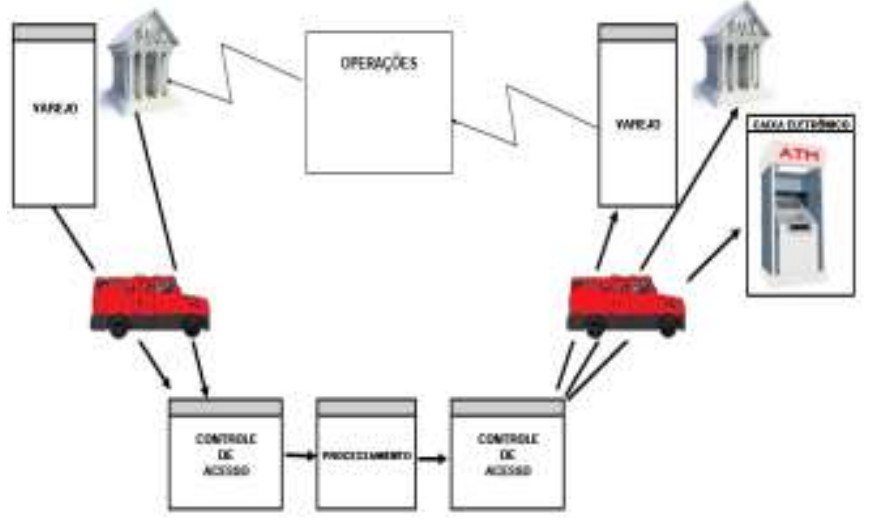

Fonte: Autoria Própria, 2019. 
Conforme o acordo de Nível do Serviço (SLA), o abastecimento diário, quando inferior a 96,7\% (ou 104 ATM), penaliza a transportadora com multa de $3 \%$ do valor bruto estabelecido no contrato. As rotas de saída e os abastecimentos realizados, são controlados pelo setor de operações e monitorados por meio de um sistema de informação denominado Desk Manager Software ${ }^{\circledR}$.

A ação descrita somente é possível por meio de melhor entendimento das atividades e das consequências no fluxo da operação (LIMA, 2014). Com base nos relatórios do software, temos o acumulado das falhas por manutenção de janeiro a março de 2019 descrito na Tabela 1 .

Tabela 1 - Acumulado quebras no controle de acesso atual

\begin{tabular}{cccc} 
Portão & Maior 30 min & 5 a 15 min & Menor 5 min \\
\hline P28 & 94 & 10 & 6 \\
P29 & 1 & 20 & 10 \\
P30 & 0 & 19 & 20 \\
\hline
\end{tabular}

Tempo: Minutos / Período: Janeiro a Março - 2019

Fonte: Saída do Excel 365, 2019.

As interrupções da função do equipamento podem ser definidas como mau funcionamento ou avarias e podem ainda ser classificadas conforme Bazi e Trojan (2014):

- Menores: menos de cinco minutos;

- Gerais: 5 a 15 minutos;

- Longa duração: mais de 30 minutos, objeto deste estudo.

Observando a Figura 3, tem-se o fluxo de saída da frota para abastecimento. Pode-se identificar o impacto na operação determinado pelo portão (P28), que é mais reforçado para inibir invasões e apresentou 94 paradas acima de 30 minutos (no acumulado dos meses).

Figura 3 - Fluxograma operacional na saída da frota

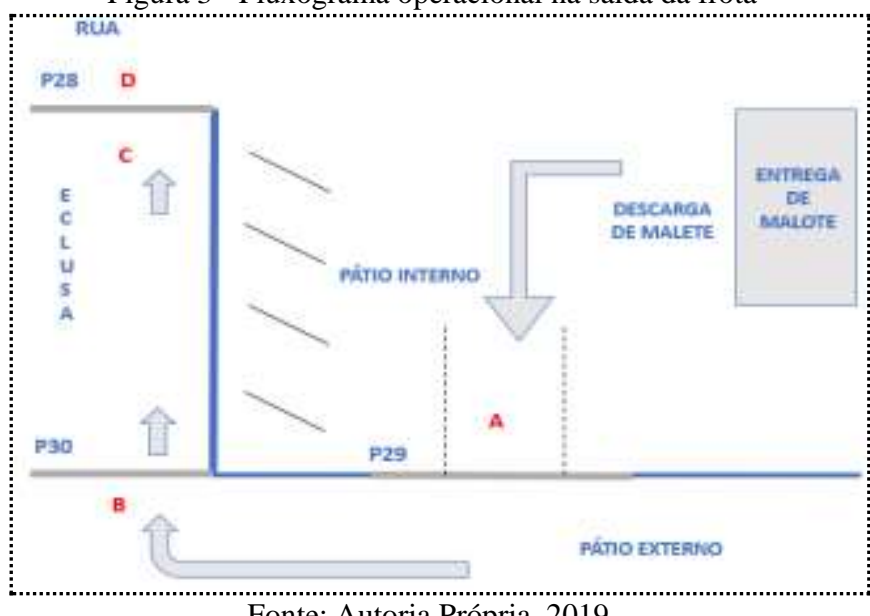

Fonte: Autoria Própria, 2019.

Na Figura 4 tem-se o valor de abastecimento médio com 101 ATMs (nos meses de Janeiro, Fevereiro e Março de 2019, que gerou uma não conformidade passiva da multa de 3\% regida pelo contrato da (SLA; mínimo 104 ATMs abastecidos).
Figura 4 - Número de abastecimentos dos caixas eletrônicos

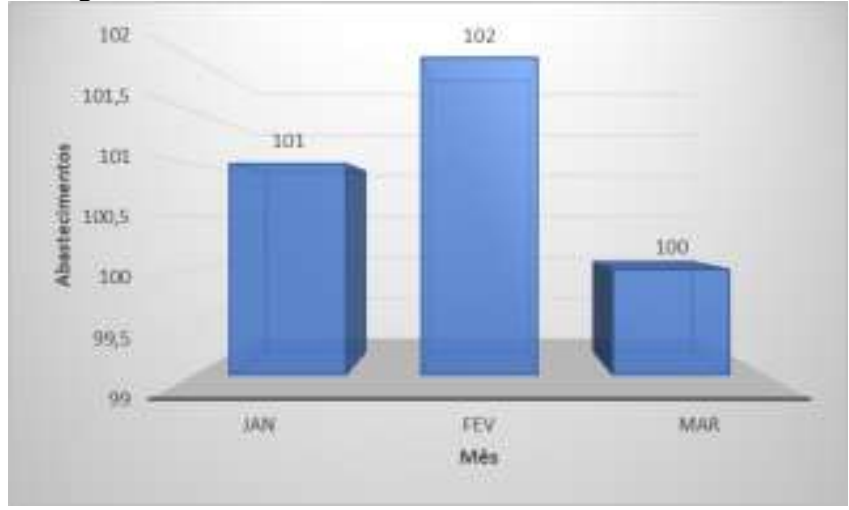

Fonte: Desk Manager software ${ }^{\circledR}$.

\section{METODOLOGIA}

Foi empregada uma pesquisa descritiva da empresa apresentada, utilizando-se técnicas da literatura científica para apresentar as variáveis empregadas.

Objetivando promover a melhoria da qualidade, foram utilizadas ferramentas da qualidade, que facilitam a aplicação de conceitos, coleta e apresentação de dados.

Com intuito de determinar as causas e as ações necessárias, esta pesquisa envolveu: (a) coleta dos pelo Desk Manager $^{\circledR}$; (b) tempo da largada (saída) in loco da frota para abastecimento; (c) aplicação das ferramentas de qualidade. Neste último item tem-se:

- Brainstorming que envolveu todas as técnicas de pensamento divergente;

- Diagrama de Causa e Efeito de Ishikawa, que permitiu organizar categoricamente os conjuntos de causas relacionadas a um determinado efeito ou problema;

- Diagrama de Pareto, determinou as causas reais no atraso pelo controle de acesso na saída dos CFs, classificando os objetos da análise entre vitais e triviais;

- Método dos 5 porquês, aplicado nos resultados apontados por Pareto determinando a causa raiz dos problemas;

- Ferramenta 5W2H, auxiliou a elaboração de um plano de ação para as atividades pré-estabelecidas e desenvolvidas com a maior clareza possível;

- O Fluxograma permitiu que o processo fosse analisado passo-a-passo;

- Por fim foi elaborado o Checklist, que funcionou como uma lista de verificação, proporcionando uma análise sistemática do processo Pinheiro, 2013)

\section{RESULTADOS}

\section{1 - Diagrama de Causa e Efeito Ishikawa}

Buscou explorar e apontar todas as causas possíveis do problema indicado, neste caso Falta de Manutenção, conforme Figura 5. 
Figura 5 - Causa e efeito por problema no portão

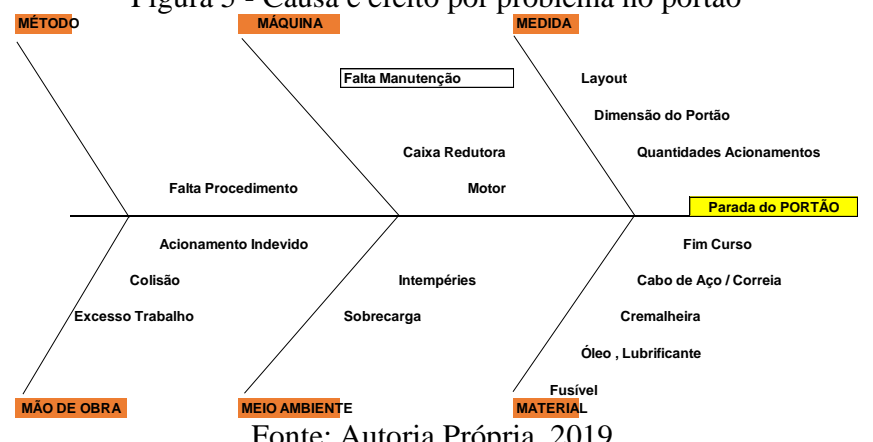

Fonte: Autoria Própria, 2019.

Com esse estudo mais detalhado conseguiu-se identificar que as principais fontes de perdas e baixa produtividade estavam na falha de manutenção do controle dos acessos.

\section{2 - Diagrama de Pareto}

Utilizou como base os dados coletados pelo Desk Manager ${ }^{\circledR}$, elaborou-se o gráfico de Pareto da Figura 6, onde as colunas representam os valores acumulados dos tipos de falhas no controle de acesso pelos portões. As colunas são ordenadas da maior frequência de ocorrência para a menor. A Linha curva registra a contribuição de cada item em porcentagem do acumulado.

Figura 6 - Classificação das falhas conforme Pareto

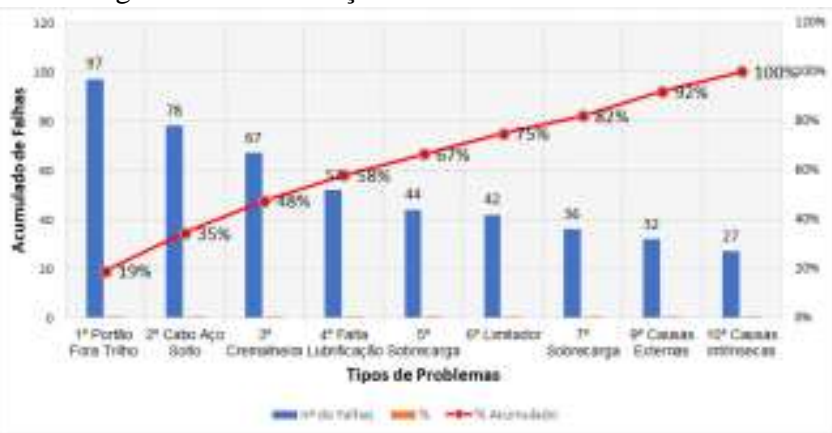

Fonte: Desk Manager Software ${ }^{\circledR}$.

Aplicando-se o princípio de Pareto onde $20 \%$ dos defeitos ( $1^{\circ}$ item, representa $\left.19 \%\right)$ causam $80 \%$ dos problemas (acumulado do $2^{\circ}$ ao $7^{\circ}$ item, representam $82 \%$ ), foi possível eliminar as maiores causas de atraso no controle de acesso pelo portão.

\section{3 - Método dos 5 Porquês}

Utilizando-se deste método que objetiva encontrar a causa raiz do problema apresentamos o problema do item $1^{\circ}$ do gráfico de Pareto, conforme mencionados na Tabela 2.

Tabela 2 - Método dos 5 Porquês na análise da causa raiz Descrição do problema

\begin{tabular}{lll}
\multicolumn{1}{c}{ Pergunta } & \multicolumn{1}{c}{ Motivo } & \multicolumn{1}{c}{ Causa } \\
\hline 1- Por quê & Portão Parou? & Saiu do trilho \\
2- Por quê & Saiu do Trilho & Cabo aço quebrou \\
3- Por quê & Cabo aço quebrou & Soltou da roldana \\
4- Por quê & Soltou da roldana & Parafuso solto \\
5- Por quê & Parafuso soltou & Falta de ajustes \\
Causa Raiz & \multicolumn{2}{c}{ Falta de manutenção atuante } \\
\hline
\end{tabular}

Fonte: Autoria Própria, 2019.
A partir dos problemas apontados, foi necessário elaborar um plano de ação para a atuação da equipe de manutenção como fator crucial na obtenção de qualidade de operação do equipamento. Seguindo entendimento de Farah (2018), sugere-se que sejam fabricados produtos mais simples, facilitando o conserto, diminuindo o tempo de execução e paradas indesejadas.

\section{4 - Aplicação da ferramenta $5 \mathrm{~W} 2 \mathrm{H}$}

Uma vez analisada as causas pelos métodos apresentados e para que as falhas sejam erradicadas, deve-se estabelecer um plano de ação que contenha contramedidas para as causas das falhas, as justificativas para cada contramedida e indicar os responsáveis. Estes dados são apresentados na Tabela 3 .

Tabela 3 - Pano de Ação criado pelo 5W2H.

\begin{tabular}{ll}
\hline O que? & $\begin{array}{c}\text { Elaborar cronograma de manutenção } \\
\text { preventiva Checklist }\end{array}$ \\
\hline Como? & Planilha digital periódica \\
Quem ? & Planejador de manutenção \\
Quando? & Prazo: 01/06/2019 \\
Onde ? & Desk Manager Software ${ }^{\circledR}$ \\
Por quê ? & Eliminar as causas com preventivas. \\
Quanto ? & Custo indiretos internos \\
Status? & Concluído \\
\hline & Fonte: Autoria Própria, 2019.
\end{tabular}

\section{5- Simulação dos resultados obtidos}

Com a análise das ferramentas da qualidade somados aos conceitos do TPM, foi possível elaborar um plano de ação. O responsável pela manutenção da Instituição desenvolveu um checklist personalizado para os portões P28, 29 e 30 do controle de acesso. Foi incluída na rotina do Desk Manager ${ }^{\circledR}$ a ação de indicar ao colaborador que todas as segundas-feiras fossem realizadas a manutenção preventiva. As informações recebidas pelo colaborador estão indicas na Figura 7.

Figura 7 - Tela do software e Checklist preventivo dos portões

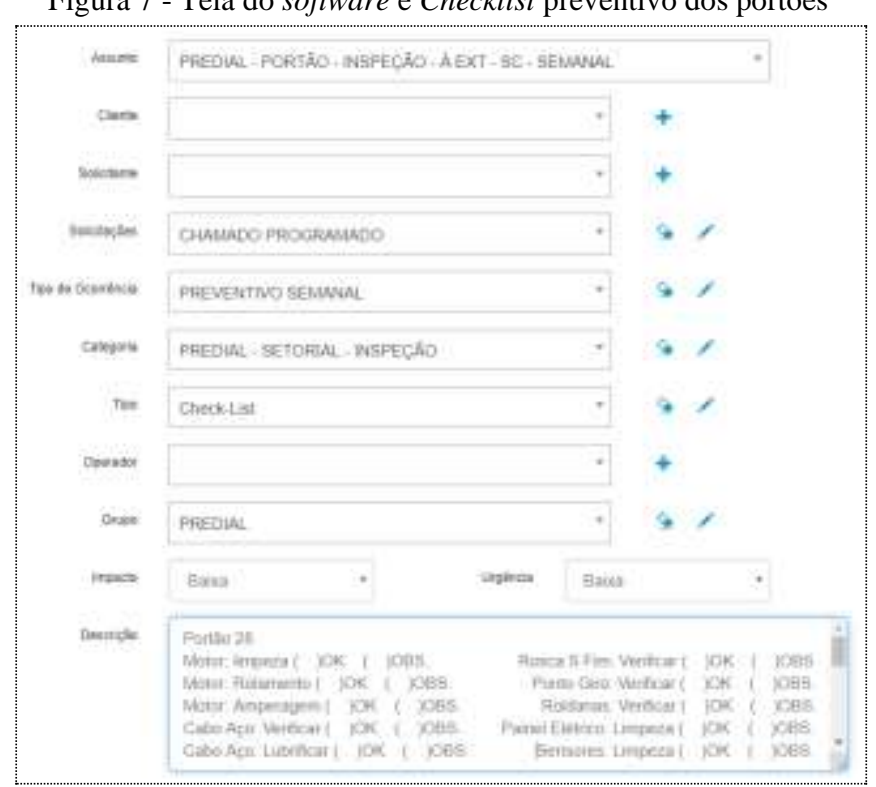

Fonte: Desk Manager Software ${ }^{\circledR}$ 
Considerando o estudo, segundo o Instituto Brasileiro de Avaliações e Perícias de Engenharia (IBAPE nacional, 2012), o desenvolvimento de um checklist constitui de medidas que promovem melhorias da comunicação e diminuem a ocorrência de falhas por omissão, atuando como uma ferramenta de intervenção para o alcance da qualidade e da segurança na assistência. Conforme constatamos na Tabela 4 entre o antes e após a aplicação das ferramentas da qualidade e TPM, de forma efetiva contribuiu para redução nas paradas do controle de acesso em média de 30\%, nas classes maiores de 30 minutos e de forma linear nas demais classes. Mostrando-se de forma geral satisfatória após a aplicação do ciclo de ferramentas.

Tabela 4 - O Antes e Após Aplicação das Ferramentas TPM.

\begin{tabular}{cccc}
\hline Antes & \multicolumn{3}{c}{ Paradas / Tempo } \\
\hline Portão & Maior 30 min & 5 a 15 min & Menor 5 min \\
P28 & 94 & 10 & 6 \\
P29 & 1 & 20 & 10 \\
P30 & 0 & 19 & 20 \\
\hline Tempo: Minutos / Período: Janeiro a Março-2019 \\
\hline \multicolumn{4}{c}{ Paradas / Tempo } \\
\hline Após & \multicolumn{4}{c}{ Maior 30 min } & 5 a 15 min & Até 5 min \\
Portão & 67 & 7 & 4 \\
P28 & 0 & 14 & 7 \\
P29 & 0 & 13 & 14 \\
P30 & 0 &
\end{tabular}

Tempo: Minutos / Período: Maio a Julho / 2019 ( -30\%) Fonte: Saída do Excel 365 (2019).

A partir da criação do checklist preventivo semanal, as falhas nas aberturas dos portões maiores que 30 minutos foram reduzidas para o total de 67 falhas/mês.

Constatou-se, conforme Tabela 5, que a empresa apresentava 101 abastecimentos diários mais uma multa gerada pelo não atingimento de metas em 3\%, decorrentes do atraso no controle de acesso. Já após a implantação passou a realizar 106 abastecimentos (SLA, mínimo 104 abastecimentos) e um aumento na arrecadação pela falta de multas; demostrando a eficácia das ações implementadas pela área de Manutenção da empresa aplicando-se os conceitos TPM e das ferramentas da qualidade.

Tabela 5 - Comparativo da Manutenção Produtiva Total no controle de acesso da frota

\begin{tabular}{|c|c|c|c|}
\hline \multicolumn{4}{|c|}{ Antes da Implantação } \\
\hline $\begin{array}{l}\text { Falhas do P28 } \\
>30 \mathrm{~min}\end{array}$ & Mês/2019 & $\begin{array}{c}\text { ATM } \\
\text { Abastecido }\end{array}$ & $\begin{array}{l}\text { Multa } \\
\text { Gerada }\end{array}$ \\
\hline \multirow{3}{*}{94} & Jan & 101 & \multirow{3}{*}{$3 \%$} \\
\hline & Fev & 102 & \\
\hline & Mar & 100 & \\
\hline \multicolumn{4}{|c|}{ Após Implantação } \\
\hline \multirow{3}{*}{67} & Mai & 104 & \multirow{3}{*}{$\begin{array}{c}\text { Ganho } \\
\text { sem } \\
\text { multa }\end{array}$} \\
\hline & Jun & 106 & \\
\hline & Jul & 107 & \\
\hline
\end{tabular}

Fonte: Desk Manager Software ${ }^{\circledR}$.

\section{CONCLUSÕES}

Foi possível identificar que o controle de acesso na empresa Serolav impactava na operação gerando multas e custo operacional.

Diante dos resultados apresentados, as principais metas do TPM foram atingidas: eliminaram-se as perdas por multas, restauraram-se as condições de uso do controle de acesso, mudou-se a rotina de trabalho com a implantação de roteiros de manutenção ou checklist com formato virtual gerenciado pelo Software da manutenção, ocorreu maior eficiência administrativa e buscou-se a redução por quebras ou falhas.

Com base no exposto, a proposta de melhoria é a implantação de manutenção preventiva com a execução do checklist de formato virtual, eliminando-se o problema de atraso pela não abertura dos portões no controle de acesso, o que impossibilitaria o atendimento, em tempo hábil, dos carros-fortes na atividade de abastecimento.

Visto que é um processo contínuo, deve-se manter toda a equipe envolvida para alcançar o desempenho desejado objetivando uma melhoria contínua em busca do "zero defeito".

\section{REFERÊNCIAS}

ARSLANKAYA, SEHER; ATAY, HATICE. Maintenance Management and Lean Manufacturing Practices in a Firm Which Produces Dairy Products. Procedia - Social and Behavioral Sciences. 207: 214-24. 2015.

BAZI, F.L.; TROJAN, F. Análise de falhas: uma visão holística da melhoria contínua através da manutenção produtiva total (TPM) em um estudo de caso. ADM Gestão Estratégica, 2014.

BHAMU, J.; SINGH SANGWAN, K. Lean manufacturing: literature review and research issues. International Journal of Operations \& Production Management, v. 34, n. 7, p. 876-940, 2014.

CHEN, C.; LU, I.; WANG, K.; JANG, J.; DAHLGAARD, J. Development of quality management in Taiwan the past, present and future. Total Quality Management Business \& Business Excellence. Routledge, London WIT, UK. v. 26, n. 1-2, p. 3-13, 2015.

FARAH, Osvaldo Elias; CAVALCANTI, Marly; PASSOS MARCONDES, Luciana. Empreendedorismo - Estratégias De Sobrevivência Para Pequenas Empresas - $2^{\mathrm{a}}$ Ed. Saraiva, 2018. São Paulo

GUPTA, A. K.; GARG, R. K. OEE Improvement by TPM Implementation: A Case Study. International Journal of IT, Engineering and Applied Sciences Research (IJIEASR), v. 1, n. 1, 2012.

HASSAN, D. K. Divergent thinking techniques discrepancy and functional creativity: Comparative study of structural and procedural techniques in architectural design. Ain Shams Engineering Journal ASEJ, Elsevier. https://doi.org/10.1016/j.asej.2016.10.002, 2016.

INSTITUTO BRASILEIRO DE AVALIAÇÕES E PERÍCIAS DE ENGENHARIA. NORMA DE INSPEÇÃO PREDIAL NACIONAL. São Paulo, 2012. Disponível em: <http://www.ibape-sp.org.br/arquivos/Norma-deInspecao-Predial\%20Nacional-aprovadaemassembleia-de25-10-2012.pdf>. Acessado em: 16 Set. 2018.

LEAN INSTITUTE BRAZIL. Lean Thinking. 2014. Disponível em < http://lean.org.br>Acesso em: 07/01/2019.

LIMA, Y. C. C. et al. Lean construction e P+L como ferramenta de gestão da qualidade na construção civil: Uma Estratégia Competitiva. In: XXXIV ENEGEP Encontro Nacional de Engenharia de Produção, 2014, Curitiba. Anais... Curitiba: ABEPRO, 2014. Disponível em: 
http://www.abepro.org.br/biblioteca/enegep2014_TN_STP_ 203_149_26057.pdf. Acesso em: 3 setembro 2019.

PINHEIRO, J. Q.; FARIAS, T. M.; ABE-LIMA, J. Y. Painel de especialistas e estratégia multimétodos: reflexões, exemplos, perspectivas. Psico. v.44, n.2, pp. 184-192, 2013. Disponível em <http://revistaseletronicas.

pucrs.br/ojs/index.php/revistapsico/article/view/11216/9635

> Acesso em 10 Julho de 2019

MOSTAFA, SHERIF; DUMRAK, Jantanee; SOLTAN, Hassan. "Lean Maintenance Roadmap." Procedia Manufacturing, 434-44. 2015.

OLIVEIRA, S. E.; ALLORA, V.; SAKAMOTO, F. T. C. Utilização conjunta do método UP' (Unidade de ProduçãoUEP') com o Diagrama de Pareto para identificaras oportunidades de melhoria dos processos de fabricação: um estudo na agroindústria de abate de frango. 2006. Custos e Agronegócio, v. 2 - n.2 2006.

OHNO, TAIICHI. Sistema Toyota de Produção Além da Produção em Larga Escala. São Paulo: Bookman, 2006.

PINTO, Alan Kardec; XAVIER, Júlio Nassif. Manutenção: função estratégica $4^{\circ}$ Ed. Revista e Ampliação. Rio de Janeiro, 2012

TAVARES, Alexandre Dias; GOMES, Carlos Francisco Simões. ISO 55000: The Evolution of Asset Management ISO 55000: A Evolução da Gestão de Ativos. Business and Management Review, V.4 N.8, 2015.

VIANA, Herbert Ricardo Garcia. PCM, Planejamento e controle da manutenção. Rio de Janeiro: Editora Qualitymark, 2002.

THANKI, SHASHANK; GOVINDAN, KANNAN; THAKKAR, Jitesh. An Investigation on Lean-Green Implementation Practices in Indian SMEs Using Analytical Hierarchy Process (AHP) Approach. Journal of Cleaner Production 135:284-98. 2016.

ZHANG, Lianying; CHEN, Xi. Role of Lean Tools in Supporting Knowledge Creation and Performance in Lean Construction. Procedia Engineering. 145:1267-1274, 2016

\section{COPYRIGHT}

Direitos autorais: Os autores são os únicos responsáveis pelo material incluído no artigo.

Submetido em: 16/09/2019

Aprovado em: 25/09/2019 


\author{
Revista SODEBRAS - Volume 14 \\ $\mathrm{N}^{\circ} 166-$ OUTUBRO/ 2019
}

\title{
DETECÇÃO DE FALHAS NO PROCESSO DE COMUNICAÇÃO E ANÁLISE DOS IMPACTOS SOBRE A SEGURANÇA DE VÔO PELO CONTROLE DE TRÁFEGO AÉREO
}

\author{
DETECTION OF FAILURES IN THE COMMUNICATION PROCESS AND \\ ANALYSIS OF IMPACTS ON FLIGHT SECURITY BY AIR TRAFFIC CONTROL
}

\author{
ROBERVANDRO SILVA DE LIMA ${ }^{1}$; PROF. DR. CLAUDERINO DA SILVA BATISTA ${ }^{2}$ (ORIENTADOR) \\ 1 - INSTITUTO DE TECNOLOGIA DA UNIVERSIDADE FEDERAL DO PARÁ (PPGEP-ITEC-UFPA); \\ 2 - INSTITUTO DE TECNOLOGIA E EDUCAÇÃO GALILEO DA AMAZÔNIA (ITEGAM) \\ robervandros@gmail.com; clauderino@ufpa.br
}

\begin{abstract}
Resumo - Sabe-se que o processo de comunicação na aviação, apesar dos avanços tecnológicos, ainda apresenta inúmeros gargalos que podem comprometer a segurança do tráfego aéreo atuados por piloto e controle; e piloto e outras aeronaves. Pois envolve aspectos da comunicação referentes à linguagem, entendimento do idioma, ambiguidade, referência incerta, inferência implícita, homofonia, entonação, repetição (ou cotejamento) e etc. Assim, o objetivo geral deste estudo é o de analisar o processo de comunicação e suas falhas no controle de tráfego aéreo e propor dispositivos de detecção dessas falhas e reduzir os impactos sobre a segurança dos vôos. $O$ atual artigo encontra relevância científica porque pode estabelecer um novo paradigma na questão da comunicação entre solo $e$ ar. Sua metodologia tem natureza bibliográfica com proposta experimental.
\end{abstract}

Palavras-chave: Controle de Tráfego Aéreo. Falhas no Processo de Comunicação. Fator Humano.

\begin{abstract}
It is known that the process of communication in aviation, despite the technological advances, still presents numerous bottlenecks that can compromise the safety of air traffic operated by pilot and control; and pilot and other aircraft. For it involves aspects of communication concerning language, understanding of language, ambiguity, uncertain reference, implicit inference, homophony, intonation, repetition (or comparison), and so on. Thus, the overall objective of this study is to analyze the communication process and its failures in air traffic control and propose devices to detect these failures and reduce the impacts on flight safety. The current article finds scientific relevance because it can establish a new paradigm in the matter of communication between soil and air. Its methodology has bibliographic nature with experimental proposal.
\end{abstract}

Keywords: Air Traffic Control. Failures in the Communication Process. Human Factor.

\section{INTRODUÇÃO}

A atuação no segmento de navegação aérea se apresenta como o principal componente da motivação para este estudo, porém, agregados a este fator está a necessidade do CRM (Crew Resourse Management) em prevenir, sobremaneira, acidentes aéreos que possam levar passageiros e tripulação ao óbito. E como este meio de transporte vem aumentando cada vez mais ao longo dos anos sua demanda, aumentou mais ainda os riscos de acidentes apesar de ser ainda, o tipo de transporte mais seguro do mundo. Assim, os cuidados que requerem este setor aumentam a urgência em se ter um sistema de comunicação o mais eficiente e eficaz possível para a preservação da vida humana. $\mathrm{O}$ estudo desenvolvido aqui provém de uma análise do processo de comunicação e fatores lingüísticos e cognitivos que geram protocolos de comunicação ar-solo definidos em manuais operacionais de uso restrito por pilotos e controladores de vôo. Especificamente, a comunicação por voz via rádio ar-solo pode gerar equívocos, que eventualmente se traduzem em riscos de segurança para vôos e para passageiros/cargas.

Ao longo das décadas o foco sobre os acidentes aéreos migrou lentamente das falhas técnicas para as falhas humanas. Este movimento se deu, em grande parte, devido ao estudo aprofundado não apenas dos acidentes em si, mas também do comportamento humano relacionado a eles. Avanços na tecnologia de investigação, como os CVR (Cockpit Voice Recorder) e os FDR (Flight Data Recoreder), mais dois conhecidos como "Caixas-Pretas", possibilitaram aos investigadores uma análise detalhada do que realmente ocorria com os tripulantes na cabine de vôo durante uma emergência.

Surgiu assim as bases de um novo conceito na aviação, o CRM ou "gestão dos recursos de cabine". O CRM advém exatamente dessa nova percepção do papel humano nos acidentes aeronáuticos. Estudos multidisciplinares envolvendo psicologia, medicina, comportamento, fisiologia de voo, gestão de pessoas e processos, metodologia entre outros, passariam a figurar e a ajudar na formação das novas práticas de segurança de voo a partir de então. "O ser humano, suas limitações, erros e acertos, agora eram o centro das ações, não mais a aeronave, suas partes e componentes físicos e técnicos" (HELMREICH et al, 1999, p. 8).

Os acidentes, na maioria das vezes ocorrem por falhas ligadas ao comportamento humano, cerca de 75 a $80 \%$ do total" (ANKA; HELMREICH, KAKI, 2010, p. 9) faz-se necessário uma análise mais aprofundada a fim de se evidenciar esse componente humano onde, aparentemente, ele não existe. A partir da problemática exposta, este estudo 
cogita a hipótese de que existe ainda uma lacuna a ser preenchida no processo de comunicação aeronáutica, e salienta que podem ser trazidas tecnologias de outros campos para garantir a segurança dos vôos no tocante a comunicação e o fator humano.

\section{REVISÃO DA LITERATURA}

\section{1 - Estrutura do Sistema Aéreo Brasileiro}

De acordo com as normas Aeronáuticas brasileiras, a prestação dos serviços de tráfego aéreo no Brasil é gerenciada pelo Comando da Aeronáutica, quem instituiu o Sistema de Controle do Espaço Aéreo Brasileiro (SISCEAB) para organizar e articular as entidades que, direta ou indiretamente, participam do processo de Fornecimento desses serviços a aviação civil na área de responsabilidade do Brasil. O SISCEAB e o instrumento para promover o cumprimento das normas da ICAO no âmbito nacional, importando as normas e os conceitos internacionais relacionados ao serviço de tráfego aéreo, aplicando-os a realidade e às necessidades do país (BRASIL, 2010).

Especificamente quanto ao Serviço Móvel Aeronáutico (SMA), a estrutura operacional genérica definida pela ICAO para o provimento desse serviço e composta por três tipos diferentes de órgãos de controle de tráfego aéreo. Os tipos e suas responsabilidades são resumidos a seguir e ilustradas na Figura 1:

Figura 1 - Estrutura operacional genérica definida pela ICAO para o provimento do SMA

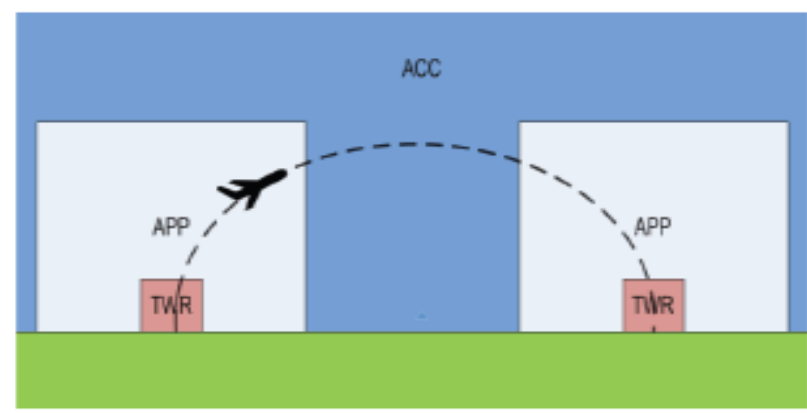

Fonte: (BRASIL, 2010).

- TWR (Tower - Aerodrome Control): responsável pela navegação e desconflito de aeronaves (em solo) em transito nos pátios e nas pistas de pouso e decolagem dos aeródromos, bem como nos instantes anteriores ao pouso e posteriores à decolagem; APP (Approach Control): responsável pela navegação e desconflito de aeronaves (em voo) que realizam as manobras anteriores ao pouso e posteriores a decolagem nas proximidades dos aeródromos, estendendo-se, em geral, por 40 milhas náuticas de distancia do aeródromo 1; e ACC (Área Control Centre): responsável pela navegação e desconflito de aeronaves (em voo) em rota, ao longo do percurso compreendido entre os APP das localidades de origem e destino.

Segundo Brasil (2010), essa estrutura é aplicada no cenário nacional, que se faz constituir por diversos órgãos de controle de tráfego aéreo espalhados pelo país, como 5 ACC cobrindo a área de responsabilidade do Brasil no cenário internacional, o que totaliza 22 milhões de quilômetros quadrados, conforme Figura 2.
Figura 2 - Disposição das regiões de responsabilidade de tráfego aéreo dos 5 ACC existentes no Brasil

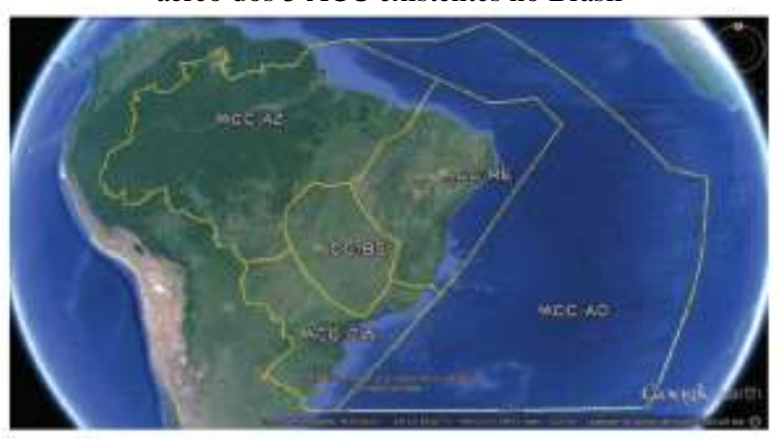

Fonte: (BRASIL, 2010).

Em síntese, os mecanismos de transmissão e recepção estabelecem um canal half-duplex de comunicação entre ATCO e aeronaves. Além disso, a capacidade mútua de falar e ouvir através do SMA é denominado de "contato bilateral" e essa capacidade é essencial para a condução segura das operações de controle de tráfego aéreo.

A partir dessas informações, é possível concluir que a solução tecnológica utilizada para o provimento do SMA oferece a possibilidade de contato bilateral entre ATCO e aeronaves, e dispensa a necessidade de recursos adicionais, quando o espaço aéreo sob responsabilidade do órgão de controle pode ser "iluminado" por uma única estação de VHF-AM instalada nas proximidades desse órgão como ilustra a Figura 3 (ROSSI, 2015).

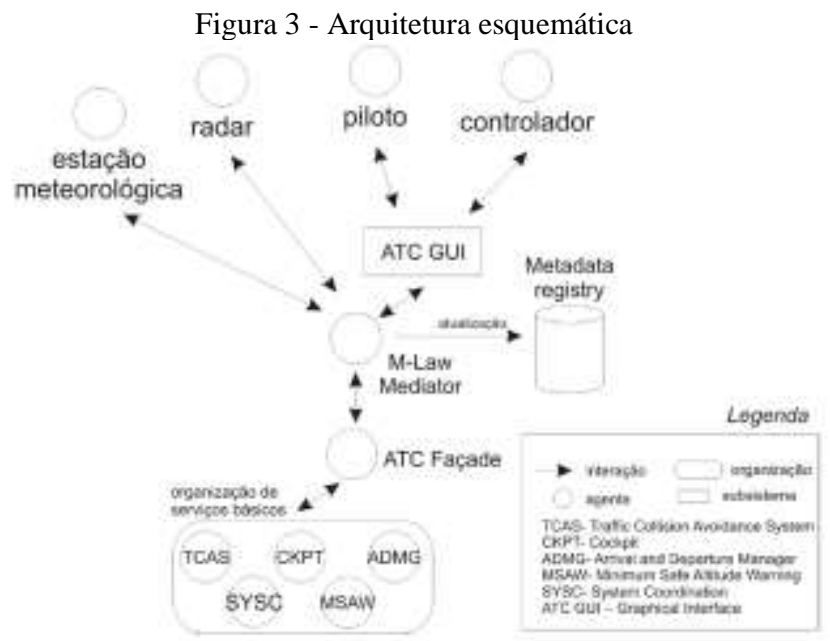

Fonte: (BRASIL, 2010).

Como mencionado, a prestação do serviço de tráfego aéreo em cada setor ocorre através da solução tecnológica definida para o SMA (difusão em VHF-AM), complementada pelo clímax. Especificamente, cada setor recebe a designação de 2 valores de frequiência na faixa do VHF (denominados "canais de VHF"), e a correspondente infraestrutura em terra, para que as modulações e de modulações dos sinais de voz do SMA ocorram naquela região. Esses 2 canais de VHF recebem a denominação de Canal Primário e Canal Secundário do setor, e os valores atribuídos aos 12 setores do ACC-CW (ROSSI, 2015).

$\mathrm{Na}$ busca pela rastreabilidade das causas de eventuais incidentes (ou acidentes) aeronáuticos, a legislação internacional exige que cada órgão de controle de tráfego aéreo registre e mantenha armazenadas as mensagens de 
coordenação realizadas entre ATCO e aeronaves. Em função desta exigência, todos os sinais de voz produzidos nas coordenações são enviados a um sistema de gravação, o qual registra os sinais de voz transmitidos e recebidos através dos canais Primário e Secundário dos setores de um ACC.

Neste contexto, adota-se comumente um agente detector de falhas através da utilização de um agente único que implementa um algoritmo de heartbeat. Este algoritmo consiste em enviar mensagens de controle periodicamente para os agentes do sistema esperando que os agentes respondam a esta mensagem. Devido ao grande número de variáveis e a simplicidade da estratégia de implementação do heartbeat, podem ocorrer falsos negativos, ou seja, a demora da resposta pode ser interpretada como indisponibilidade do agente, como mostra a Figura 4.

Figura 4 - Arquitetura esquemática com agente detector de falhas

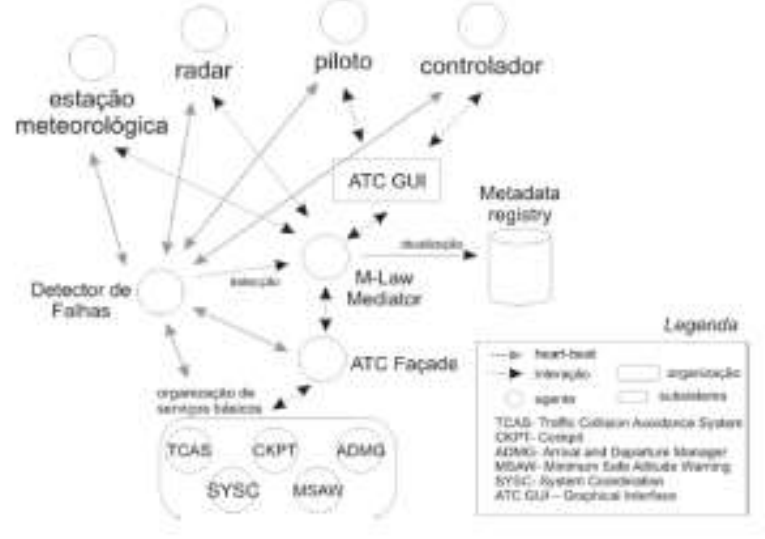

Fonte: (BRASIL, 2010).

Sendo assim, para minimizar este problema, o agente tentará pelo menos 3 vezes antes de indicar que o agente está indisponível. Se ainda assim, esta estratégia não for suficiente para um determinado domínio de aplicação, então o agente detector poderia ser substituído por implementações mais sofisticadas, como por exemplo o Globus Heartbeat Monitor (STELLING, DEMATTEIS et al. 1999).

A sobreposição desses sinais em um único stream impede, a priori, a rastreabilidade automática do locutor da mensagem, pois um computador, desprovido de inteligência, não seria capaz de diferenciar as transmissões de ATCO e das de aeronave. A ausência dessa rastreabilidade automática não representa empecilho para a condução de eventuais investigações aeronáuticas, uma vez que as investigações são conduzidas por especialistas humanos capazes de distinguir o locutor da mensagem de maneira intuitiva e inequívoca, mas representa um obstáculo no processamento computacional dos dados. Esse problema, no entanto, é superado ao se conciliar os registros de gravação dos canais Primário e Secundário com o modus operandi.

Em um estudo desenvolvido por Steven Cushing publicado sob o título de Fatal Words, Communication Clashes and Aircraft Crashes (1997) descreveu diversos tipos de problemas relacionados à comunicação aeronáutica no segmento radiofônico. Como este estudo foi desenvolvido nos Estados Unidos da América do Norte, a maior parte dos casos relatados e por ele estudados tem origem nas comunicações realizadas dentro do espaço aéreo norte americano, onde há a ocorrência de muitas expressões informais e o uso da linguagem coloquial é muito presente nas comunicações entre pilotos e controladores. E este tipo de atitude tem sido muito questionado por ter grande parcela nos acidentes ocorridos nos EUA (BARTELSKY, 2001).

Com a grande variedade de elementos de comunicação, Cushing (1997) divide em dois tipos de problemas de comunicação: o primeiro baseado especificamente na linguagem humana, onde a forma da construção da mensagem determina em grande parte o contexto ocorrido, gerando interpretações ambíguas por parte de pilotos e controladores. E essa comunicação também sobre a influência de fatores individuais como a fadiga, fatores sociais e cognitivos; o segundo baseou-se nos problemas gerais, que são aqueles relacionados a fatores externos, como um rádio defeituoso, que impede a mensagem de ser claramente recebida (ruído), elementos climáticos e possíveis alterações da influência solar (AMERICAN ACCIDENT, 1997).

Um dos casos retratado no estudo de Cushing é o do acidente no aeroporto John Wayne Orange Country, Santa Ana, Califórnia, em 17 de Fevereiro de 1981, que teve sua origem em parte, num mal-entendido relacionado ao verbo "hold", que significa na aviação "pare de fazer o que está fazendo", mas que pode significar no idioma Inglês comum "continue fazendo o que está fazendo", deixando claro que há uma influência da compreensão humana dos pilotos e torre (AMERICAN ACCIDENT, 1997).

Algumas confusões também estão relacionadas ao som das palavras "to" e "tão". O controlador autoriza a aeronave a descer para "tão four zero zero" (2.400 pés). O piloto coteja "Ok. Four zero zero" pois entendeu o controlador dizer "to four zero zero" e então desce para 400 pés ao invés de 2.400 pés (AIB - HMSO, 1973, p. 64).

De acordo com a ANAC (2018) os principais atores de um CTA são o piloto e o controlador. Assim, controladores necessitam lidar com situações muitas vezes complexas em intervalos e tempo bastante rígidos. Igualmente, as ações dos pilotos quanto dos controladores necessitam estar em conformidade com as regras definidas pelas agências reguladoras. Alguns problemas são destacados quanto a sua frequiência pela ANAC: Falta de conhecimento técnico - a ignorância de fatores técnicos tais como estruturas, materiais e aerodinâmica foi responsável por um grande número de acidentes. Entretanto, conforme o conhecimento científico e tecnológico avança, acidentes com esta causa são cada vez mais raros (MATTHEWS, 2002).

Software - faltas que não tratadas adequadamente induzem a falhas no sistema. Embora não tenha sido encontrado nenhum artigo sobre percentual de falhas de software no total das causas dos acidentes aéreos, um demonstrativo que no período de 12 anos entre 1994 e 2005, $36 \%$ das falhas apresentadas em infraestruturas consideradas críticas, dentre elas, transporte aéreo, fornecimento de água e transportes ferroviários, foram causadas por software. O segundo maior percentual foi falhas de hardware com $21 \%$, seguido por falhas humanas com 7\%. (RAHMAN, BEZNOSOV et al., 2006).

Hardware - em sistemas de CTA exemplos de falhas de hardware podem ser um radar que deixou de funcionar, ou o link da comunicação entre o piloto e o controlador que não conseguiu ser estabelecido. Problemas durante o voo, esta categoria de problemas agrupa as situações como terrorismo, passageiros sob efeito de álcool e brigas, dentre outras.

Falha Humana - com o avanço do conhecimento técnico, falhas nos aviões tem se tornado cada vez mais raras. 
Isto tem levado a exposição das falhas humanas. Em 2004, nos Estados Unidos, a falha de pilotos foi considerada como a principal causa de $78,6 \%$ dos acidentes fatais e $75,5 \%$ de todos os acidentes ocorridos na aviação civil (KREY, 2006).

Condições do tempo - geralmente esta categoria é classificada como uma subcategoria de falha humana. Embora os acidentes causados por condições adversas de tempo, como temporais, ocorram com freqüência relativamente baixa $(4,5 \%$ do total de acidentes por falha humana), eles correspondem por 19,7\% dos acidentes fatais causados por falha humana (KREY, I., \& MOREIRA, 2009).

Assim, é possível observar que diversos estudos têm se ocupado não somente da comunicação, mas também dos aspectos que envolvem os atores aeronáuticos. Nesse sentido, a análise do comportamento humano na aviação vem tomando um espaço cada vez maior ao longo das últimas três décadas.

A pesquisa também revela que em $45 \%$ do tempo os interlocutores ouvem, em $30 \%$ falam e em $25 \%$ estão escrevendo ou lendo. O elemento que mais contribui para os acidentes aeronáuticos ainda hoje é o erro humano ou, tecnicamente, o fator humano. Cerca de $60 \%$ dos acidentes ocorridos com aeronaves de transporte aéreo regular foram causados por falha humana tais como erros de julgamento, imprudência, imperícia entre outros como mostra a Figura 5.

Figura 5 - Fatores de influência em acidentes aéreos

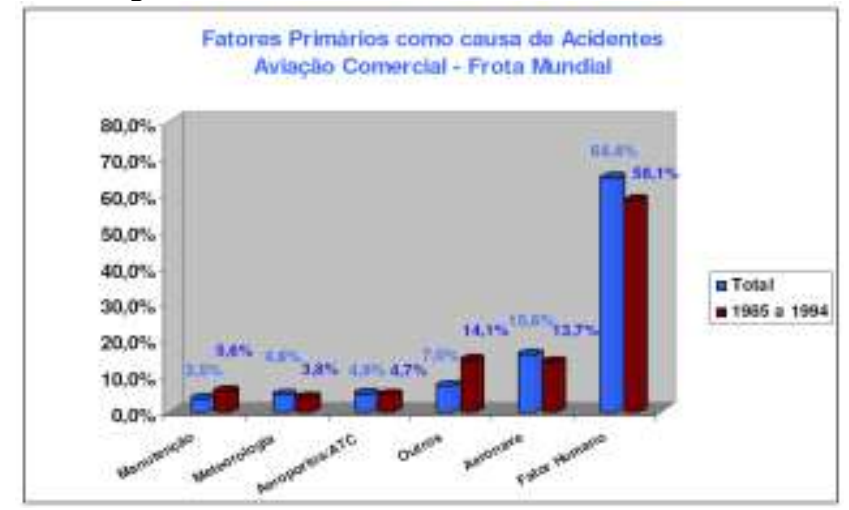

Fonte: Boeing Commercial Airplane Group (1995) - ANAC, 2010.

\section{2 - Sistemas de conversão de voz para texto}

A partir da evolução da tecnologia, os sistemas de conversão de voz vêm se aprimorando e auxiliando diversos setores da indústria, engenharia entre outros. Sistemas como o Siri da Apple, teve sua origem no instituto de pesquisa SRI International e foi co-fundada por Dag Kittlaus, Adam Cheyer e Tom Gruber (BOOSKER, B, 2013).

Um dos exemplos mais relevantes que alcançou todo o mundo em termos domésticos foi quando a gigante Microsoft, lançando em 2014 um assistente digital denominado de Cortana, que se comunicava com o usuário através da voz e, transformava os sons da voz do usuário em comandos textificados na tela do computador presente nos dispositivos com sistema Windows 10 (ASH, M, 2015).

Nas mídias sociais, em 2016, Mark Zuckerberg, o CEO do Facebook, declarou o desenvolvimento de um sistema de inteligência artificial, controlado por voz, que pudesse se conectar, comunicar e controlar residências à distância através do laptop ou celulares.

Estes avanços têm se dado em setores mais relacionados às necessidades mais sociais e no âmbito doméstico, porém, para questões de segurança em grandes setores, como a aviação, tem tido pouca visibilidade, e devido a este fato, o presente projeto propõe que seja inserido nos sistemas aeronáuticos os conversores de voz para texto e vice-versa, já que ao se aplicar a tecnologia de um para o outro, simultaneamente se tem os mesmos resultados ao contrário. $\mathrm{O}$ controle por voz demanda menos tempo de execução e decodificação para o fator humano no caso da aviação, não havendo a necessidade de utilizar dispositivos e/ou buscar opções que realizam a função desejada, ou a consulta de manuais que, obviamente tomaria um tempo muito grande diante de uma emergência, precisando apenas que a torre e piloto apenas falem.

\section{METODOLOGIA EXPERIMENTAL}

O presente artigo teve como metodologia a observação direta dos aspectos pertinentes à logística de comunicação ao setor de comunicação para a observação de Aeronaves AM e apresentado ao Comando Geral para inserir alternativas de redução de custos com segurança de tripulação e passageiros. Desta forma, como elemento norteador para a estrutura e execução do projeto, adotou-se o Project Management Body of Knowledge (PMBOK), que é um conjunto de práticas na gestão de projetos organizado pelo Project Management Institute (PMI) e é considerado a base do conhecimento sobre gestão de projetos por profissionais da área.

Por ser baseado em processos e subprocessos para descrever de forma organizada o trabalho a ser realizado durante $\mathrm{o}$ projeto. Essa abordagem se assemelha à empregada por outras normas como a ISO 9000 e o Software Engineering Institute's, CMMI. Os processos descritos se relacionam e interagem durante a condução do trabalho. A descrição de cada um deles é feita em termos de: Entradas (documentos, produtos etc.); Ferramentas e técnicas (que se aplicam às entradas); Saídas (documentos, produtos etc.).

A ênfase sobre a importância da qualidade no processo da comunicação reitera que a eficiência e eficácia não se consegue não pelo esforço isolado de um departamento específico, mas pela participação de todos na organização. Surgiram assim os conceitos de Controle Total da Qualidade e Gestão da Qualidade Total, este mais adequado para enfatizar que a qualidade faz parte do processo de gestão (Costa Neto, 2007). Posteriormente, veio a mudança do enfoque corretivo para o enfoque preventivo. Esta importante mudança de enfoque ficou conhecida como a base do Controle Total da Qualidade (FEIGENBAUM, 1994). Sobre o Sistema de Controle Total, para que este seja efetivo, é necessário observar todo o processo, que começa e termina na comunicação e em seu entendimento, para obter um processo mais eficiente e gere a eficácia necessário para torre e piloto, mas que levem em conta a satisfação total do cliente (CARVALHO, et al., 2006).

\section{PROPOSTA DO USO DE COMUNICAÇÃO APROFUNDADA PARA REDUÇÃO DE FALHAS NO PROCESSO DE COMUNICAÇÃO HUMANA EM AVIAÇÃO}

O projeto consta de uma proposta do uso de cabine de Comunicação com tecnologia de estúdio de som com recurso de software IBM Voice customizada para cabine de aviação em Unidade de controle de Tráfego e do Espaço 
Aéreo do Quarto Centro Integrado de Defesa Aérea e Controle de Tráfego Aéreo - CINDACTA IV.

Dois pontos são fundamentais e que sintetizam a proposta deste artigo:

Customizar duas cabines de aeronaves com tecnologia de ponta de estúdio de áudio com a finalidade de tornar registrável o mais baixo ruído para gravação de toda a cena de vôo. Os benefícios têm abrangência inclusive no caso de acidentes que necessitem de registro da caixa preta. A tecnologia de som e cabine com isolamento adequado pode fornecer em tempo real toda a comunicação oral ocorrida entre terra e ar, piloto e controladores, oferecendo uma espécie de backup virtual de toda operação aérea da citada aeronave; a segunda parte do projeto inclui equipar terra e ar com o Software IBM Voice.

O principal motivo pelo qual se propõe este projeto é a complexidade do processo de comunicação entre terra e ar na aviação. $\mathrm{O}$ que tem um teor extremamente técnico que pode confundir ou tornar menos eficiente o fator humano. Abaixo um exemplo do Manual Facilitador para Controladores da ANAC (2010), onde, nesta análise, verifica-se as estratégias de mitigação de cada ameaça analisadas pelo sistema detector XMLaw. Para isto, apresenta-se o identificador da ameaça, o contexto de lei no qual a ameaça afeta, a estratégia de detecção da ameaça e finalmente, quando for necessário, o exemplo de código XMLaw da implementação na Figura 5 com Ameaça CDL01.

Figura 5 - Parâmetro de análise do sistema XMLaw

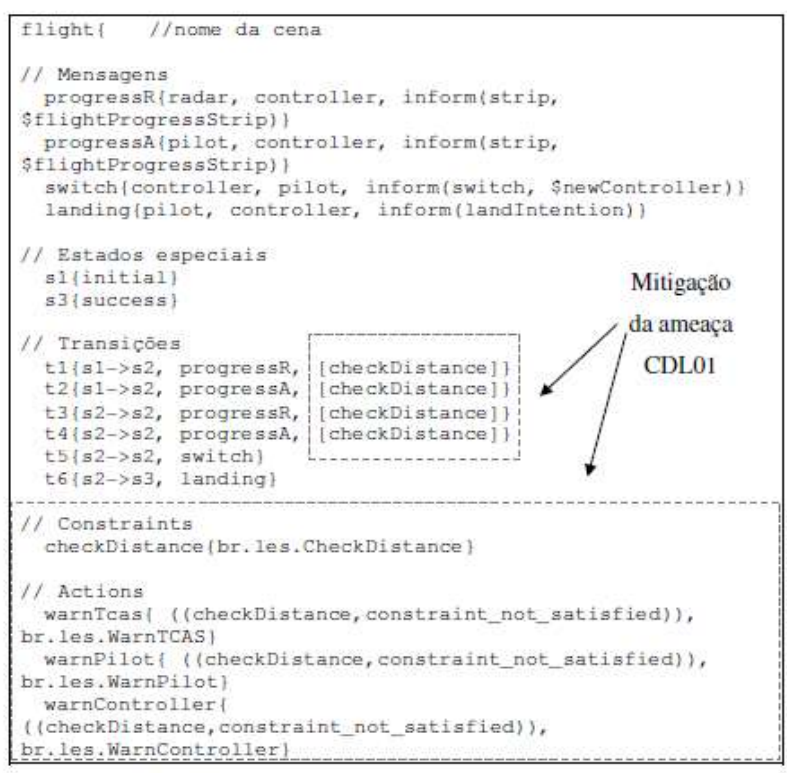

Fonte: ANAC (2010).

Observa-se que os códigos são interpretados por parâmetros técnicos que podem, facilmente, confundir tanto controladores como pilotos pela sua natureza técnica de linha de comando. Adiciona-se a esta problemática a interpretação idiomática, pois ele trabalha na língua inglesa. Tem-se que considerar também o silêncio das transmissões que são parâmetros de análise para os eventos ocorridos durante os vôos, isso significa dizer que há uma complexidade tanto na transmissão do som quanto do silencio e que ambos, tem interpretação diferenciada.

É possível observar com esta pequena amostra, que há um nível extenso de complexidades que produzem diversas interpretações, os resultados obtidos através destas amostras oferecem aval para verificar que no que tange a tecnologia, os dados não apresentam erros ou incoerências, porém, para a interpretação desses dados, pode-se verificar que há um montante de dados extremamente extensos que levam a desequilíbrios de interpretação e até mesmo de estresse por parte do fator humano.

Esse processo reproduzido continuamente e extenuadamente oferece ameaças maiores por parte da condição do fator humano no processo de comunicação. É possível ver que ele não é acumulativo no sentido de produzir maior desempenho, mas sim maior cansaço da atenção concentrada e da condição da interpretação dos dados oferecidos pela tecnologia disponível.

\section{CONCLUSÃO}

Verificou-se que aspectos humanos, chamados de fatores humanos da comunicação, são relevantemente no que tange a existência de falhas menores ou maiores para a segurança de vôos. Verificou-se ainda que a linguagem escrita apresentada pelos sistemas de comunicação para detecção de falhas na comunicação é extremamente técnica e que ainda oferecem a problemática, para os controladores e pilotos brasileiros, de estarem configurados em idioma inglês.

A implantação de elementos tecnológicos de captação de som e fidelidade, combinadas com softwares com tradutores múltiplos como o IBM Via Voice, permitiriam trabalhar dentro das condições humanas, e não ignorando seus limites.

A partir do exposto, as sugestões pertinentes para melhoria do processo de comunicação e detectação de falhas passa, sobretudo na questão da valorização do elemento humano, não subestimando, mas sim trabalhando com suas melhores qualidades, que não são apenas técnicas, mas de cognição, de comportamento, de psicologia funcional e de melhoria do desempenho a partir de suas próprias qualidades. Assim, as recomendações são tornar mais intuitivo o processo de comunicação através de softwares tradutores que possam transcrever a sonoridade da voz humana em texto legível, do próprio idioma do receptor e que se possa registrar em tempo real, o percurso do processo em cena de vôo.

Outrossim, trazer a tecnologia de outro setor, no caso o da produção dos recursos de áudio-fidelidade de estúdio para dentro das cabines aeronáuticas. Esse processo não excluiria a participação dos sistemas de detectação de falhas com parâmetros técnicos, mas sim adicionaria um poder de reação e interpretação bem maiores para a redução dos riscos de falhas na comunicação no aspecto humano.

Sabe-se cientificamente que, um determinado texto técnico tem um tempo maior para o processo de compreensão e reação. E que um texto oriundo do entendimento humano cotidiano tem velocidade de compreensão cerca de 20 vezes mais rápido que o texto técnico. Dessa forma, as sugestões para as presentes problemáticas de falhas na comunicação passam não somente por tecnologia oriundas de outros segmentos, quanto na consideração das variáveis dos fatores humanos.

\section{REFERÊNCIAS}

AIB - ACIDENT INVESTIGATION BRANCH - AIB Civil Aircraft Accident Report 4/73 - Trident 1 G-ARPI. Report of Public Inquiry into the Causes and Circumstances of the Accident near Staines on 18 June 1972. Londres: HMSO, 1973. 
AMERICAN ACCIDENT. Fatal Words, Communication Clashes and Aircraft Crashes, 1997. Disponível em: http://www.tenerifecrash.com/. Acessado em: 15/02/2018.

ANAC, Agência Nacional de Aviação Civil - ANAC. Manual do Facilitador em CRM: Introdução ao treinamento do CRM. Compilado e traduzido por Tereza Freire Breves. Rio de Janeiro. 2010. 107p. Disponível em: http://www2.anac.gov.br/arquivos/pdf/

manualTreinamentoFacilitadorCRM3.pdf $>$. Acesso em: 24/02/2018.

ANCA, Jose; HELMREICH, Robert; KANKI, Barbara. Crew Resourse Management. $2^{a}$ ed. Londres: Academic Press Elsevier. 2010. 528 p.

ASH, M. How Cortana Comes to Life in Windows 10. Disponível

<https://blogs.windows.com/windowsexperience/2015/02/1

0/how-cortana-comes-to-ife-inwindows-

10/\#9kSs4udLFil6hhep.97> Acesso em: 09/10/2018.

ASCHENBRUCK, N. et al. Modelling voice communication in disaster area scenarios. In: Local Computer Networks, Proceedings 2006 31st IEEE Conference on. [S.1.: s.n.], 2006. p. 11-220. ISSN 07421303.

ASCHENBRUCK, N.; MARTINI, P. Evaluation and parameterization of voice traffic models for disaster area scenarios. In: Local Computer Networks, 2008. LCN 2008. 33rd IEEE Conference on. [S.1.: s.n.], 2008. p. 236-243.

ASCHENBRUCK, N.; MARTINI, P.; GERHARZ, M. Characterisation and modelling of voice raffic in first responder networks. In: Local Computer Networks, 2007. LCN 2007. 32nd EEE Conference on. [S.1.: s.n.], 2007. p. 295-302. ISSN 0742-1303.

BOSKER, B Siri Rising: The Inside Story Of Siri's Origins (And Why She Could Overshadow The iPhone). $<$ http://www.huffpostbrasil.com/entry/siri-do-engineappleiphone_n_2499165> Acesso em: 09/10/2018.

BARTELSKY, Jan. Disasters in the Air: mysterious air disasters explained. $2^{a}$ ed. Shrewsbury: Air Life Publishing, 2001.

BRASIL. Sistema de Controle do Espaço Aéreo Brasileiro. Fev 2010. Boletim do Comando da Aeronáutica, [Brasília, D DF], 11 feb 2010. Comando da Aeronáutica. Portaria no 29/DGCEA, e 29 de janeiro de 2010.

HELMEREICH, Robert L.; MERRIT, Ashleigh C.; WILHELM, John A. The Evolution of Crew Resource Management Training in Commercial Aviation. Texas: Department of Psychology, University of Texas at Austin, 1999.

ICAO. Annex 10 - Aeronautical Telecommunications. International Standards and Recommended Practices, 1996.

KREY, I., \& MOREIRA, M. A. Abordando Tópicos de Física Nuclear e Radiação em uma Disciplina de Estrutura da Matéria do currículo de licenciatura em ciências através de situações-problema. Lat. Am. J. Phys. Educ., 3(3), 595605. 2009.
MICROSOFT, Cortana. Disponível em: $<$ https://www.microsoft.com/en-us/windows/cortana> Acesso em: 09/10/2018.

ROSSI, D. S. Z.; FONSECA, M.; MUNARETTO, A. Caracterizando o uso de canais de comunicação do controle de tráfego aéreo. In: 33॰ Simpósio Brasileiro de Telecomunicações, 2015.

SOUSA, Linardy De M.; COSTA NETO, Pedro Luiz De O.; IBIAPINO, Thaís R.; PORTELA, Carla S. P.; LIMA, Nayguel Richel De Souza. Princípios da Qualidade no Sistema de Gestão de Saúde e Segurança do Trabalho SGSST. V. 12 - $\mathrm{N}^{\circ} 135$ - Março / 2017 XXXVI International Sodebras Congress, 2017.

STELlinG, P., C. DeMatteis, et al. A fault detection service for wide area distributed computations. Cluster Computing (2): 117-128. (1999).

VERGara, S. Projetos e Relatórios de Pesquisa em Administração. 5.ed. São Paulo: Ed. Atlas, 2014.

\section{COPYRIGHT}

Direitos autorais: $\mathrm{O}$ autor é o único responsável pelo material incluído no artigo.

Submetido em: 22/02/2019

Aprovado em: 08/10/2019 